\title{
Wind Gust Measuring at Low Altitude Using an Unmanned Aerial System
}

\author{
by \\ Alton Yeung \\ Bachelor of Engineering, Ryerson University (2015) \\ A thesis \\ presented to Ryerson University \\ in partial fulfillment of the \\ requirements for the degree of \\ Masters of Applied Science \\ in the Program of \\ Aerospace Engineering
}

Toronto, Ontario, Canada, 2017

(C)Alton Yeung 2017 


\section{AUTHOR'S DECLARATION FOR ELECTRONIC SUBMISSION OF A THESIS}

I hereby declare that I am the sole author of this thesis. This is a true copy of the thesis, including any required final revisions, as accepted by my examiners.

I authorize Ryerson University to lend this thesis to other institutions or individuals for the purpose of scholarly research.

I further authorize Ryerson University to reproduce this thesis by photocopying or by other means, in total or in part, at the request of other institutions or individuals for the purpose of scholarly research.

I understand that my thesis may be made electronically available to the public. 


\title{
Wind Gust Measuring At Low Altitude \\ using An Unmanned Aerial System
}

\author{
Alton Yeung \\ Masters of Applied Science, Aerospace Engineering, Ryerson University, Toronto
}

$(2017)$

\begin{abstract}
A small unmanned aerial vehicle (UAV) was developed with the specific objective to explore atmospheric wind gusts at low altitudes within the atmospheric boundary layer (ABL). These gusts have major impacts on the flight characteristics and performance of modern small unmanned aerial vehicles. Hence, this project was set to investigate the power spectral density of gusts observed at low altitudes by measuring the gusts with an aerial platform. The small UAV carried an air-data system including a fivehole probe that was adapted for this specific application. The air-data system measured the local wind gusts with an accuracy of $0.5 \mathrm{~m} / \mathrm{s}$ by combining inputs from a five-hole probe, an inertial measurement unit, and Global Navigation Satellite System (GNSS) receivers. Over 20 flights were performed during the development of the aerial platform. Airborne experiments were performed to collect gust data at low altitudes between $50 \mathrm{~m}$ and $100 \mathrm{~m}$. The result was processed into turbulence spectrum and the measurements were compared with the MIL-HDBK-1797 von Kármán turbulence model and the results have shown the model underpredicted the gust intensities experienced by the flight vehicle. The anisotropic properties of low-altitude turbulence were also observed when analyzing the measured gusts spectra. The wind and gust data collected are useful for verifying the existing turbulence models for low-altitude flights and benefit the future development of small UAVs in windy environment.
\end{abstract}




\section{Acknowledgements}

This research was made possible through support by the Molson Foundation, the Ontario Centres of Excellence and Aventech Research Inc., which provided the air-data system. The author is particularly grateful for the help and advice from Stephen Foster at Aventech. The author also like to express his thanks to the piloting of Frank van Beurden and other members at Toronto Electric Model Aviation Club (TEMAC) for allowing the experiments to take place at the airfield. 


\section{Table of Contents}

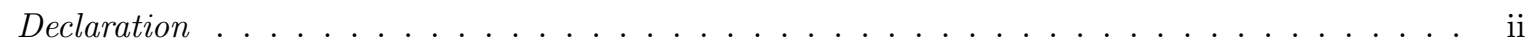

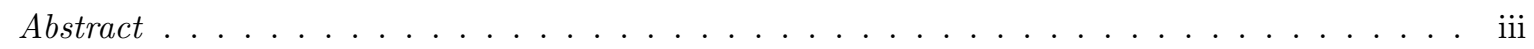

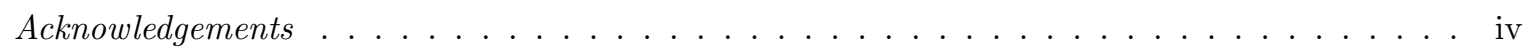

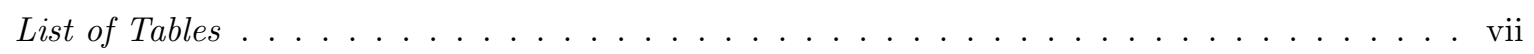

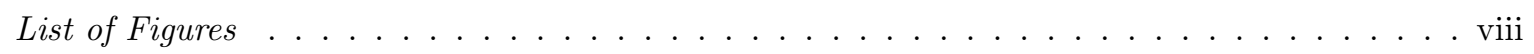

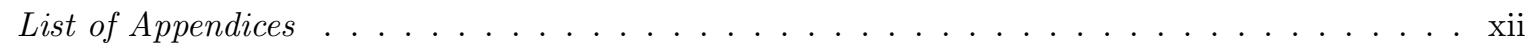

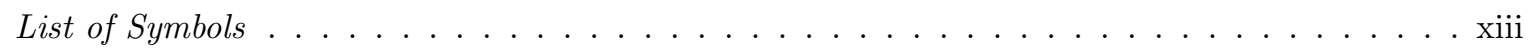

\begin{tabular}{lll}
\hline 1 & Introduction & 1
\end{tabular}

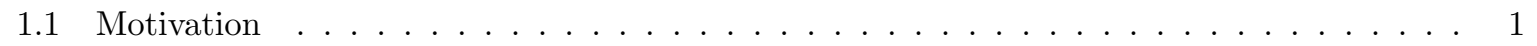

1.2 Atmospheric Boundary Layer $\ldots \ldots \ldots \ldots \ldots \ldots \ldots \ldots$

1.3 Flying in Gust $\ldots \ldots \ldots \ldots \ldots \ldots \ldots \ldots \ldots \ldots$

1.4 Atmospheric Gust Research $\ldots \ldots \ldots \ldots \ldots \ldots$

$1.4 .1 \quad$ Existing Gust Models $\ldots \ldots \ldots \ldots \ldots \ldots$

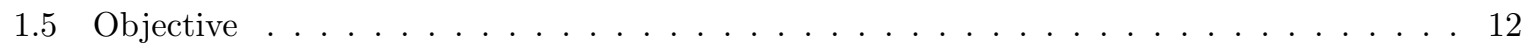

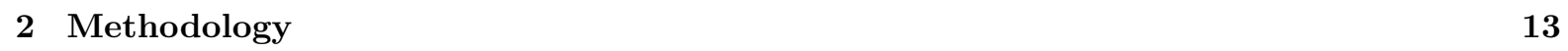

$2.1 \quad$ Atmospheric Turbulence Experiment $\ldots \ldots \ldots \ldots$

$2.1 .1 \quad$ Instrument Platforms $\ldots \ldots \ldots \ldots \ldots \ldots$

2.2 GustAV Aerial Research Platform . . . . . . . . . . . . . . . . . . . . 15

$2.2 .1 \quad$ Aircraft Configuration $\ldots \ldots \ldots \ldots \ldots \ldots \ldots \ldots$

$2.2 .2 \quad$ Propulsion $\ldots \ldots \ldots \ldots \ldots$

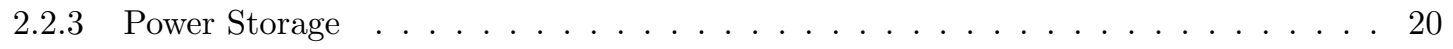


$2.2 .4 \quad$ Autopilot and Flight Control System . . . . . . . . . . . . . . . . . . . 22

$2.2 .5 \quad$ Airspeed Sensor . . . . . . . . . . . . . . . . . . . . . 24

$2.2 .6 \quad$ Flight Data Logging $\ldots \ldots \ldots \ldots \ldots \ldots \ldots \ldots \ldots$

2.2 .7 Software in the Loop $\ldots \ldots \ldots \ldots \ldots \ldots \ldots \ldots$

2.3 Ground Control Station $\ldots \ldots \ldots \ldots \ldots \ldots$

2.4 Air-Data System . . . . . . . . . . . . . . . . . . . . . . . . 28

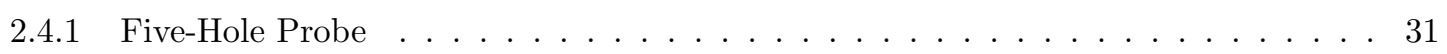

2.4 .2 Inertial Measurement Unit $\ldots \ldots \ldots \ldots \ldots \ldots$

$2.4 .3 \quad$ Global Navigation Satellite System $\ldots \ldots \ldots \ldots \ldots$

2.5 Weather Ground Station . . . . . . . . . . . . . . . . . . . . . . . . . . . . . . 39

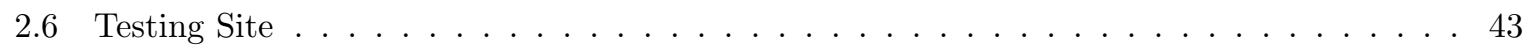

\begin{tabular}{|ll|}
\hline 3 & Wind Tunnel and In-Flight Experiments
\end{tabular}

3.1 Wind Tunnel Test . . . . . . . . . . . . . . . . . . . . . . . . . . . . . . . . . . . 44

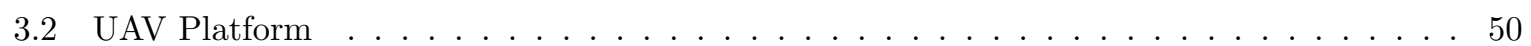

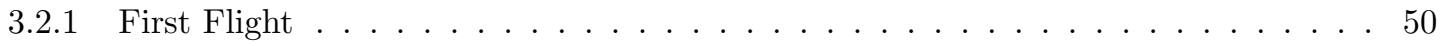

$3.2 .2 \quad$ Aircraft Performance, Stability, and Control . . . . . . . . . . . . . . . . . 51

$3.2 .3 \quad$ Autopilot System Tuning . . . . . . . . . . . . . . . . . . . . 53

3.3 Gust Measurement . . . . . . . . . . . . . . . . . . . . . . . . . . . . . . . 54

$3.3 .1 \quad$ Air-Data System Integration $\ldots \ldots \ldots \ldots \ldots$. . . . . . . . . . . 54

3.3 .2 Gust Measurement Experiment . . . . . . . . . . . . . . . . . . . . . 57

\begin{tabular}{|lll}
\hline 4 & Results and Discussion of Inflight Wind-Speed Measurements & 59
\end{tabular}

$\begin{array}{lll}5 \text { Conclusion } & 71\end{array}$

\begin{tabular}{lr}
\hline References & 99
\end{tabular} 


\section{List of Tables}

2.1 Specification and performance of GustAV. $\ldots \ldots \ldots \ldots \ldots \ldots$

2.2 Weather station sensor specifications. . . . . . . . . . . . . . . . . . . . 42

3.1 Root-mean-square values of the five-hole probe sample error. . . . . . . . . . . . . . . 49

4.1 Summary of flight 23 with segments flown at $100 \mathrm{~m}, 75 \mathrm{~m}$, and $50 \mathrm{~m}$. . . . . . . 61

4.2 Calculated parameters for von Kármán turbulence model of flight 23. . . . . . . . . . . 65

4.3 Turbulence intensities and scale length parameters parameters calculated using non-linear

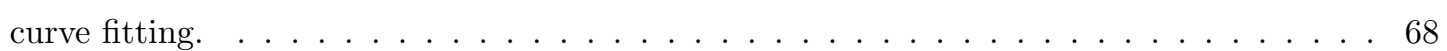

$1.1 \quad$ Flight testing $\log$ of Bix $3 . \ldots \ldots \ldots \ldots \ldots \ldots \ldots$

1.2 Flight testing $\log$ of GustAV $\ldots \ldots \ldots \ldots \ldots \ldots \ldots \ldots$ 


\section{List of Figures}

1.1 Mean wind profiles for a range of ground roughness. $[15] \ldots \ldots \ldots \ldots$

1.2 The earth-fixed frame aliged to the direction of mean wind. . . . . . . . . . . . . . 4

1.3 Change in angle of attack by upward gust $U .[23] \ldots \ldots \ldots \ldots \ldots \ldots$

1.4 Gust field creating an effective rolling and pitching gust 24$] \ldots \ldots \ldots \ldots$

1.5 A one-minus-cosine discrete approximation within a continuous gust profile $[25]$. . . . . 7

$1.6 \quad$ Von Kármán and Dryden gust power spectral density curves, $\mathrm{L}=2500 \mathrm{ft}[25]$. . . . . . 9

1.7 Turbulence intensity and exceedance probability $[30] \ldots \ldots \ldots \ldots \ldots$

1.8 MIL-HDBK-1797 low altitude turbulence model. $\ldots \ldots \ldots \ldots \ldots$. . . . . . . . . . . 11

2.1 Examples of atmospheric research platform. . . . . . . . . . . . . . . . . . . . 14

2.2 GustAV aerial research platform flying with a five-hole probe mounted on wing-tip. . . . . 16

$2.3 \quad$ 3-view of GustAV and the five-hole probe location 33$] \ldots \ldots \ldots \ldots$

$2.4 \quad$ Isometric drawing of GustAV structure layout and major components. . . . . . . . . . . 18

2.5 Electric motor and propeller combination selected for GustAV. . . . . . . . . . . . . . . 19

2.6 Two Lithium Polymer batteries onboard GustAV to power electric motor and avionics respectively. . . . . . . . . . . . . . . . . . . . . . . 21

2.7 Battery power distribution layout on GustAV. . . . . . . . . . . . . . . . . . 21

2.8 Pixhawk, an open source autopilot module onboard GustAV with embedded IMU and ARM processor. . . . . . . . . . . . . . . . . . . . . . . . . 22

2.9 Flight control system block diagram. . . . . . . . . . . . . . . . . . . . 23

2.10 Pixhawk autopilot avionics sub-assembly. . . . . . . . . . . . . . . . . . 24

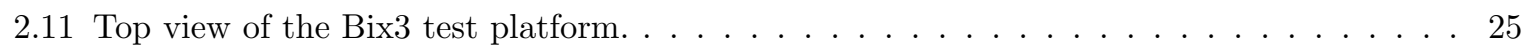




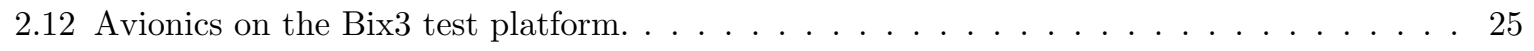

2.13 Airspeed sensing equipment on GustAV for navigation in autonomous mode. . . . . . . . 25

2.14 Software-in-the-loop (SITL) simulation running on a computer. . . . . . . . . . . . 26

2.15 Ground control station (GCS) and Spektrum DX7s radio controller. . . . . . . . . . . 27

2.16 Performing diagnosis on GustAV with the portable GCS. . . . . . . . . . . . . . 27

2.17 Graphic user interface of Mission Planner. . . . . . . . . . . . . . . . . 28

2.18 Wind measurement reference frames. . . . . . . . . . . . . . . . . . . . 29

2.19 Block diagram of air-data system setup on GustAV. $\ldots \ldots \ldots \ldots$

2.20 GustAV air-data system integration architecture. . . . . . . . . . . . . . . . 30

2.21 Five-hole probe and the flow angles, modified from 37$] \ldots \ldots \ldots$. . . . . . . 31

2.22 Relative wind sensors. . . . . . . . . . . . . . . . . . . . 32

2.23 Five-hole probe mounted on the right wing tip of GustAV. . . . . . . . . . . . 33

2.24 Steps taken to calculate the induced velocities using potential flow panel code. . . . . . . 34

2.25 Predicted angle of attack measurement offset at 5 degrees angle of attack. . . . . . . . . 34

2.26 Predicted angle of sideslip measurement offset at 5 degrees angle of attack. . . . . . . . 35

2.27 Angle of attack and angle of sideslip measurement offset acorss various angles of attack. . 36

2.28 Schematic of GNSS attitude determination 45$] \ldots \ldots \ldots \ldots$

2.29 Intersection of the lines of position from ambiguous range measurements. 45$]$. . . . . . . 39

2.30 GNSS receiver and antenna used on GustAV. . . . . . . . . . . . . . . . . . 39

2.31 Components of the weather ground station. . . . . . . . . . . . . . . 40

2.32 Weather ground station in operation at the flying field during experiment. . . . . . . . . 41

2.33 The cup anemometer and wind vane calibration setup in wind-tunnel at Ryerson University. 42

2.34 Elevation contour map of GustAV flight testing region at TEMAC field. . . . . . . . . 43

$3.1 \quad$ Ryerson University large wind tunnel 54$] \ldots \ldots \ldots$. . . . . . . . . . . 45

$3.2 \quad$ Five-hole probe experiment setup in the large wind tunnel at Ryerson University. . . . . . 45

$3.3 \quad$ Pressure port convention of the Aventech five-hole probe, modified from $[39] \ldots$. . . . . 46

3.4 The measured differential pressure $\left(p_{3}-p_{1}\right)$ at various speeds of freestream flow. . . . . . 47

3.5 The distribution of the signal noise at various freestream velocities and angles of attack with normal distribution fits. . . . . . . . . . . . . . . . . . . . . . 48 
3.6 Wing bending under aerodynamic load. $\ldots \ldots \ldots \ldots \ldots \ldots \ldots \ldots$

$3.7 \quad$ Balsa and fiberglass wing skin. $\ldots \ldots \ldots \ldots \ldots \ldots \ldots \ldots$

$3.8 \quad$ Flight $\log$ showing GustAV experienced directional instabilities during flight 7. . . . . . . 52

3.9 Dimensions of the new vertical stabilizer design on the left and the old design on the right. 53

3.10 Demanded roll and achieved roll after the flight control system has been tuned. . . . . . . 54

3.11 Flight path of the 'racecourse' circuit performed during flight $20 . \ldots$. . . . . . . . 55

3.12 Roll angle of the aircraft and GNSS satellite count during flights 20 and 23. . . . . . . 56

3.13 'Racecourse' pattern performed in flights 22 and 23 to collect wind measruements. . . . . 57

3.14 Flight path of the 'racecourse' circuit performed during flight $20 . \ldots \ldots \ldots$

$4.1 \quad$ Flight test profile of flight 23 with gusts measurement segments highlighted and labeled. . 59

$4.2 \quad$ Altitude and airspeed profiles of flight 23. Atmospheric gusts were measure from times-

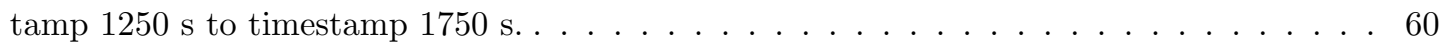

4.3 Wind speed and direction measured by GustAV $(50-100 \mathrm{~m})$ and weather ground station $(2 \mathrm{~m})$ from timestamp $1250 \mathrm{~s}$ to timestamp $1750 \mathrm{~s}$ during flight $23 . \quad \ldots \ldots$. . . . . . 62

4.4 Gust measurements at altitude of $100 \mathrm{~m}$ from timestamp $1330 \mathrm{~s}$ to timestamp $1460 \mathrm{~s}$

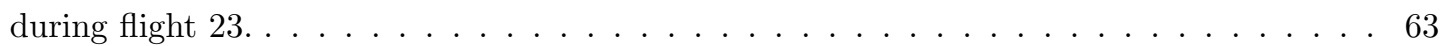

4.5 Gust measurements at altitude of $75 \mathrm{~m}$ from timestamp $1485 \mathrm{~s}$ to timestamp $1615 \mathrm{~s}$ during

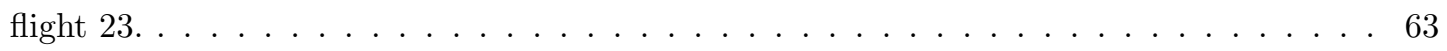

4.6 Gust measurements at altitude of $50 \mathrm{~m}$ from timestamp $1630 \mathrm{~s}$ to timestamp $1730 \mathrm{~s}$ during

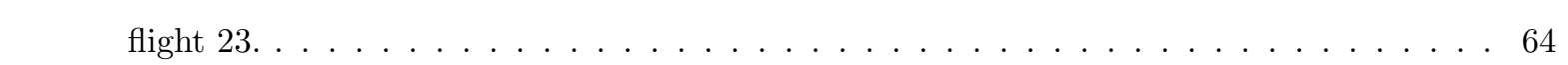

4.7 Gust spectra at altitudes of $100 \mathrm{~m}, 75 \mathrm{~m}$, and $50 \mathrm{~m}$ measured during flight 23 . . . . . 64

4.8 Wind speed estimation curve provided by wind power law and instantaneous wind speed measured at various altitudes during flight $23 . \ldots \ldots \ldots \ldots 6$

4.9 Gust spectra measured at altitudes of $100 \mathrm{~m}$ during flight 23 and the von Kármán models. 67

4.10 Gust spectra measured at altitudes of $75 \mathrm{~m}$ during flight 23 and the von Kármán models. 67

4.11 Gust spectra measured at altitudes of $50 \mathrm{~m}$ during flight 23 and the von Kármán models. 68

4.12 Turbulence intensities and scale length parameters derived from gust measurements and the comparison against the von Kármán models from MIL-HDBK-1797. . . . . . . . . . . 69

2.1 Recorded airspeed, altitude, and position during flight $17 . \ldots \ldots \ldots$ 
2.2 Recorded airspeed, altitude, and position during flight 18. . . . . . . . . . . . . . 77

$2.3 \quad$ Recorded airspeed, altitude, and position during flight $19 . \ldots \ldots \ldots$. . . . . . 78

2.4 Recorded airspeed, altitude, and position during flight 20. . . . . . . . . . . . . . 79

2.5 Recorded airspeed, altitude, and position during flight $21 . \ldots \ldots$. . . . . . 80

2.6 Recorded airspeed, altitude, and position during flight $22 . \ldots \ldots \ldots$. . . . . 81

2.7 Recorded airspeed, altitude, and position during flight 23. . . . . . . . . . . . . . 82

$3.1 \quad$ Thrust output as functions of airspeed and propeller RPM. . . . . . . . . . . . . . . . 83

3.2 Electrical power input as functions of airspeed and propeller RPM. . . . . . . . . . . . . 84

$3.3 \quad$ Mechanical power output as functions of airspeed and propeller RPM. . . . . . . . . . . 84 


\section{List of Appendices}

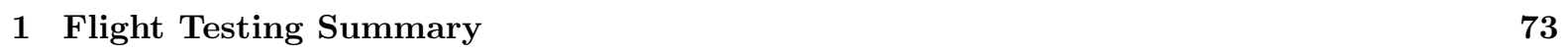

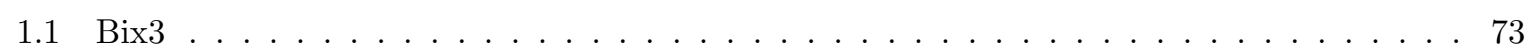

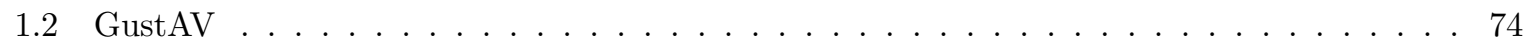

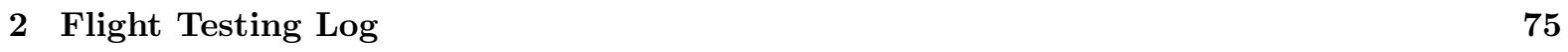

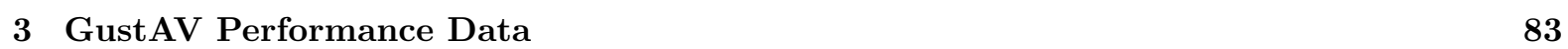

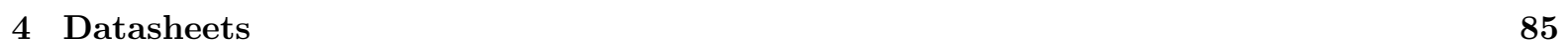




\section{List of Symbols}

\section{General Symbols}

$C_{L} \quad$ Lift coefficient

$C_{L_{\alpha}} \quad$ Slope of the lift curve

$g \quad$ Gust velocity

$L \quad$ Turbulence length scale

$p_{g} \quad$ Rolling rotary gust

$p_{i} \quad$ Pressure measured by the $i$ th probe port

$q_{g} \quad$ Pitching rotary gust

$S \quad$ Reference wing planform area

$s \quad$ Distance penetrated into the gust

$T / W \quad$ Thrust-to-weight ratio

U Longitudinal wind velocity

$u^{\prime} \quad$ Longitudinal gust velocity

$\bar{U} \quad$ Longitudinal mean wind velocity

$U_{0} \quad$ Design gust velocity

$V \quad$ Lateral wind velocity 


$\begin{array}{ll}v^{\prime} & \text { Lateral gust velocity } \\ \bar{V} & \text { Lateral mean wind velocity } \\ V_{\infty} & \text { Airspeed } \\ W & \text { Vertical wind velocity } \\ w^{\prime} & \text { Vertical gust velocity } \\ \bar{W} & \text { Vertical mean wind velocity } \\ W / S & \text { Wing loading } \\ z_{g} & \text { Heights above ground }\end{array}$

\section{Greek Symbols}

$\begin{array}{ll}\alpha & \text { Angle of attack } \\ \alpha & \text { Wind profile power law terrain roughness exponent } \\ a_{0} & \text { Angle of attack calibration offset } \\ a_{\alpha} & \text { Angle of attack calibration coefficient } \\ \beta & \text { Angle of sideslip } \\ \Omega & \text { Spatial frequency } \\ \omega & \text { Circular frequency } \\ \Phi & \text { Power spectral density } \\ \sigma & \text { Air density } \\ & \end{array}$

\section{Acronyms}

ABL Atmospheric Boundary Layer

ADC Analog-to-Digital Converter 


\author{
AGL Above Ground Level \\ BEC Battery Eliminator Circuit \\ CFD Computational Fluid Dynamics \\ EET Early Evening Surface-Layer Transition \\ ESC Electronic Speed Control \\ FAR Federal Aviation Regulations \\ FBW Fly-by-Wire \\ FFT Fast Fourier Transform \\ GNSS Global Navigation Satellite System \\ GPS Global Positioning System \\ GS Ground Speed \\ IAS Indicated Airspeed \\ IMU Inertial Measurement Unit \\ RMS Root-Mean-Square \\ SITL Software-in-the-Loop \\ TEMAC Toronto Electric Model Aviation Club \\ UAV Unmanned Aerial Vehicle \\ WAAS Wide Area Augmentation System
}




\section{Chapter 1}

\section{Introduction}

\subsection{Motivation}

Over the last couple of decades, small unmanned aerial vehicles (SUAVs) have been gaining popularity and are becoming more widely used. Traditionally used mainly for military purposes, advanced miniaturized sensors, have led small unmanned aerial vehicles being adopted by the commercial sector, consumer market, and research communities. Small unmanned aerial vehicles are versatile when equipped with a combination of sensors and pre-programmed flight plans to meet the mission requirement such as search and rescue, mapping, environmental studies, aerial imaging, and meteorology [1 5 . Many of these small unmanned aerial vehicles are performing missions at less than half a kilometer above the terrain due to the nature of their missions, engine output capability, and regulatory limitations. For example, several small multi-rotor unmanned vehicles use advanced control algorithms that allow operation and target following at extremely low altitudes of less than several meters above the ground 6 .

In many applications, small and mini unmanned aerial vehicles are required to operate in proximity of obstacles, which requires precise control algorithms [1,2,7]. These vehicles are sensitive to a gusty environment because of their smaller overall dimensions and inertia. Slower flight speed also means atmospheric turbulence would have greater effects on these small vehicles while not affecting full-sized aircraft [8]. Therefore, atmospheric gusts have a significant impact on flight control and vehicle endurance

performance on small and micro UAVs. Previous work has attempted to model autonomous flight under windy conditions [9]. Galway has investigated the effect of turbulent wind generated by buildings on 
small unmanned aerial vehicles using computational fluid dynamics [10. The difficulties of describing the turbulence characteristics at low altitudes have been outlined by Watkins [11. The wind profile within the atmospheric boundary layer is influenced by factors including elevation, time of day, seasons, and terrain roughness. Low altitude winds are also subject to local features, such as buildings and obstacles.

A representative model can be used to describe the physical characteristics of the atmospheric wind profile within the atmospheric boundary layer. Such a model can help in improving our understanding of flight characteristics of small unmanned aerial vehicles. Accuracy and reliability of flight performance prediction of small UAVs can be further improved. For example, research has been directed towards extracting energy from atmospheric turbulence by using 'gust-soaring' 12. These studies have shown the possibility of improving the range and endurance of small unmanned aerial vehicles through such an approach. They also pointed out that there are little empirical data on gusts experienced by small UAVs are available in literature. Although the Dryden and von Kármán models were frequently used to provide the power spectral density of the gust in research papers, they were developed mainly to characterize turbulence encounter by full-scale aircraft $[13$. Since there is a lack of validated small scale aircraft turbulence models, researchers especially ones who focus on control system design were forced to adopt Dryden or the von Kármán gust models which may not be truly descriptive of reality for small aircraft. Hence extra efforts have to be made to validate the results on small scale aircraft which often is out of the scope of these research. Wind and gust data measured at low-altitudes can enhance and update the existing model and benefit the future development of small UAVs in windy environment.

\subsection{Atmospheric Boundary Layer}

The atmospheric boundary layer can be defined as the closest part of the atmosphere that is directly influenced by the earth's surface 14]. In this portion of the troposphere, it is subjected to high energy dissipation caused by atmospheric forces. These forces include frictional drag with earth's surface, heat transfer, pollutant emission, evaporation, etc. In other words, it is highly dependent on the terrain features and the activities taking place on the planet's surface. The atmospheric boundary layer thickness can vary due to the surface roughness of the earth's surface. Therefore as shown in Fig. 1.1, due to the presence of buildings, urban areas would create a thicker boundary layer than the rural counterpart 14. 15. Moreover, the heating effects of buildings ('urban heat island') creates upward air motion 


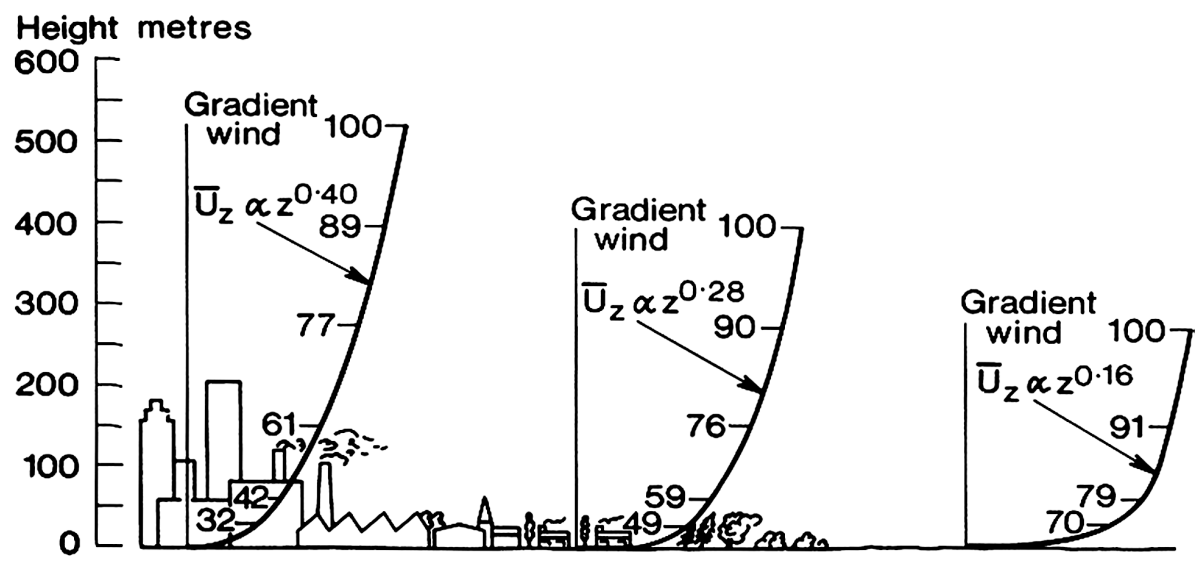

Figure 1.1: Mean wind profiles for a range of ground roughness. 15.

through buoyancy effect that further increases the thickness of the boundary layer [10].

The boundary layer is also affected by the heat exchange in the atmosphere through out the day, hence, the thickness of the boundary also varies in time. One example of the phenomenon which is related to the time of day is the Early Evening Surface-Layer Transition (EET) which takes place in the first one or two hours after sunset. Temperature drops and wind speed decays abruptly during the transition at the highest rates during the EET [5]. This shows the properties of the atmospheric boundary layer is localized and changes at the timescale of hours. Due to the nature of the applications of SUAVs, these vehicles spend their mission almost exclusively inside this rapidly changing, localized atmospheric boundary layer. Therefore, measuring the properties of low-altitude gust profile can improve the insight of predicting flight performance of UAV flying at in the atmospheric boundary layer. Multiple methods of probing the boundary layer have been used in past studies ranging from fixed based measurement using the sodar (acoustic) wind profiler 16, 17, on a tethered weather balloon and full-size manned aircraft 18 20]. Previous experiments have shown that SUAVs can perform atmospheric boundary layer probing in more cost-effective fashion than equipping full-size aircraft with the advantage of large survey area coverage than ground-fixed equipment can achieve [16,21]. Thus, an unmanned aerial vehicle with a five-hole probe was developed and has been used as an experimental platform to measure atmospheric wind gusts within the atmospheric boundary layer. 


\subsection{Flying in Gust}

For aircraft design and certification, the study of gust and its effect on aircraft is important in two perspectives. This document refers atmospheric turbulence and gust as the positive and negative deviations of the wind velocity about the mean:

$$
u^{\prime}=U-\bar{U}
$$

where the turbulence deviation $u^{\prime}$ is calculated by subtracting the mean wind velocity, $\bar{U}$, for any time period from the actual instantaneous velocity, $U$. The gust component can be positive or negative depends on which the actual wind is faster or slower than the average wind velocity 14 .

Consequently, atmospheric gusts also cause fluctuations in other atmospheric properties such as temperature, humidity, and gas concentration. However, for aeronautic applications, the focus is on the wind velocities of the three-dimensional wind field:

$$
\begin{gathered}
U=\bar{U}+u^{\prime} \\
V=\bar{V}+v^{\prime} \\
W=\bar{W}+w^{\prime}
\end{gathered}
$$

In the field of gust research, the longitudinal turbulence, $u^{\prime}$, aligns to the mean wind vector as shown in 1.2. The lateral gust turbulence, $v^{\prime}$, is orthogonal to the direction of mean wind and the vertical axis, $w^{\prime}$, is defined vertical down 22 .

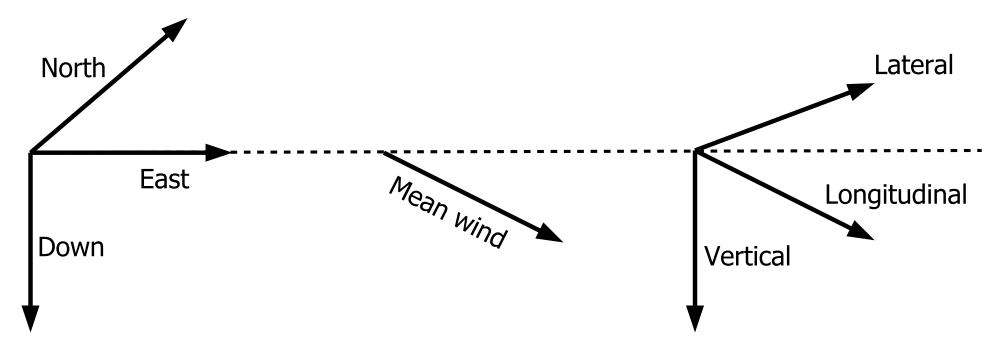

Figure 1.2: The earth-fixed frame aliged to the direction of mean wind.

One of the important aspects of studying gusts is to determine the strength of the gust an aircraft 
can encounter on its flight path. In a static load analysis case, gust loading can be related to the maximum aerodynamic turbulence load the aircraft may experience during its flight mission. Moreover, the frequency aspect of a given gust can affect the load cases as it can relate to the natural frequencies of the structure. Therefore when describing a gust load, the frequency and strength of a gust are equally important when considering the dynamic motion of an aircraft. Another aspect is related to stability and control of the aircraft. While traveling through disturbances in the atmosphere, development of control algorithms for navigation and guidance also requires the amplitude and frequency of the gust to be described in mathematical forms or they can also be referred as gust models.

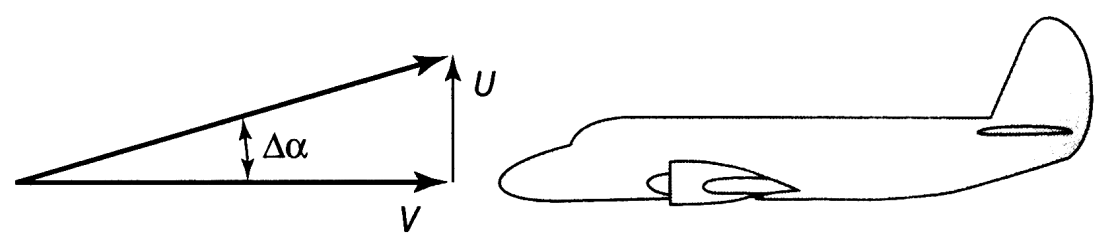

Figure 1.3: Change in angle of attack by upward gust $U .23$.

In order to calculate the aerodynamic forces that the aircraft experience gusts during encounter, the gust models get applied onto kinematics equations. For example, as shown in Fig. 1.3, when the aircraft encounters an upward gust of velocity $U$, the changes in the angle of attack can be approximated:

$$
\Delta \alpha=\tan ^{-1} \frac{U}{V_{\infty}} \simeq \frac{U}{V_{\infty}}
$$

The aircraft lift is shown in Eq. is proportional to the gust velocity combining with the lift-curve slope:

$$
\Delta L=\frac{1}{2} \rho V_{\infty}^{2} S\left(C_{L_{\alpha}} \Delta \alpha\right)=\frac{1}{2} \rho V_{\infty} S C_{L_{\alpha}} U
$$

Finally, the resultant change in load factor caused by the upward gust is derived:

$$
\Delta n=\frac{\Delta L}{W}=\frac{\rho U V_{\infty} C_{L_{\alpha}}}{2 W / S}
$$

The above equations provide a very crude approximation of the resulting change in lift force and the 
load factor of an aircraft flying through a gust. In most cases, it is an unrealistic estimate while assuming the aircraft instantly encounters the gust and it is affecting the entire aircraft. However, Eq. 1.7 shows that the change in load factor is inversely proportional to the aircraft's weight. Therefore, gusts have a greater effect on small and lightweight UAVs than aircraft with higher wing loading [23].

A more realistic approach to determine the aircraft response to atmospheric gust field is to include the spatial variations in the gust components. This method provides a direct representation of the gust effects on aircraft's flying qualities. Gusts are represented in terms of the rolling or pitching effects the vehicle experiences caused by the gusts. For example, the vertical gusts can produce a variation in wind velocity along the span-wise direction of the aircraft, causing an effective rolling gust. Similarity, gusts along the X-axis of the aircraft can be causing an effective pitching motion as both cases are illustrated in Fig. 1.4 [24. The rolling rotary gust $p_{g}$ and pitching rotary gust $q_{g}$ can be related to the vertical gust field $w_{g}$ :

$$
\begin{aligned}
& p_{g}=\frac{\partial w_{g}}{\partial y} \\
& q_{g}=\frac{\partial w_{g}}{\partial x}
\end{aligned}
$$

The response to gusts of the aircraft can be computed by including the turbulence forces and moments with the equations of motion. Depends on the application, different types of gust model such as step or sinusoidal function can be incorporated into the state space model. For continuous stochastic turbulence profiles, they can be described with power spectral densities which are shown in Section 1.4.1.

\subsection{Atmospheric Gust Research}

In this section, existing gust models are described and explained their shortfalls, along with the applications of gust models in UAV developments. Also, atmospheric probing and low-altitude gust research done previously are listed to provide an overview of the current development in this research field.

\subsubsection{Existing Gust Models}

Different models can be used to describe the profile of atmospheric turbulence depending on the application and methodology of the analysis. A one-minus-cosine profile can represent a segment of a larger 

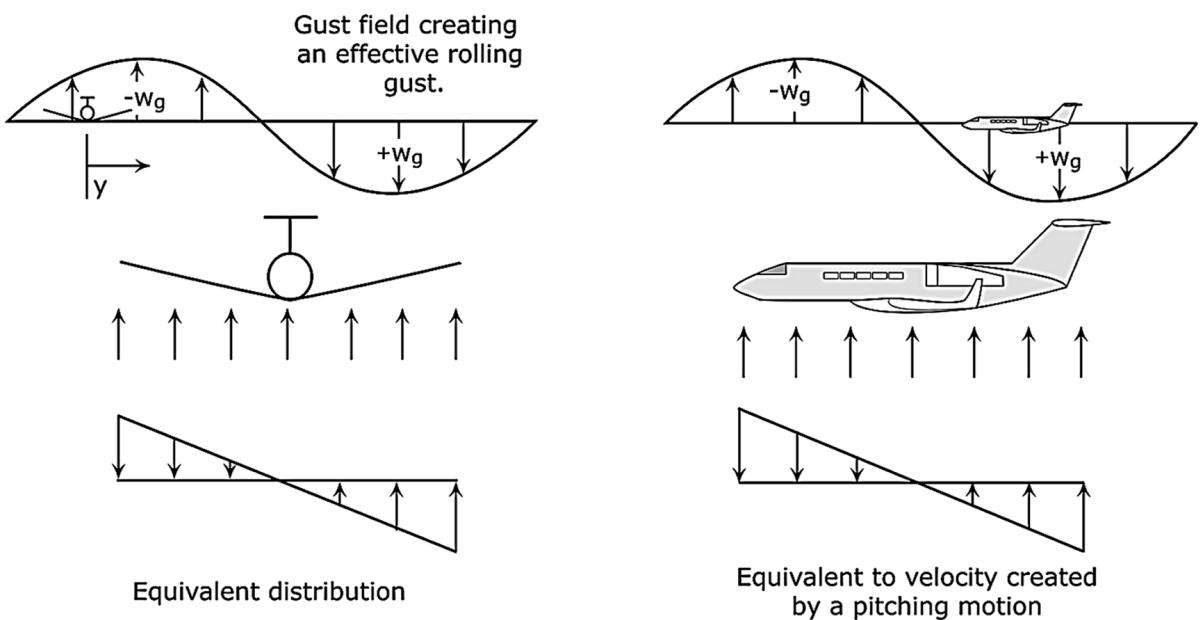

Figure 1.4: Gust field creating an effective rolling and pitching gust 24.

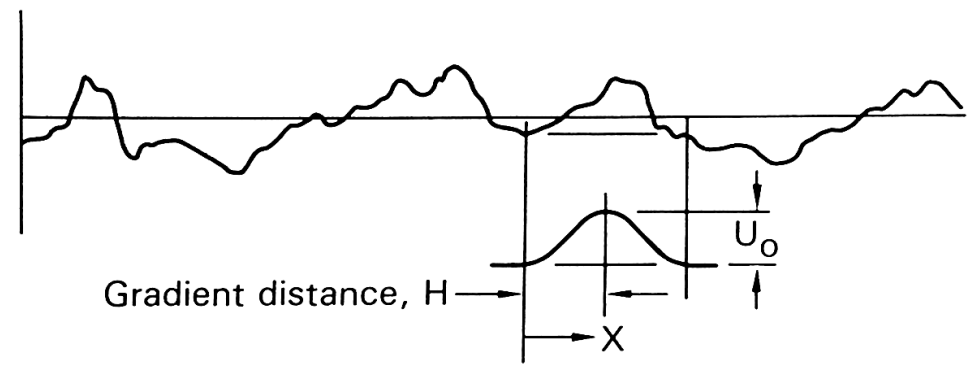

Figure 1.5: A one-minus-cosine discrete approximation within a continuous gust profile 25.

continuous turbulence profile (Fig. 1.5). This simplified approximation is an example of a discrete gust model. The one-minus-cosine discrete gust model is widely used to evaluate the effects of gusts on an aircraft structure. The gust velocity defined in Eq. 1.10 is included in the Federal Aviation Regulations (FAR) Part 25.341 to outline the acceptable methods to determine the response of the aircraft to encounters with gusts 26 .

$$
U=\frac{U_{0}}{2}\left[1-\cos \left(\frac{\pi x}{H}\right)\right]
$$

where $x$ is the distance penetrated into the gust in feet and $H$ is the distance in feet between the start of the gust to the point where the gust is at its peak velocity. The value $U_{0}$ is the design gust velocity which varies in strength relative to the flight altitude defined in the regulations. Although discrete gust model provides a simple way to model a subset of atmospheric gust for structural analysis useful 
when determining critical aerodynamic loads 23, 27. For more detailed and advanced analyses such calculating the dynamic behavior of an aeroelastic structure or validation of a control system algorithm would require a more sophisticated continuous turbulence model.

Since a gust is defined as random deviations of wind speed from the mean value, when constructing a statistical model of wind gusts, it is considered to be a stochastic process. In gust measurement and modeling, it is practical to assume the statistical properties of the gusts are stationary and homogeneous 14 24 28. A continuous gust field can be represented by power spectral density (PSD), a distribution of power across the frequency spectrum. By describing the gust field in frequency domain, a whole spectrum can be fitted into a mathematical modal compared to a single wavelength discrete-gust model. Therefore the two commonly used turbulence models, von Kármán and Dryden, use the power spectral density to model the continuous gust fields. Both models are widely used in applications such as flight simulation and control system design $[22$. While, the spectral density modeled by the Dryden turbulence model is still heavily used in control algorithm research because it is able to derive the exact filter for the Dryden spectrum when the filter can only be approximated with the von Kármán spectrum [28]. However, the von Kármán turbulence model allows a better fit to previously observed data 25.

The mathematical expressions of the von Kármán power spectral density function $\Phi(\Omega)$ for longitudinal gust and transverse gust (vertical or lateral) are shown in equations 1.11 and 1.12 respectively.

$$
\begin{aligned}
\Phi_{u}(\Omega) & =\sigma^{2} \frac{L}{\pi} \frac{1}{\left[1+(1.339 L \Omega)^{2}\right]^{5 / 6}} \\
\Phi_{v}(\Omega)=\Phi_{w}(\Omega) & =\sigma^{2} \frac{L}{\pi} \frac{1+\frac{8}{3}(1.339 L \Omega)^{2}}{\left[1+(1.339 L \Omega)^{2}\right]^{11 / 6}}
\end{aligned}
$$

where $\sigma$ is the turbulence intensity and $L$ is the length scale parameter of the turbulence. The $\sigma$ can also be described as the root mean square value of the gust velocities and he value of $L$ describes the scale of the turbulence patch. To apply the appropriate parameter settings to the von Kármán model, empirical data from the Military Specification MIL-F-8785C is often used 29]. These empirical expressions relate the turbulence intensity and length scale of the turbulence with altitude and mean wind speed. Fig. 1.6 shows an example of a von Kármán power spectral density plot with turbulence intensity of $1 \mathrm{ft} / \mathrm{s}$ and length scale parameter of $2500 \mathrm{ft}$. The common practice is to draw the power spectral density function, $\Phi(\Omega)$, against the spatial frequency, $\Omega$ on a logarithmic scale. The power spectrum density curves 
produced by the von Kármán turbulence model have a knee and a straight line segment. The length parameter, $L$, determines where the power spectrum density curve occurs. The staright line will always have a $-5 / 3$ slope at the higher frequencies matching Kolomogorov's $-5 / 3$ power law 21 .

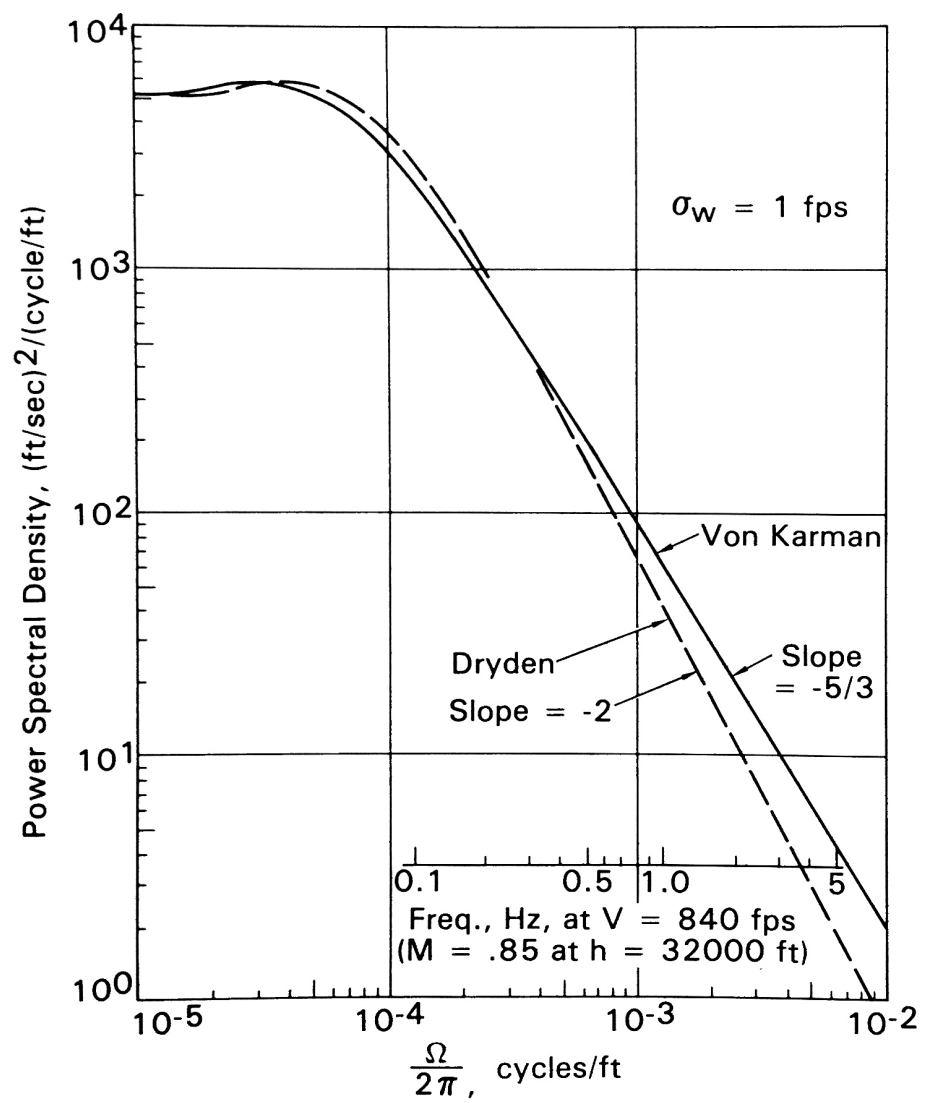

Figure 1.6: Von Kármán and Dryden gust power spectral density curves, L $=2500 \mathrm{ft}[25]$.

These results are based on the early effort by the U.S. military in studies of flying qualities and later adopted by aircraft manufacturers and government agencies to use on aircraft design and certification. In the Military Handbook MIL-HDBK-1797 published in 1997 reiterates the model given in with minor adjustment [30]. Since this latest model had been widely used on full-sized manned aircraft design, it will be used to compare against the experimental data in Chapter 4

To recall from Section 1.3 gusts across a period of time have a mean value of zero because of its normally distributed fluctuations. The standard deviation of the gust velocities can be calculated by 
the root-mean-square (RMS) value, also known as the intensity of the gust. The gust intensity can be evaluated with Eq. 1.13 where $N$ is number of samples taken in the data and $g$ is the gust velocity.

$$
\sigma_{g}=\sqrt{\overline{g^{2}}}=\sqrt{\lim _{T \rightarrow \infty} \frac{1}{2 T} \int_{T}^{-T} g^{2} d t}=\sqrt{\lim _{N \rightarrow \infty} \frac{1}{N} \sum_{i=N}^{i=1} g_{i}^{2}}
$$

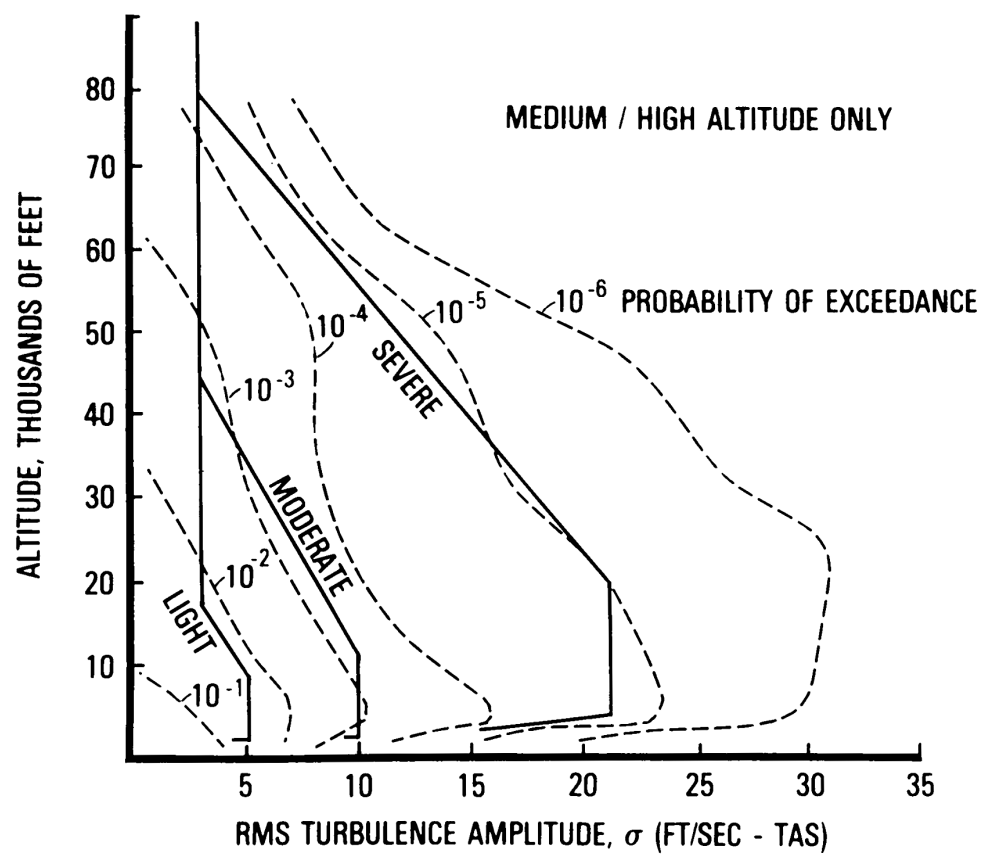

Figure 1.7: Turbulence intensity and exceedance probability 30 .

Gust model under different altitudes and weather scenarios can be described in statistical model by applying different gust intensities and exceedance probability at varies altitude and mean wind speed specified in the Military Handbook MIL-HDBK-1797 as shown in Fig. 1.7. The handbook also suggests that the free atmosphere at altitudes above 2000 feet can be considered isotropic. Hence, the assumption of equal turbulence intensities through out all three directions where $\sigma_{u}=\sigma_{v}=\sigma_{w}$ while the assumption does not apply to altitudes below 2000 feet which is within in atmospheric boundary layer. For altitude below 1000 feet, the MIL-HDBK-1797 provides a sets of empirical equations to model the turbulence intensities and the scale length parameters [30]. The vertical turbulence intensity, $\sigma_{w}$, of the lowaltitude model provided by the handbook is defined in terms of the mean wind speed at 20 feet above 
the surface, $U_{20}$ :

$$
\sigma_{w}=0.1 U_{20}
$$

The longitudinal turbulence intensity, $\sigma_{u}$, and lateral turbulence intensity, $\sigma_{v}$, are defined as:

$$
\sigma_{u}=\sigma_{v}=\frac{\sigma_{w}}{(0.177+0.000823 h)^{0.4}}
$$

The length scale parameters are represented:

$$
\begin{aligned}
2 L_{w} & =h \\
L_{u}=2 L_{v} & =\frac{h}{(0.177+0.000823 h)^{1.2}}
\end{aligned}
$$

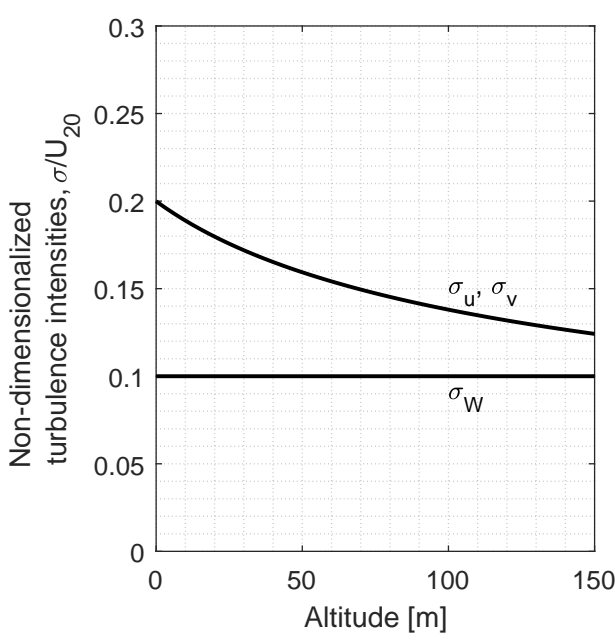

(a) Turbulence intensites model.

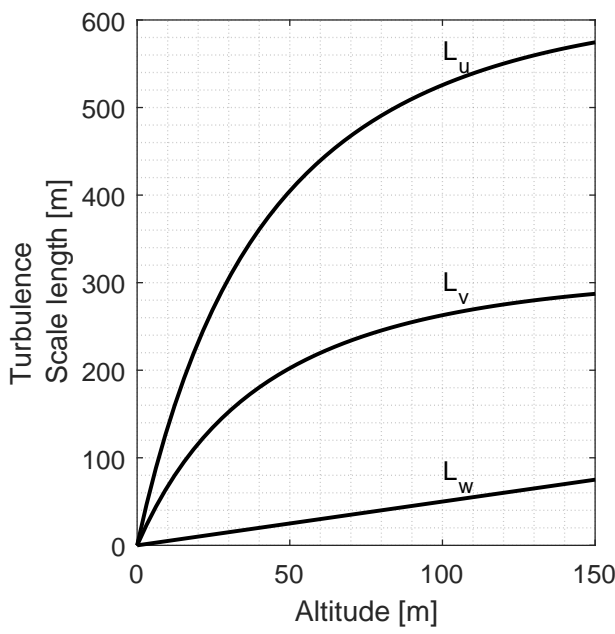

(b) Turbulence scale length model.

Figure 1.8: MIL-HDBK-1797 low altitude turbulence model.

The low altitudes turbulence intensities and scale length parameters models shown in Fig. 1.8 are designed to work with the von Kármán turbulence model and governed by the altitude. Experimental gust measurements are compared to these empirical models in Chapter 5. 


\subsection{Objective}

The research objective is to gather experimental wind gust data at altitudes below $200 \mathrm{~m}$, compare the result with existing gust models, and discuss the effectiveness of using existing models for developing small unmanned aerial vehicles. In order to fulfill this goal, the tasks include:

- design and construct a radio-controlled aircraft suitable for low-altitude meteorological sensing.

- The aircraft needs to be able to fly autonomously and follow programmed flight path with an onboard autopilot system. Flight testing has to be done to ensure the aircraft can perform flight missions as designed.

- Mount and calibrate the air-data sensors on the flight vehicle.

- Extract wind-gust data from the experimental data adn compare the data with analytical models.

Chapter 2 outlines the methodology of the flight experiments and the equipment used. The wind tunnel and in-flight testings are presented in Chapter 3 with results discussed in Chapter 4 . Finally, Chapter 5 contains the conclusion of the project and recommendations for future work. 


\section{Chapter 2}

\section{Methodology}

\subsection{Atmospheric Turbulence Experiment}

In the past, various types of platforms have been utilized in order to measure atmospheric turbulence within the atmospheric boundary layer. The three major platforms that are commonly used by meteorological researchers are tower-based platform, manned aircraft, and unmanned aircraft and each of these methods were developed for different experiment duration, coverage, and sensitivity.

\subsubsection{Instrument Platforms}

The tower-based platform is often used for atmospheric boundary layer research as they range from a $30 \mathrm{~m}$ mast to a to $200 \mathrm{~m}$ tall tower to perform surface layer measurement in the air. In some cases, making measurement at one point over a long time period is preferable as capturing a snapshot picture of a large region of space at a specific instant in time seems impractical. Therefore, the 'picture' of the boundary layer observation can be composed by using a time record of the measurement as the air blows past the sensors over time. 


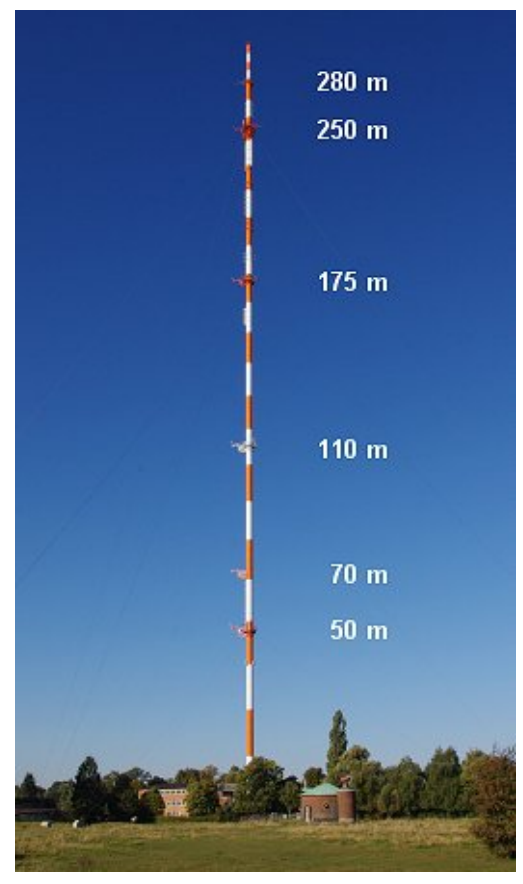

(a) Hamburg Weather Mast 31.

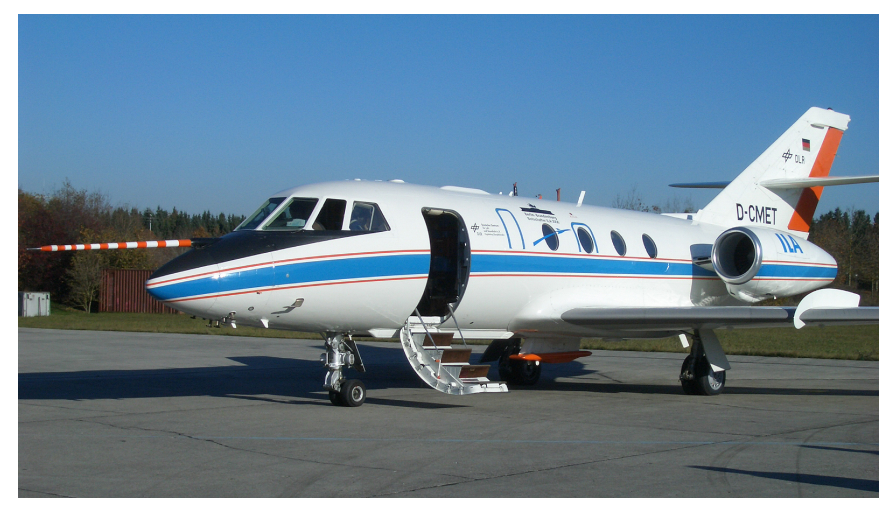

(b) DLR research aircraft Falcon 20E 32 .

Figure 2.1: Examples of atmospheric research platform.

\section{Tower-Based Platform}

Tower-based platforms are ideal for these type of long-term measurement at a specific location and various altitudes can be measured simultaneously with equipment mounted at different levels on the mast or tower. A typical mast height is $10 \mathrm{~m}$ to $50 \mathrm{~m}$ and can be erected at relatively inexpensive cost 14]. Some tall expensive towers have been erected which can reach the height of over $200 \mathrm{~m}$. Example include the $280 \mathrm{~m}$ Hamburg Boundary Layer Measurement Tower in Germany (Fig 2.1a] 32. Although these tall towers can reach higher altitudes, which is desirable for coverage of flight altitudes of small unmanned vehicles, construction of such tall structure would be costly and time-consuming. The large structure and its support wires can disturb the flow close to the tower. Therefore in most setups, multiple horizontal booms are extended out from the tower to capture the undisturbed airflow in the upwind direction which further increases the cost of performing such experiment. 


\section{Manned Aircraft}

Manned aircraft ranging from ultra-light to multi-engine transport aircraft had also been used in the past to perform boundary layer meteorology research. One example is the DLR research aircraft Falcon 20E (Fig 2.1b which is able to conduct atmospheric measurement with the onboard LIDAR and other optical instruments $[32$. To collect data of boundary layer, typical flight mission consists of level horizontal flight in ' $L$ ' or 'race-course patterns. Usually, sensors are mounted forward to the nose of the aircraft to get the instruments out of the disturbed flow due to the aircraft itself. In some cases, passive instruments such as doppler radar/lidar/sodar are also mounted on the side of the aircraft. Compare to a fixed platform, an airborne platform has coverage areas which are orders of magnitude larger than a tower based system can offer and can perform measurement at the higher altitude of above $300 \mathrm{~m}$. The larger manned aircraft allow heavier instruments to be onboard along with engineers and scientists to perform real-time analysis. Drawbacks of unitizing manned aircraft platform include high setup and operating costs. Moreover, since typical aircraft operate at speed of 50 to $100 \mathrm{~m} / \mathrm{s}$, the turbulence sensors onboard must have a correspondingly fast response in order to gather data with robust statistics.

\section{Unmanned Aircraft}

Recently, with the development of miniaturized airborne sensors and increasingly realizable autonomous flight control system, unmanned aerial vehicles have become a major tool used in atmospheric research. Many UAVs are capable of reaching altitude of over $1000 \mathrm{~m}$ with a payload of various shapes and sizes. UAVs provide advantages of an airborne platform at drastically lower cost compare with manned aircraft platform. Moreover, electrically powered UAVs are especially suitable for doing atmospheric measurement as exhaust gas from internal combustion engine can cause problems on measuring gas composition. Unmanned vehicles can also perform flights a lot closer to the ground, which is beneficial to low-altitude gust measurement. UAVs can maintain flight path at altitude as low as $25 \mathrm{~m}$ above ground, which is considered to be too low and dangerous for a manned aircraft.

\subsection{GustAV Aerial Research Platform}

The primary objective was to build a radio-controlled unmanned aerial vehicle that provides an experimental platform for an air-data system in order to measure the wind fields. The aircraft has to carry the 
meteorological instrument while performing autonomous flight missions with an endurance of 25 minutes. It was determined that existing consumer products from radio-controlled airframe manufacturers were unsuitable for the mission and payload. The Gust Aerial Vehicle, or GustAV, is shown in Fig. 2.2. It is a fixed-wing model aircraft with a conventional configuration. Figure 2.3 shows the three-view outline of the design.

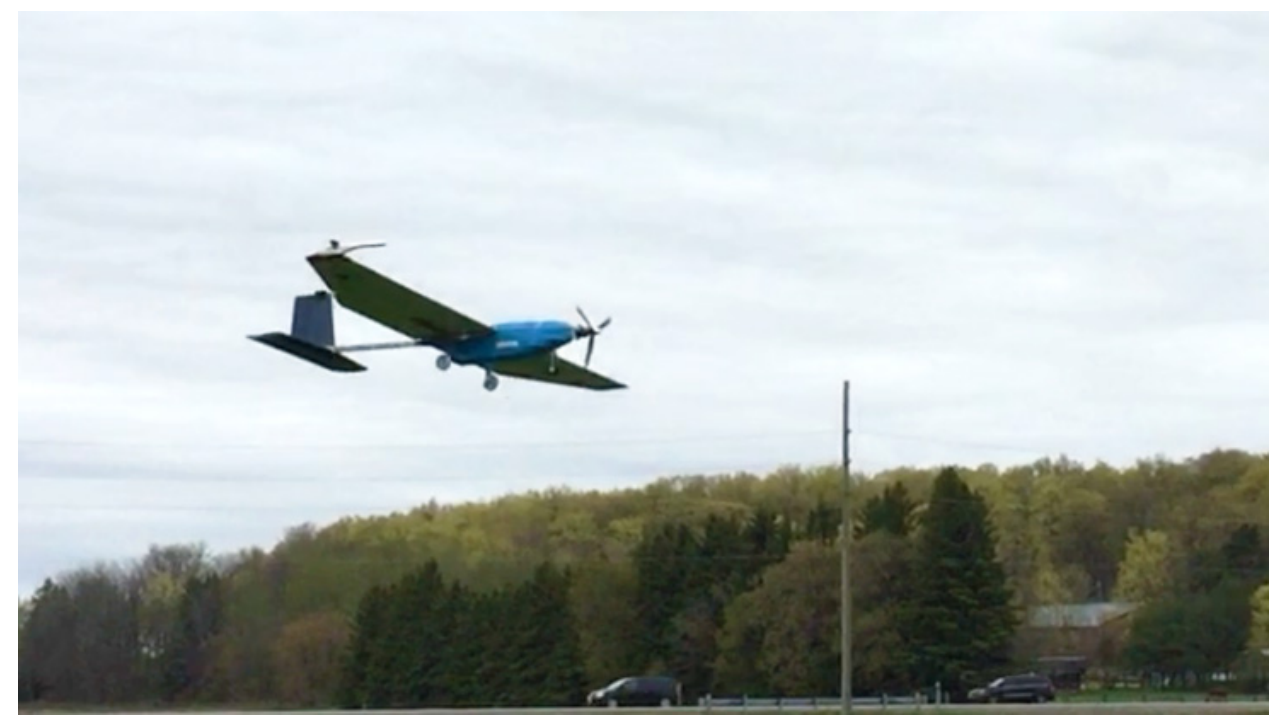

Figure 2.2: GustAV aerial research platform flying with a five-hole probe mounted on wing-tip.

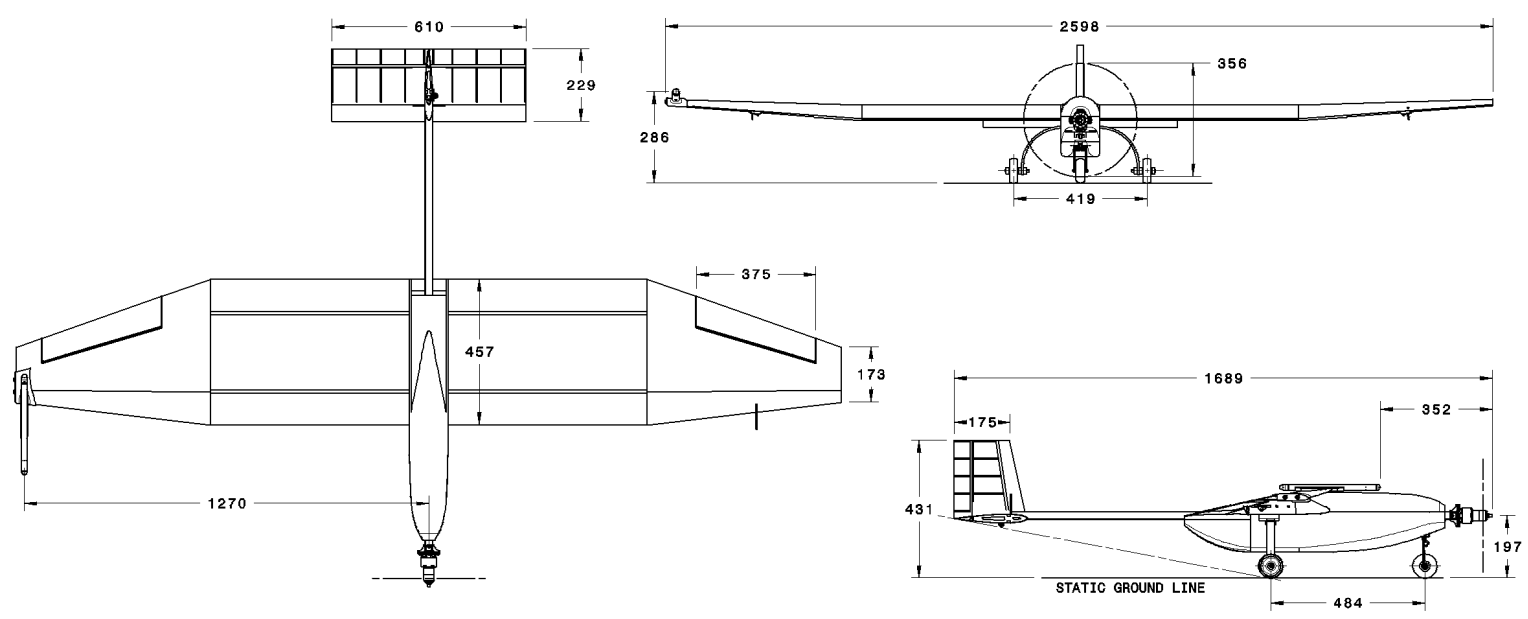

Figure 2.3: 3-view of GustAV and the five-hole probe location 33. 
Table 2.1: Specification and performance of GustAV.

\begin{tabular}{ll}
\hline \hline Mass & $7.52 \mathrm{~kg}$ \\
Wing span & $2.54 \mathrm{~m}$ \\
Length & $1.69 \mathrm{~m}$ \\
Wing planform area & $1.0 \mathrm{~m}^{2}$ \\
Mean aerodynamic chord & $0.41 \mathrm{~m}$ \\
Airspeed (cruise/min/max) & $15 \mathrm{~ms}^{-1} / 10 \mathrm{~ms}^{-1} / 25 \mathrm{~ms}^{-1}$ \\
Endurance & $25 \mathrm{mins}^{\mathrm{m}}$ \\
Motor & $900 \mathrm{~W}$ electric brushless \\
Main battery & $22.2 \mathrm{~V}, 8000 \mathrm{mAh}$ \\
Avionics battery & $11.1 \mathrm{~V}, 2200 \mathrm{mAh}$ \\
\hline
\end{tabular}

Several modifications were applied to the wing and stabilizers in order to improve handling qualities and the structure integrity of the aircraft. GustAV has a wing span of $2.54 \mathrm{~m}$ at an operational weight of $7.52 \mathrm{~kg}$. The airframe was made with balsa wood structure with fiberglass skin reinforcement, which made it unusually strong and heavy for a UAV. This was to maximize the longevity of the airframe against the repeating grass landing and flying in strong and turbulent wind.

The primary objective of the GustAV airframe is to provide an aerial platform to perform atmospheric gust measurements at low altitudes. The summary of specification and performance of GustAV are listed in Table 2.1. The design of GustAV was inspired by the radio-controlled model aircraft built by the Ryerson Aero Design student team in 2016. Sharing similar design parameters and manufacturing methods sped up the development process of GustAV and allowed the research to be focused on the experiment. However, modifications of the designs was still to be made to adopt the atmospheric sensors and extra avionics which were not incorporated in the original design.

To complete the GustAV experimental platform, the airframe had to be integrated with sensing hardware. The avionics package was required to be robust and efficient by balancing the cost, power consumption, and mass. There are two types of electronic equipment, first is the flight control avionics which controls the aircraft. This part of the system provides the autonomous flight capability and communication for in-flight system monitoring. Most of the flight control system consists of commercial off-the-shelf components. However, customizations were done on both hardware and software levels in order to achieve the specific goals of this project.

The second type of electrics onboard GustAV supports the scientific research goal of this thesis, to measure the atmospheric gust at altitudes. Therefore, a commercially available air-data system, Aventech 
AIMMS-30, was integrated in the airframe. The air-data system was made available by Aventech Research Inc. of Barrie, Ontario. Detailed description of the air-data system is listed in Section 2.4 . The major elements of this air-data system include a five-hole probe, Global Navigation Satellite System (GNSS) receivers, and an inertial measurement unit (IMU). The five-hole probe measures the relative inflow angles of the local flow field. Along with the data measured the GNSS receivers and IMU, the direction and magnitude of the wind can be determined by performing data filtering and reference frame transformation. Challenges associated with the integration of the air-data system included significant weight reduction that had to be made to the air-data system as it was originally designed for full-sized aircraft. The datasheet provided by Aventech Research Inc. is included in Appendix 4 which outlines specifications of the air-data system.

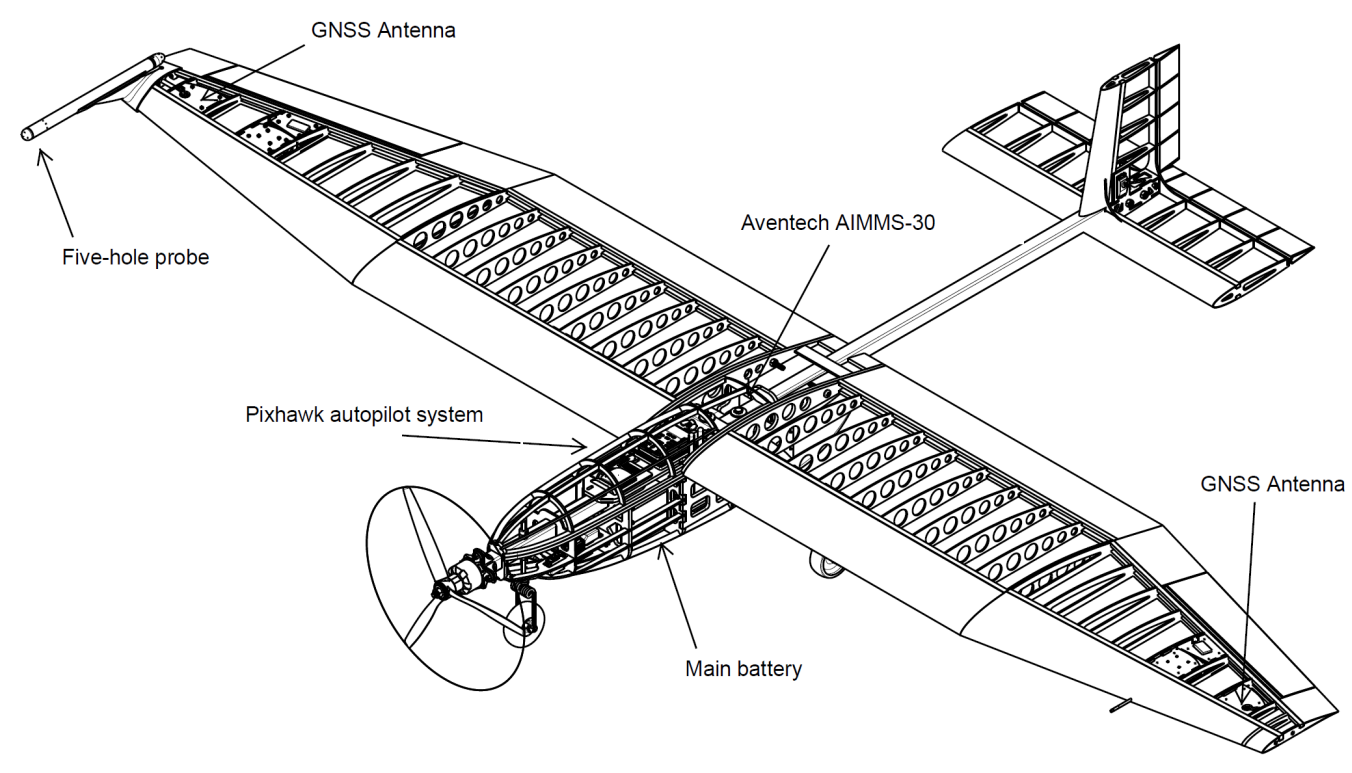

Figure 2.4: Isometric drawing of GustAV structure layout and major components.

\subsubsection{Aircraft Configuration}

GustAV consists of a balsa wood structure on an aluminum frame, to which the wing, landing gears, tail, and the motor are mounted (Fig. 2.4. The main wing is reinforced with fiberglass skin in order to minimize bending during flight and reduce the chance of damage during ground handling. The modular construction allows the airframe to be taken apart for transportation and regular maintenance. The 
main fuselage can be accessed from the top or at the rear in order to easily install and remove the batteries between flight missions. Along with the batteries, the avionics are enclosed inside the fuselage. As part of the air-data system, two GNSS antennas and a five-hole probe are mounted on the main wing. The technical drawings of the five-hole probe are included in Appendix 4

\subsubsection{Propulsion}

GustAV has a Scorpion SII-4020-420KV brushless motor (Fig. 2.5a) that is mounted at the nose of the aircraft. It is rated at approximately 900 Watts while running at full throttle. The motor has a machined aluminum housing. The rear threaded mounting holes are used to attach the motor to dedicated mounting points on the motor mount. The electrical wires are rated to operate at $180^{\circ} \mathrm{C}$ $\left(356^{\circ} \mathrm{F}\right)$ in order to reduce the risk of overheating the motor windings at high power output. The motor operates at $450 \mathrm{RPM} /$ volt. The outer diameter of the motor is $48.9 \mathrm{~mm}$ and body length of $46.15 \mathrm{~mm}$. The motor is rated for maximum continuous current and power of 70 Amps and 1500 Watts respectively. The total weight of the motor is $288 \mathrm{~g}$.

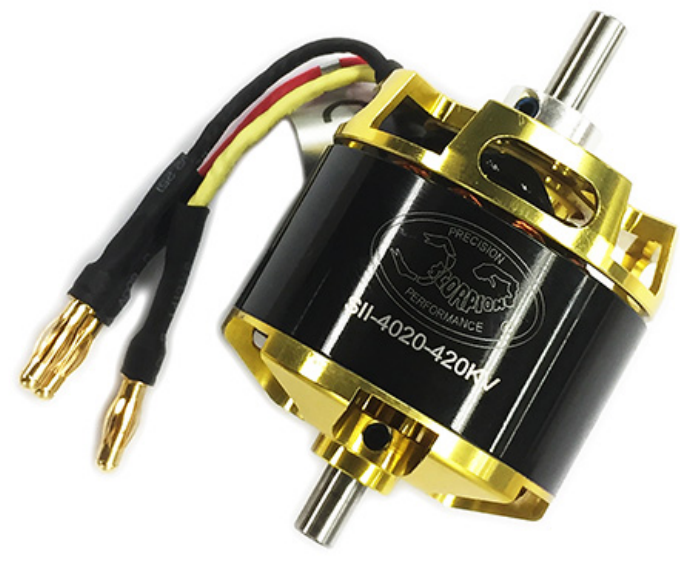

(a) Scorpion SII-4020-420KV brushless motor.

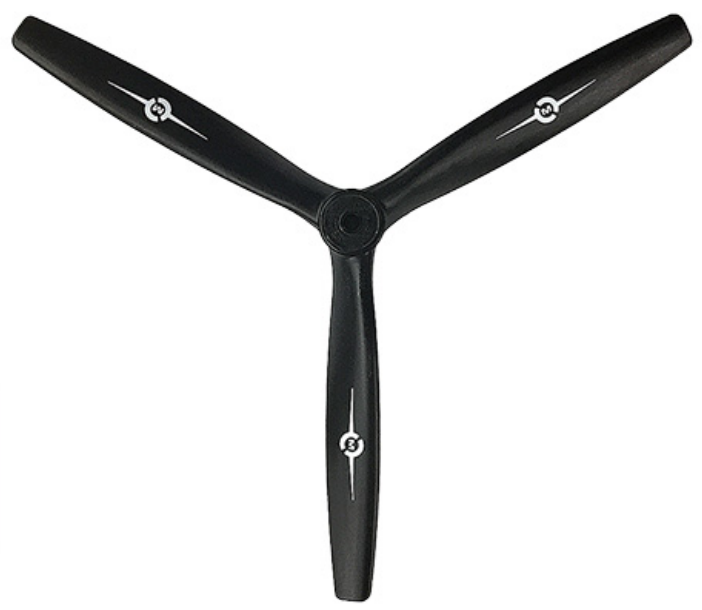

(b) Master Airscrew 14 inch 3-blade propeller.

Figure 2.5: Electric motor and propeller combination selected for GustAV.

GustAV has a 14 inch 3-blade glass fiber reinforced propeller by Master Airscrew (Fig. 2.5b).The thrust output can be expressed as thrust-to-weight ratio of the aircraft. It affects several factors of the flight performance, such as takeoff, climb, and turning performance. The motor and propeller were 
tested in the large wind-tunnel at Ryerson University and the performance was measured at various flow velocities. The thrust, torque, and mechanical power output were measured during the test. Results can be find in Appendix 3

\subsubsection{Power Storage}

The power source of main propulsion system consists of two Lithium-Polymer batteries, commonly used on radio-controlled aircraft and various UAS systems for its high energy density and high discharge performance. The main battery has capacity of $8000 \mathrm{mAh}$ at nominal voltage of $22.2 \mathrm{~V}$ to power the electric brushless motor and the avionics battery has capacity of $2200 \mathrm{mAh}$ at $11.1 \mathrm{~V}$ to power the flight control system and air-data sensors required for the experiment. A diagram describes the power system on GustAV is shown in Fig. 2.7.

The front face of the main battery locates in the payload bay and weighs $1080 \mathrm{~g}$. The length, width, and height of the battery are $203 \mathrm{~mm}, 51 \mathrm{~mm}$, and $54 \mathrm{~mm}$ respectively. The battery capacity had to be carefully considered in the early stage of the development because 1) it dictates the mission endurance of the aircraft since GustAV is fully electrically powered, and 2) the main battery is the single heaviest part of the aircraft and affects greatly on the aircraft weight and balance. Therefore, it has to be carefully incorporated with other components inside the fuselage to ensure a safe center of gravity location. As part of the safety precaution, the main battery is equipped with a quick access shunt plug which is in place only when the aircraft is in flying mode. With the shunt plug disconnected during vehicle inspection and after each flight to prevent the main motor from spinning up accidentally during the handling of the vehicle and causing damage or injury.

As shown in Fig. 2.7 the remaining system such as autopilot module, control surface servo motors, and air-data system are powered by the avionics battery. This setup allows onboard electronics to operate in separation from the high current circuit. The avionics battery was sized to supply power to the system of one hour, significantly longer endurance than the main battery. This is to ensure in an unlikely event of the main battery is fully discharged mid-flight, the avionics battery would still have the capability to supply power to the rest of the system. Therefore the control system and communication link would allow the aircraft to be landed in gliding mode.

To further mitigate the risk of emptying the battery prematurely during the flight mission, voltage and current draw of both batteries are monitored by sensors and the readings are sent to the ground 


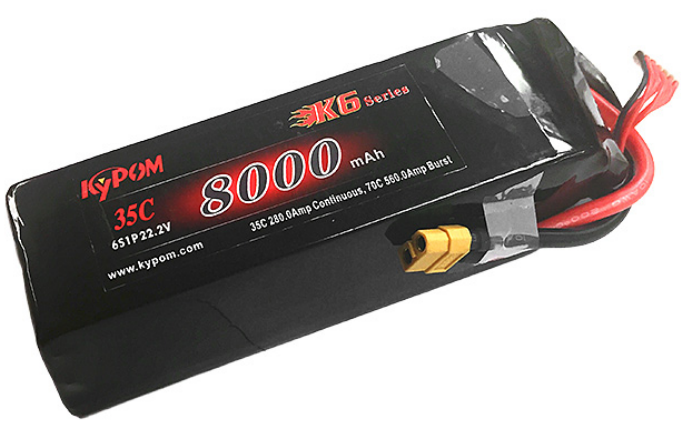

(a) 6-Cell 8000 mAh Li-Po Battery.

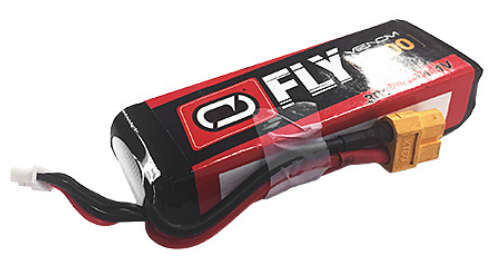

(b) 3-Cell 2200 mAh Li-Po Battery.

Figure 2.6: Two Lithium Polymer batteries onboard GustAV to power electric motor and avionics respectively.

control station via real-time radio telemetry link. The position of the batteries is also an important issue in the design process as the batteries will have to be swapped between flight missions as each battery can take up to three hours to recharge. Therefore, the rear of the fuselage structure is kept open to allow access to the main battery. The main battery is also secured by an aluminum bolt where it anchors the battery from sliding out of the fuselage during the flight mission.

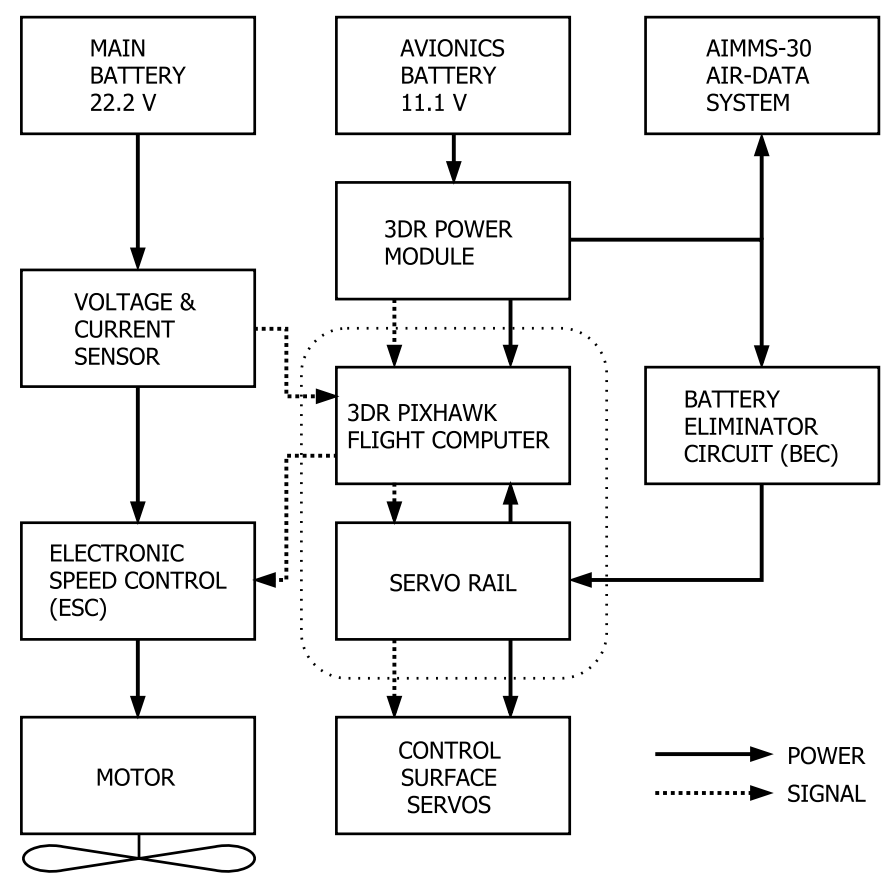

Figure 2.7: Battery power distribution layout on GustAV. 


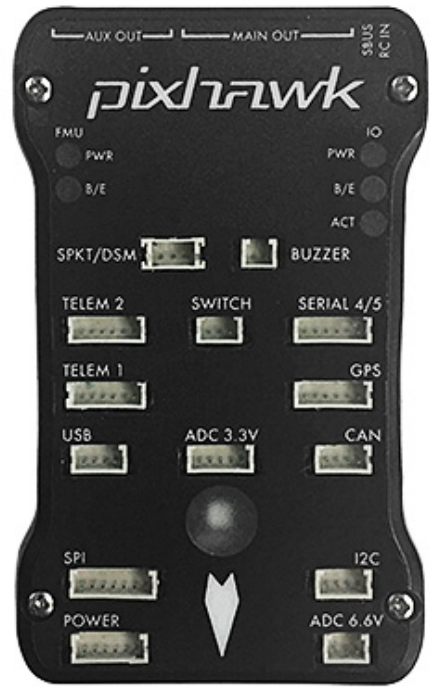

(a) Encloseure.

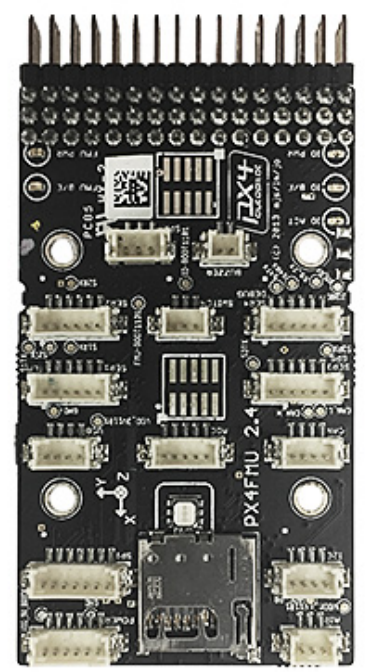

(b) Circuit board (Front).

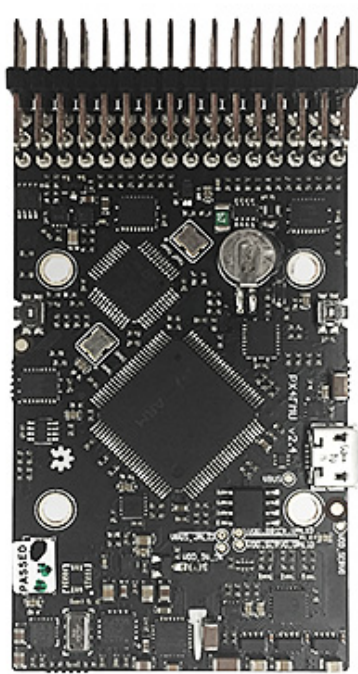

(c) Circuit board (Back).

Figure 2.8: Pixhawk, an open source autopilot module onboard GustAV with embedded IMU and ARM processor.

\subsubsection{Autopilot and Flight Control System}

A Pixhawk autopilot system, as shown in Fig. 2.8, was integrated in the airframe in order to provide navigation, control, and data telemetry functions during the in-flight experiments. The Pixhawk autopilot system consists of a Global Navigation Satellite System (GNSS) receiver, magnetometer, inertial measurement unit, telemetry transceiver, barometric pressure sensor, and pitot-static airspeed sensor. Detailed specifications of the Pixhawk flight controller is included in Appendix 4 An Ardupilot, opensource flight controller software package was installed onto the Pixhawk onboard $168 \mathrm{MHz}$ processor and command all the digital servo motors that actuates the control surfaces of the aircraft.

There are three operation modes to control GustAV: manual, fly-by-wire, and autonomous mode.

The manual mode allows the pilot to control via direct inputs to the control surface servo motors. Takeoff and landing of the aircraft are always performed in manual mode to ensure full control of the aircraft.

The fly-by-wire control mode provides assistance and stabilization to the flight controls. This mode has been valuable as it was used to verify the flight performance of the aircraft during early testing. The aircraft will maintain the roll and pitch angles specified by the pilot control stick inputs and stay within 


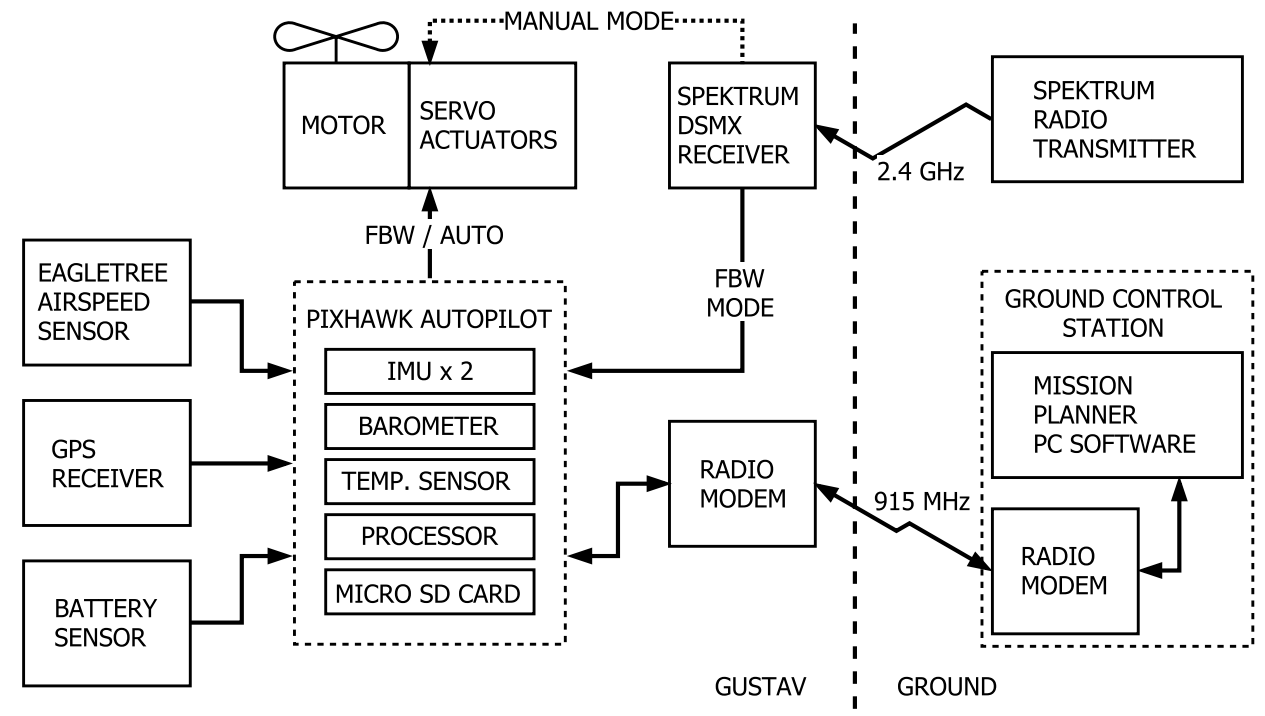

Figure 2.9: Flight control system block diagram.

pre-defined flight envelope such as high and low-speed limits.

Lastly, the autonomous mode is used during atmospheric gust measuring experiment. GustAV can follow pre-programmed flight mission including speed following and altitude change with the onboard IMU, GNSS and airspeed sensor. The autonomous mode allows GustAV to fly towards a waypoint, loiter within defined radius, climb, and descent. Once the flight mission is completed, it will return and loiter above the specified home position until the pilot regained control. The flight mission can be monitored and modified via telemetry data-link at the ground control station.

A commercially available and relatively inexpensive Bix3, which is shown in Fig. 2.11, was used in order to gather experience with the Pixhawk autopilot before using the autopilot on GustAV. The Bix2 has a wingspan of $1.55 \mathrm{~m}$ was used as an early test platform for the autopilot system. The Bix3 is constructed with high-density foam with carbon-fibre reinforced structure. It is durable, versatile, and has a payload capacity of approximately $7 \times 7 \times 15 \mathrm{~cm}$. During the test, electronics equipment included the Pixhawk autopilot system, a GPS receiver, and a telemetry radio transceiver were placed in the payload bay as shown in Fig. 2.12. A pitot-static tube is also mounted on the wing to measure the airspeed of the aircraft during the flights. The Bix3 is equipped with a 3-cell $2200 \mathrm{mAh}$ to supply power to the motor and avionics about 10 minutes. Simple flight patterns were flown in order to gain experience with the avionics and ground control station data-link. A total of 11 flights took place at TEMAC during the 


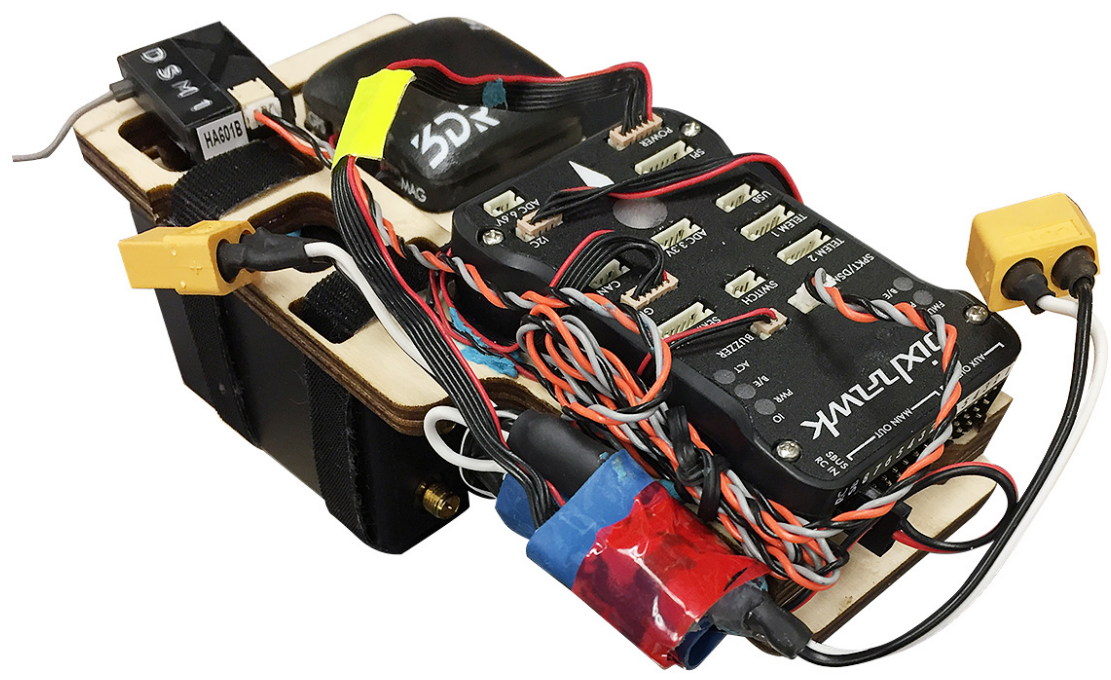

Figure 2.10: Pixhawk autopilot avionics sub-assembly.

summer of 2016. These tests involve maneuvers of flight mission following, loitering around a waypoint, maintaining a constant airspeed, and changing altitude at a specific rate. By doing the avionics tests on a smaller and commercially available test platform, the risk was isolated from the experimental aircraft GustAV.

\subsubsection{Airspeed Sensor}

In order for the autopilot system to obtain accurate airspeed readings, GustAV is equipped with a pitotstatic airspeed sensor on its left wing. This pitot-static tube is only used for navigation and not used as part of the air-data system for atmospheric measurement that is described in Section 2.4 .

As shown in Fig. 2.13, the pitot-static tube is mounted in the wingtip of GustAV. The probe is attached to two pressure transducer that are located inside the wing structure. The transducers that are powered by the Pixhawk autopilot, measure the differential pressure between the pressure tabs and the ADC converts the raw pressure analog reading into digital signal which gets transmitted to the Pixhawk autopilot module via I2C databus as shown in Fig. 2.9. 


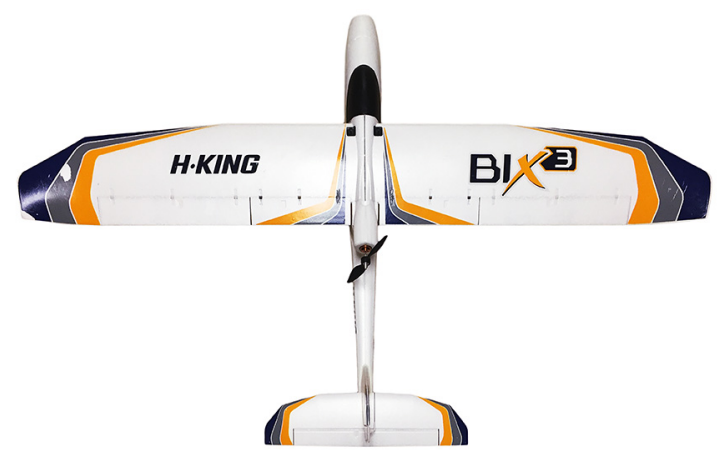

Figure 2.11: Top view of the Bix3 test platform.

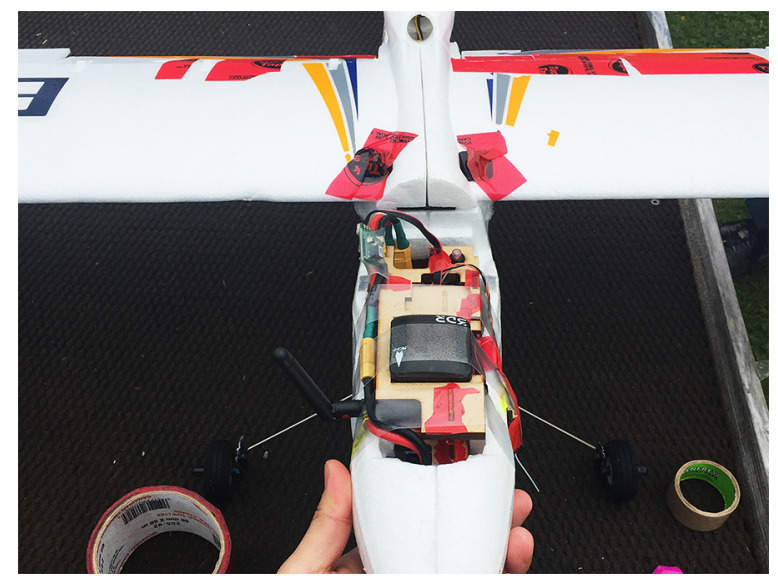

Figure 2.12: Avionics on the Bix3 test platform.

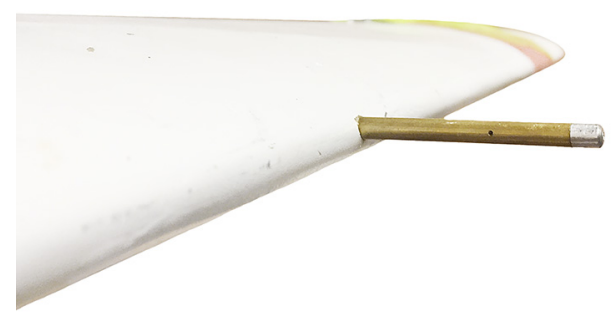

(a) Pitot-static tube mounted on the left wing.

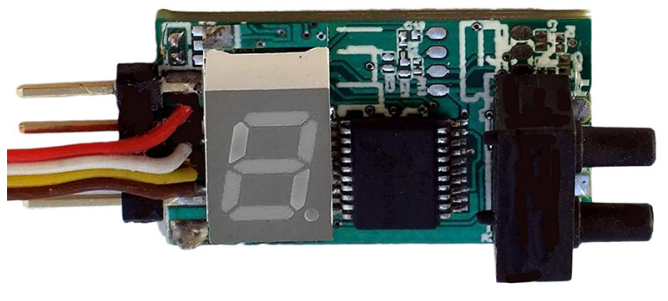

(b) Airspeed sensor located in the wing 34 .

Figure 2.13: Airspeed sensing equipment on GustAV for navigation in autonomous mode.

\subsubsection{Flight Data Logging}

The Pixhawk autopilot system records over 150 flight parameters onto the onboard micro SD card. The data $\log$ files are formatted as a binary file to optimize data storage space. Critical flight parameters such as the velocity, attitude, and position of the aircraft are recorded at $50 \mathrm{~Hz}$. Other flight status parameters such as battery voltage and current are being recorded at a slower rate of $10 \mathrm{~Hz}$. After each flight, the flight data files are downloaded from the autopilot system and analyzed using Mission Planner and custom-made MATLAB scripts.

One of the most important tasks during the flight vehicle development is the autopilot control pa- 


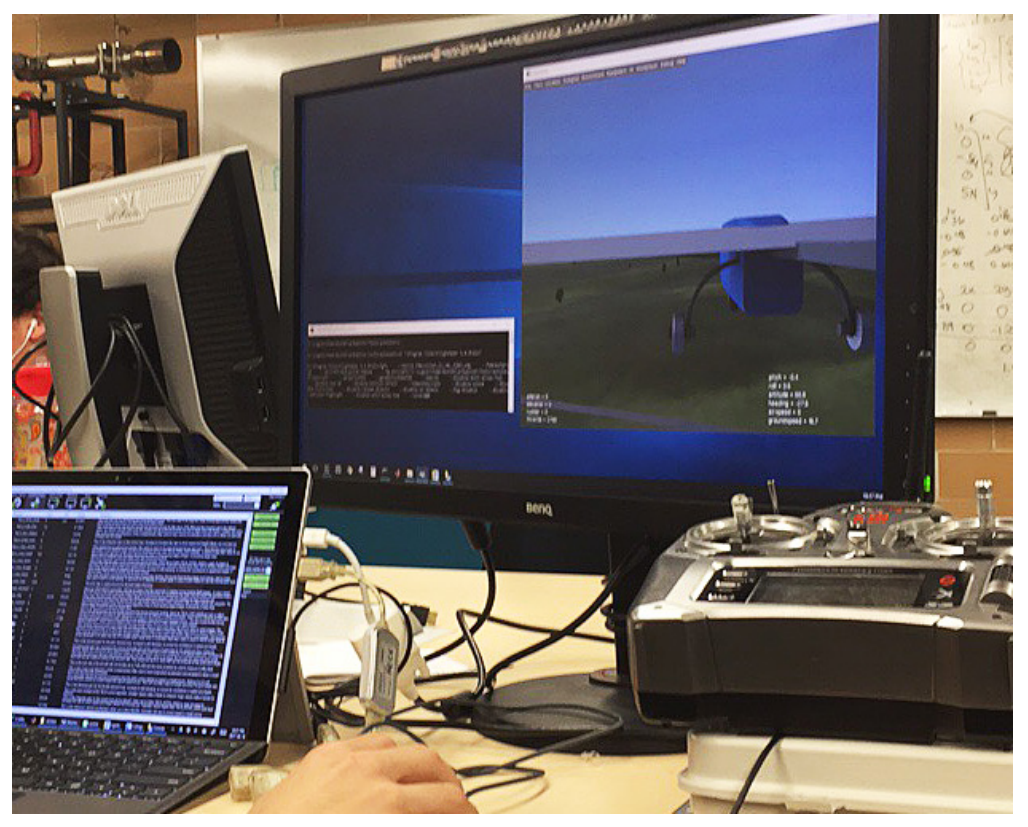

Figure 2.14: Software-in-the-loop (SITL) simulation running on a computer.

rameter tuning which is discussed in detailed in Section 3.2.3. The objective of the tests is to adjust the PID parameters of the flight control system until the desired flight control response is achieved. The test result can only be revealed by analyzing the flight data log after the flight.

\subsubsection{Software in the Loop}

One of the useful features which the Ardupilot flight control software offers is the ability to run Softwarein-the-loop (SITL) test on a computer flight simulator setup. In this setup, the flight control software uses sensor data from a flight dynamics model in the flight simulator 35. Fig. 2.14 shows the simulation model of GustAV running on a computer where flight planning and system familiarization can be done. Before each flight experiment, the mission was programmed onto the SITL simulation and tested in the simulation environment. The proposed flight mission plan was thoroughly tested in the SITL environment before being finalized and sent to the aircraft onboard autopilot. 


\subsection{Ground Control Station}

Part of the unmanned aerial system is a bi-directional data link which provides real-time telemetry at the ground control station (GCS) with a pair of radio transceivers. This setup provides the aircraft's position, orientation, velocity, and trajectory on a Microsoft Surface laptop with touchscreen operating the flight monitoring software (Fig. 2.15).

The Microsoft Surface was selected for this setup because of the touchscreen interface provides convenient ways to interact with the Mission Planner software during the flight mission. For example, the map view with the flight trajectory being superimposed on top of a satellite image can be navigated with finger gestures. Other advantages such as bright display and long battery life make the Microsoft Surface a good candidate for outdoor flight experiment field operation (Fig. 2.16).

The Mission Planner, a flight monitor software, provides the ability to monitor the aircraft status in real-time (Fig. 2.17). The flight mission can also be modified via this setup if necessary. As a safety precaution, the ground control station provides a backup control link in case the main $2.4 \mathrm{GHz}$ radio control frequency had experienced failure. To achieve this $915 \mathrm{Mhz}$ data-link as shown as part of the control system block diagram in Fig. 2.9, both the aircraft and the computer have to equip with the radio modem.

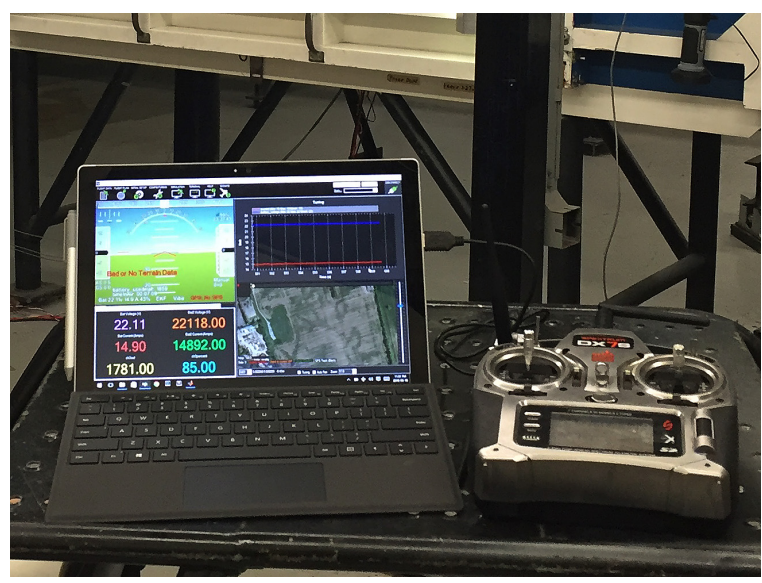

Figure 2.15: Ground control station (GCS) and Spektrum DX7s radio controller.

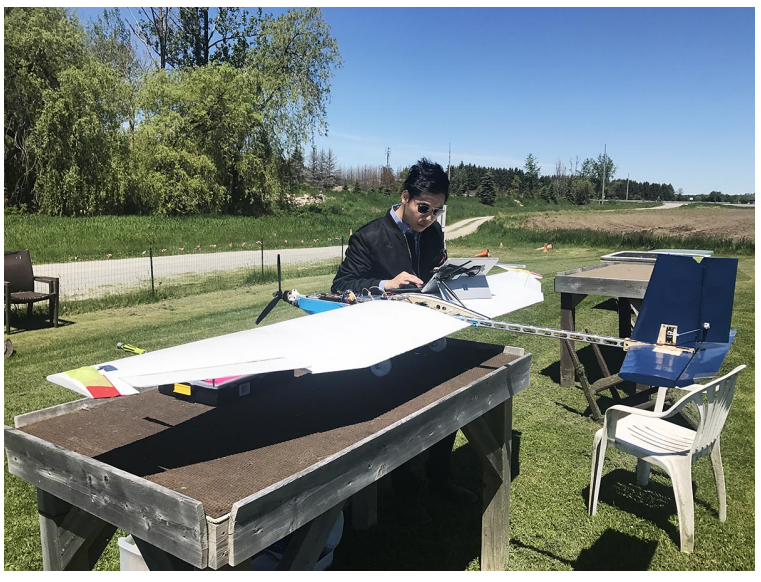

Figure 2.16: Performing diagnosis on GustAV with the portable GCS. 


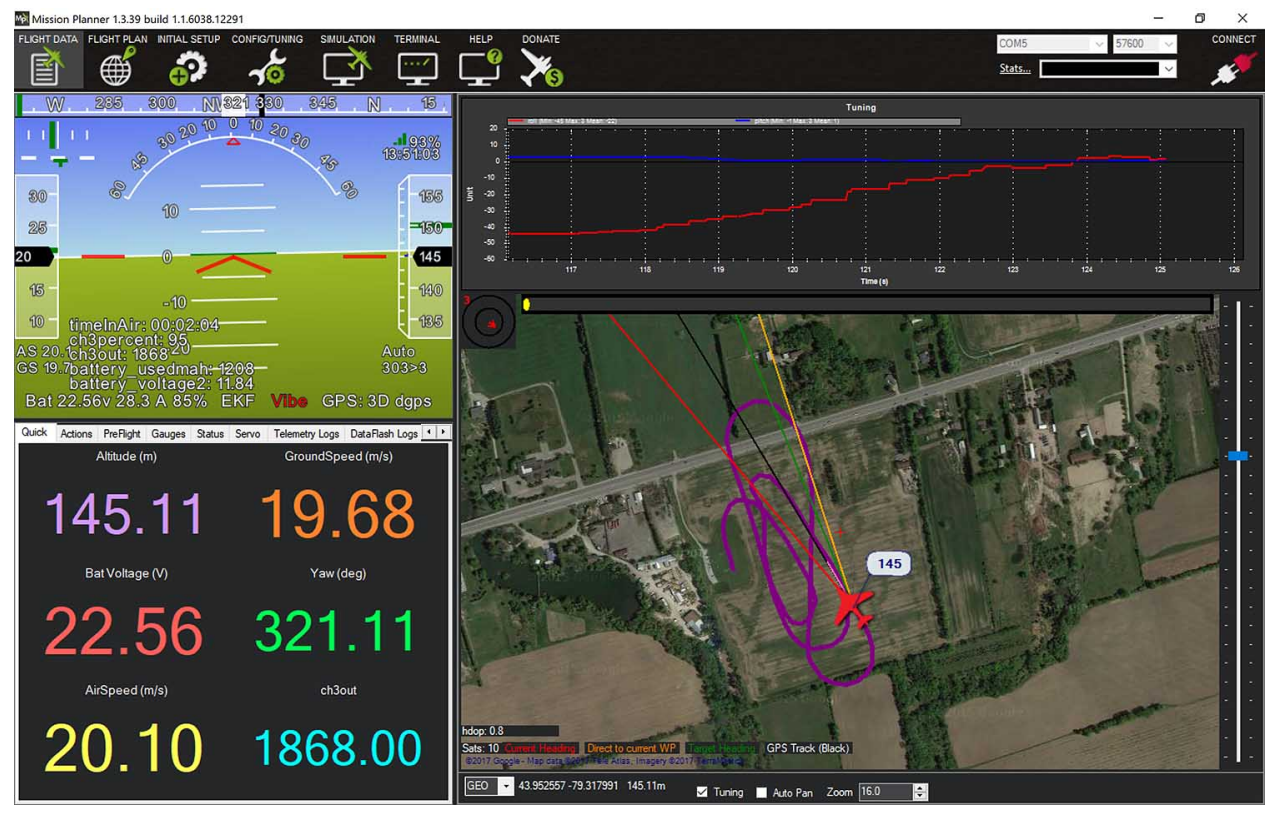

Figure 2.17: Graphic user interface of Mission Planner.

The telemetry data-link is transmitted on the $915 \mathrm{MHz}$ spectrum which is suitable for short-range audio and video transmissions. The transceivers used on the GustAV system outputs at $1 \mathrm{~W}$ and adequate for a range of more than 10 kilometers. A pair $100 \mathrm{~mW}$ transmitter was originally used, however, the telemetry link was performance was unstable and transmission rate was substantially slower while the aircraft was operating in the air. Although GustAV only operates within the pilot's line-of-sight, an extra range available on the 1 Watt transceivers were preferred to increase the reliability of the communication system.

\subsection{Air-Data System}

The air-data system, AIMMS-30, on GustAV is responsible of measuring the three dimensional wind vector while the aircraft is flying. The system designed by Aventech Research Inc. consists of three types of sensors: a wing mounted five-hole probe to measure the three dimensional flow field, Inertial Measurement Unit (IMU) to measure the accelerations and orientation of the vehicle, and Global Navigation Satellite System (GNSS) units to measure the position and velocity of the aircraft relative to the ground. By combining the signals from the sensors and compute the reference frame transformations 
(Fig. 2.18), the air-data system is capable of measuring atmospheric gusts of $0.5 \mathrm{~m} / \mathrm{s}$ 36].

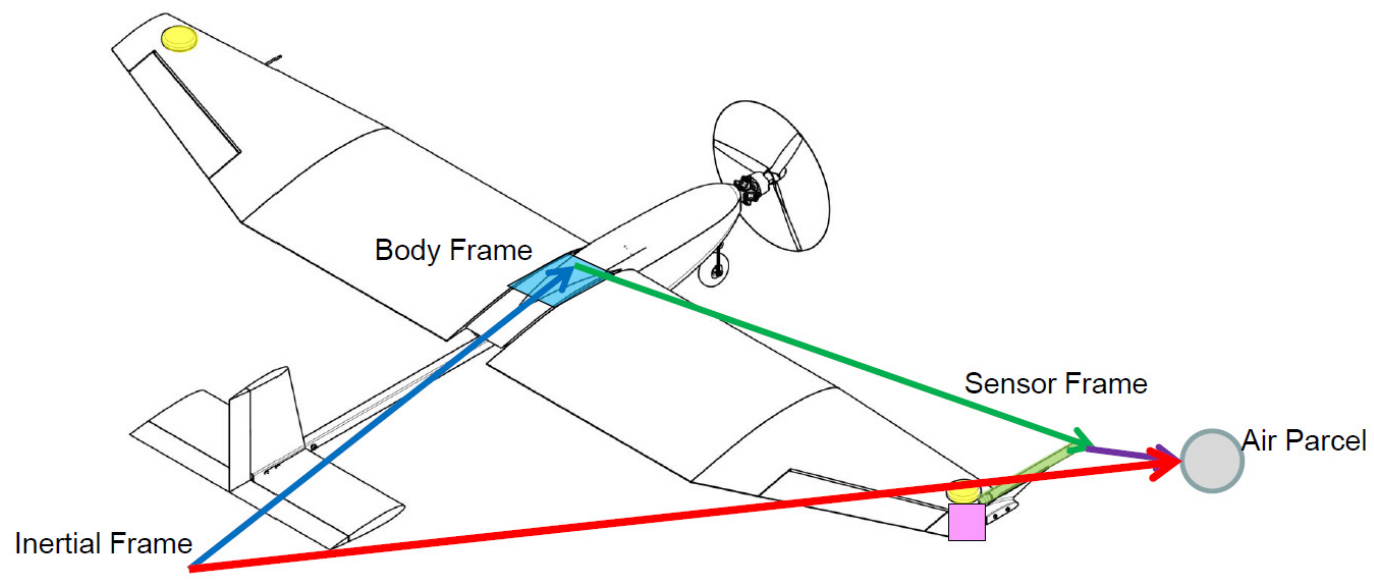

Figure 2.18: Wind measurement reference frames.

The main circuit board of the AIMMS-30 air-data system hosts two Global Navigation Satellite System (GNSS) receivers, an Inertial Measurement Unit (IMU), a processor, and a data logger. The length, width, and height of the main circuit board are $120 \mathrm{~mm}, 95 \mathrm{~mm}$, and $30 \mathrm{~mm}$ respectively. The main circuit board is positioned inside the main payload bay of the aircraft close to the center of gravity and other onboard electronics. Other major components include the five-hole probe on the right wing and GNSS antennas. The block diagram of the air-data system in Fig. 2.19 shows the list of sensors and the connections of the system. To transform the raw measurement of the IMU, GNSS, and five-hole probe into global wind vector, Kalman filter is used which uses the GNSS position and velocity measurements to predict the error caused by the IMU drift and the algorithm can operate either on the onboard hardware or in the post-processing program. The estimated error state is then being fed back to the IMU time-marched kinematics integration to correct the drift. The aircraft's velocity solution provided by this Kalman filter setup retains the fast data of the IMU (100 Hz) while greatly improving the accuracy of the IMU measurements with GNSS solutions. In the event of losing GNSS signal which is required at $1 \mathrm{~Hz}$ to update the error state, the IMU kinematics integration continues to function without interference. The error state would be updated again when the GNSS solution once again becomes available to the Kalman filter. This ensures robustness of the system and increases the chance of success. Fig. 2.20 shows the block diagram of the Kalman filter and data transformation 
process used on the AIMMS-30 air-data system.

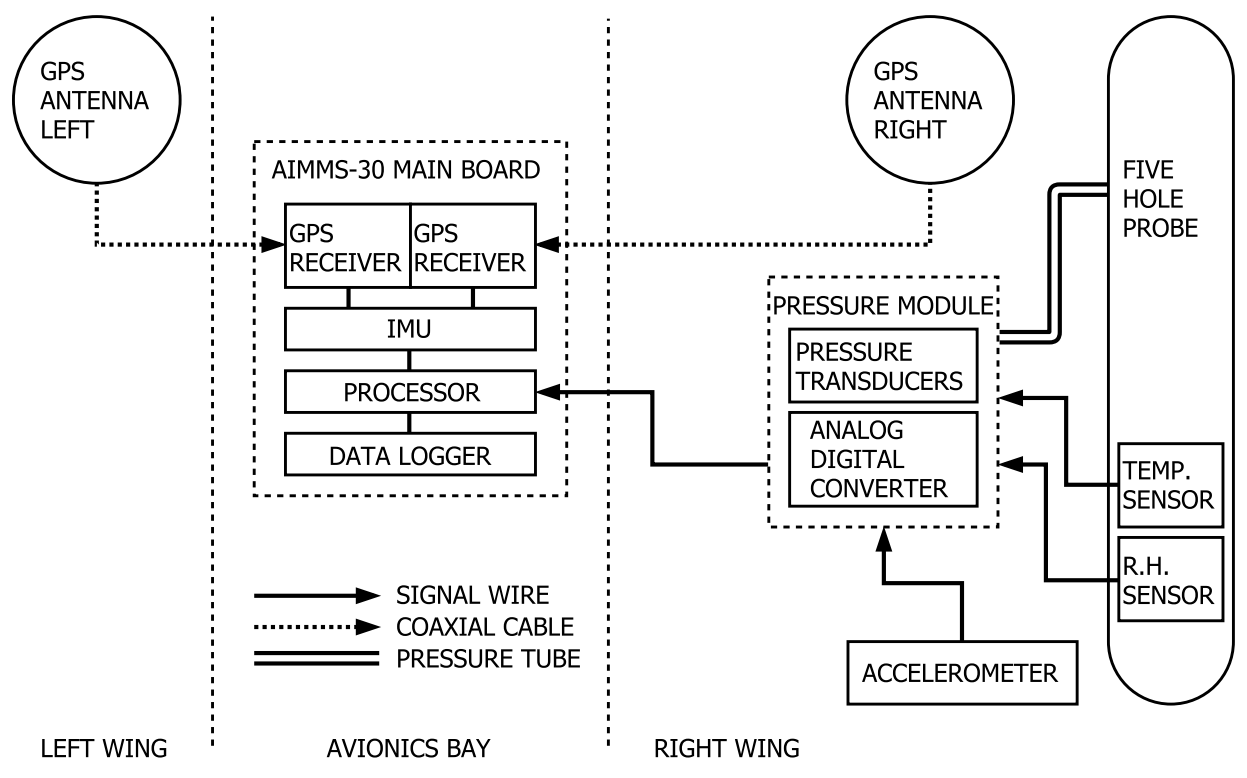

Figure 2.19: Block diagram of air-data system setup on GustAV.

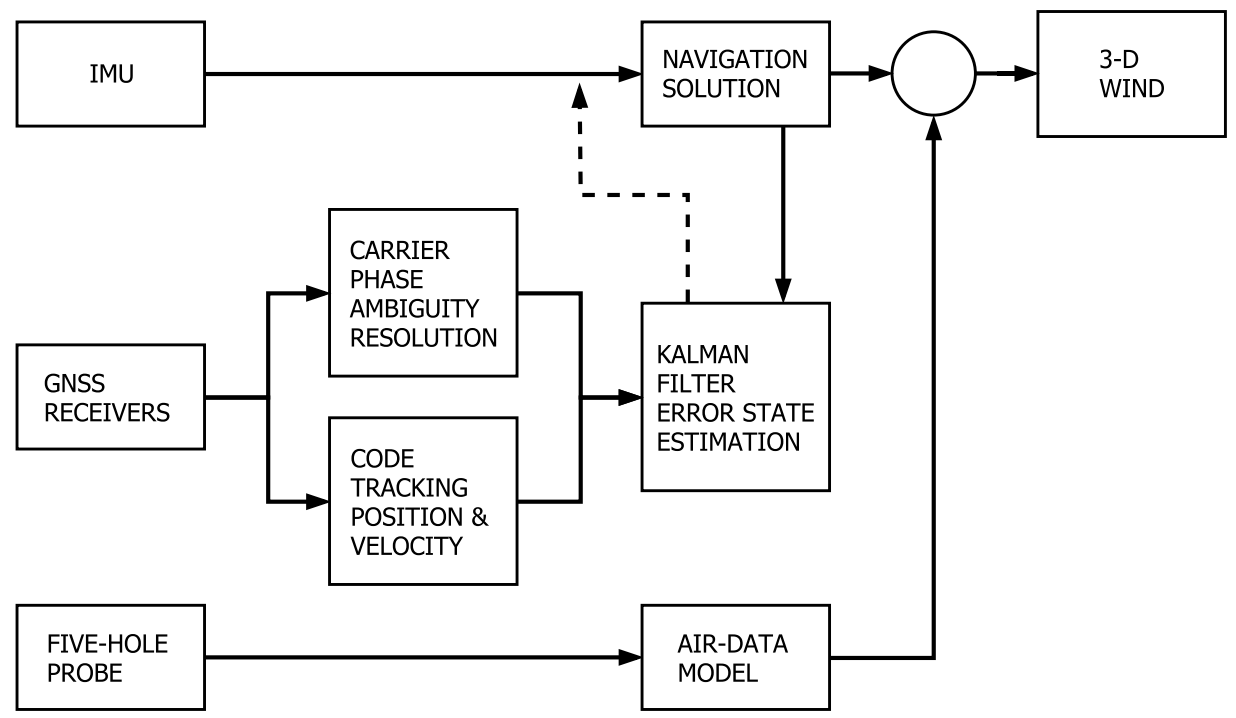

Figure 2.20: GustAV air-data system integration architecture. 


\subsubsection{Five-Hole Probe}

Multi-Hole pressure probes are frequently used in experiments that are required to measure the aerodynamic flow angles 37]. Fig. 2.21 shows the tip of a five-hole probe and the probe can measure the flow direction and velocity. The Pressure ports are placed around the spherical head of the probe. Each pressure tab is connected to a pressure transducer.

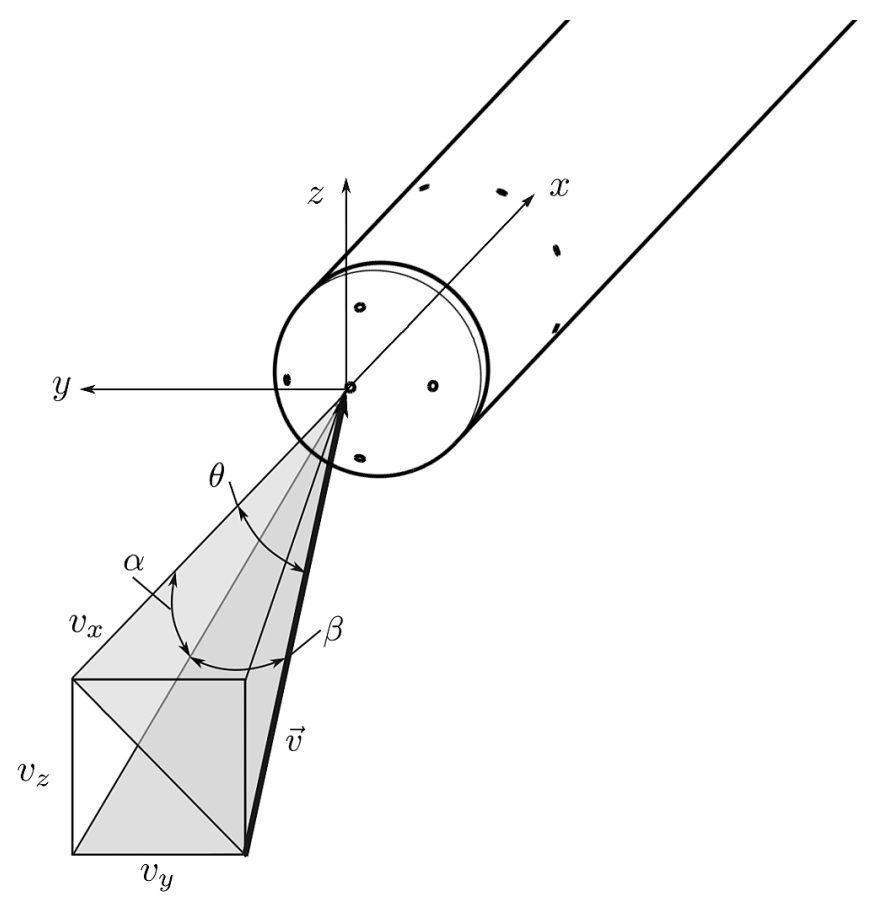

Figure 2.21: Five-hole probe and the flow angles, modified from 37.

The differential pressure measurement between the opposite pressure ports along with the pitot-static pressure can be correlated to compute the angle of attack, $\alpha$, and angle of sideslip, $\beta$, relative to the three-dimensional flow field 38 . These differential pressure readings show a linear relationship to the inflow angles up to about \pm 15 degrees and wind tunnel testing has been done and shown in section 3.1 . These probes come in different sizes and probes with five, seven, or more ports are available depends on the application.

Besides the multi-hole probe (Fig. 2.22a), other types of anemometers were considered to be placed on GustAV to measure the wind velocity and direction. Alpha-Beta vanes (Fig. 2.22b) consist of two vanes which pivot in orthogonal directions to provide the direction of the air flow and a pitot static tube 
to measure the wind velocity. However, the vane type sensors are more capable of measuring mean wind value than the turbulent fluctuation which is more capable to be measured by fast-response sensors. Hot wire anemometer (Fig. 2.22c) is a type of fast-response sensors which can provide wind velocity by measuring the electrical current needed to maintain the temperature of wire against cooling of wind. It is common to have hot wire set up in a tri-axis configuration to measure the three-dimensional flow field. The hot wire on the anemometer is usually made out of tungsten wire with a diameter of several micrometers. Putting the fragile hot wire on an aerial platform and sustain the takeoff and landing is a challenging task. Lastly, remote sensors that listens to reflected waves (microwave, light, sound) 14]. These are called doppler radar/lidar/sodar (Fig. 2.22d) and depend on that the wave medium the sensors are utilizing. Disadvantages of remote sensors include their size and cost. The antenna or receiver dish required to send and measure the wave signals also add complexity to the system and may not be an ideal choice for operation on an aerial platform.

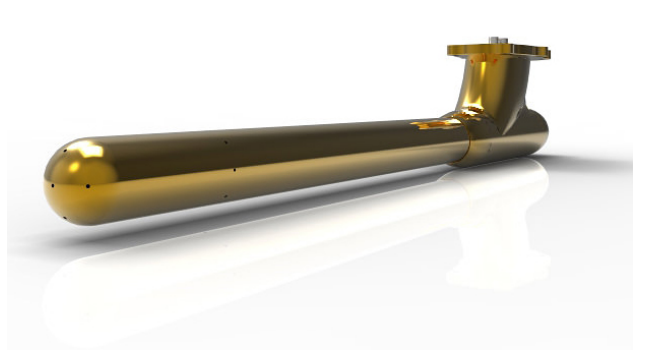

(a) Five-hole probe 36.

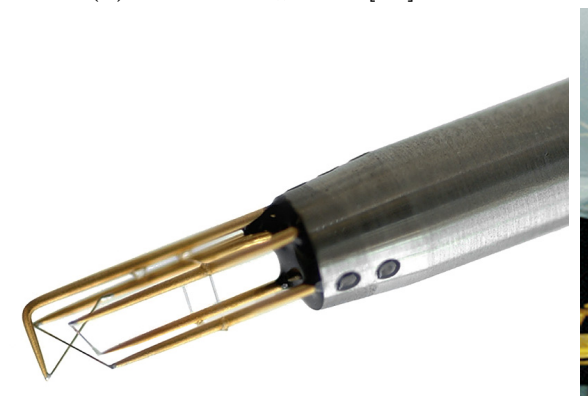

(c) Hot wire anemometer 42 .

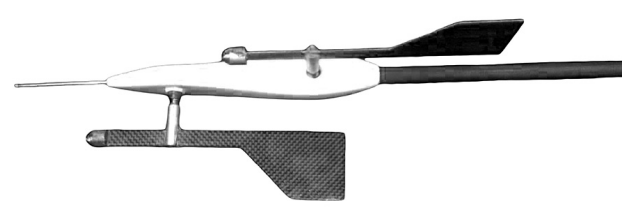

(b) Alpha-Beta vanes 41.

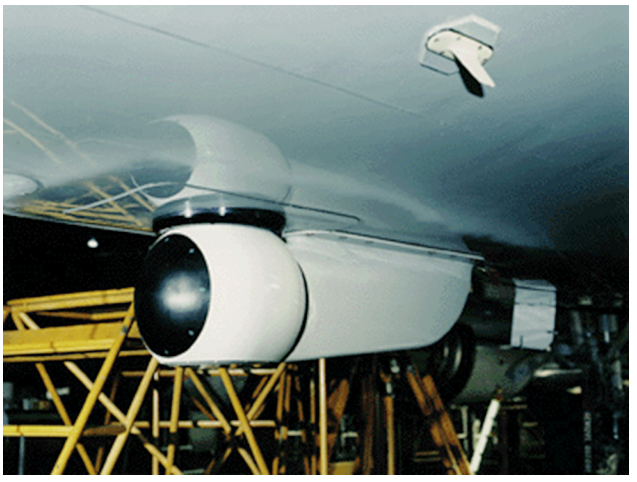

(d) Doppler lidar 43 .

Figure 2.22: Relative wind sensors. 


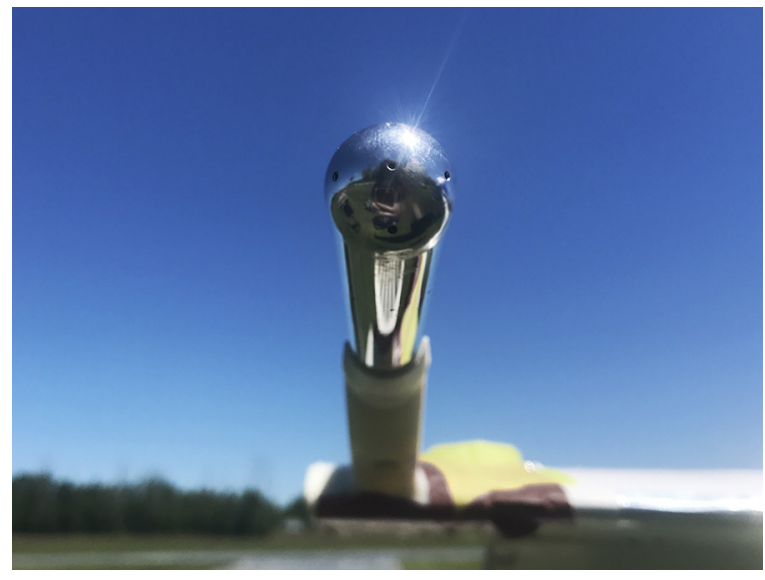

(a) Front view.

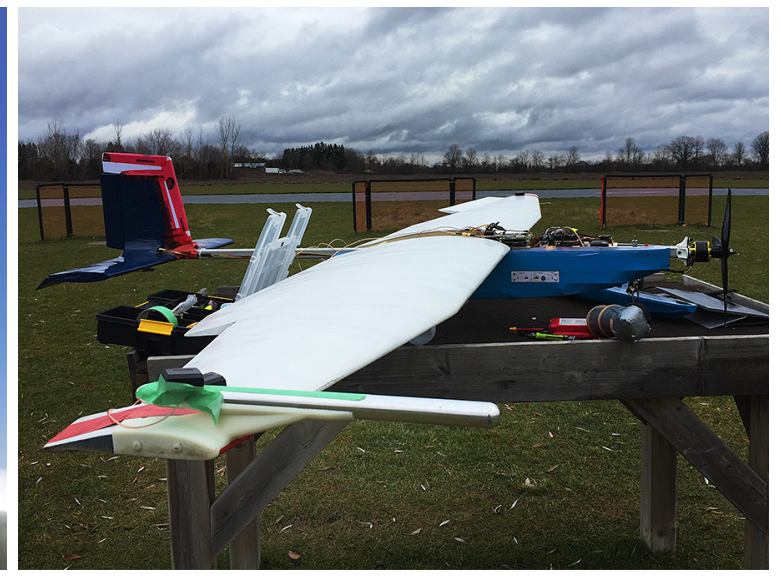

(b) Side view.

Figure 2.23: Five-hole probe mounted on the right wing tip of GustAV.

Regardless of the type of flow measuring device, it must be placed strategically to minimize the flow effect influenced by the vehicle in itself which leads to inaccuracy. On GustAV, the five-hole probe is positioned with the intend to minimize any disturbance caused by the aircraft such as the propeller, fuselage, and wing. The five-hole probe was positioned at the wing-tip extending forward in order to measure the flow in front of the wing. Mounting the five-hole probe in front of the airplane's nose was not viable, since the GustAV has a tractor configuration. Therefore, Fig. 2.23 shows the five-hole probe positioned on the right wing tip of GustAV with 3D printed plastic mount, which allows the probe to protrude forward. Further analysis was performed using a potential flow code method to calculate the turning and acceleration of local flow field around the five-hole probe. It is a relatively simple and fast approach to estimate the performance of a complex geometry. This approach employs a higherorder potential flow method that uses elements of distributed vorticity 44. It provides solutions of the velocity field around the geometry at a relatively low computational expense compared to an approach using CFD.

Fig. 2.24a shows the distributed vorticity elements placed to form the half-wing geometry and the relaxed wake shed from the trailing edge. The program calculated the induced velocity field around the geometry within the volume of interest shown in Fig. 2.24b. Finally, the results can be plotted and viewed in slices to reveal the three dimensional flow field (Fig. 2.24c). The probe location was selected using this method which the goal was to minimize the upwash flow effect caused by the lifting surfaces. 


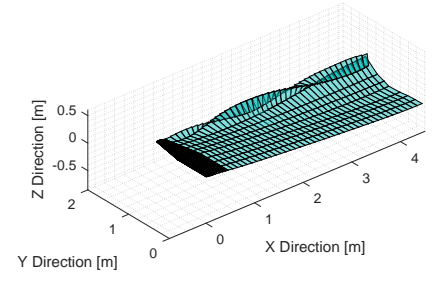

(a) Wing and wake geometry.

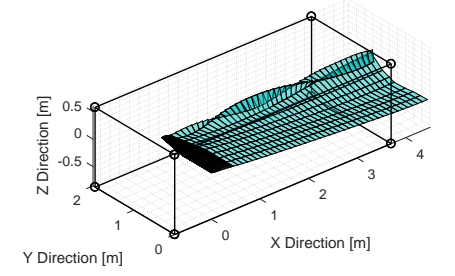

(b) Point cloud bounding box.

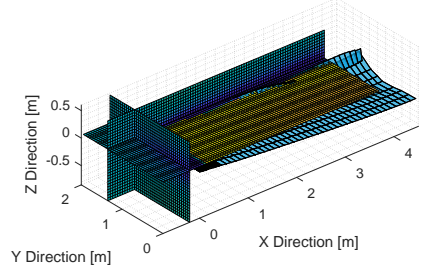

(c) 3D flow field velocity.

Figure 2.24: Steps taken to calculate the induced velocities using potential flow panel code.

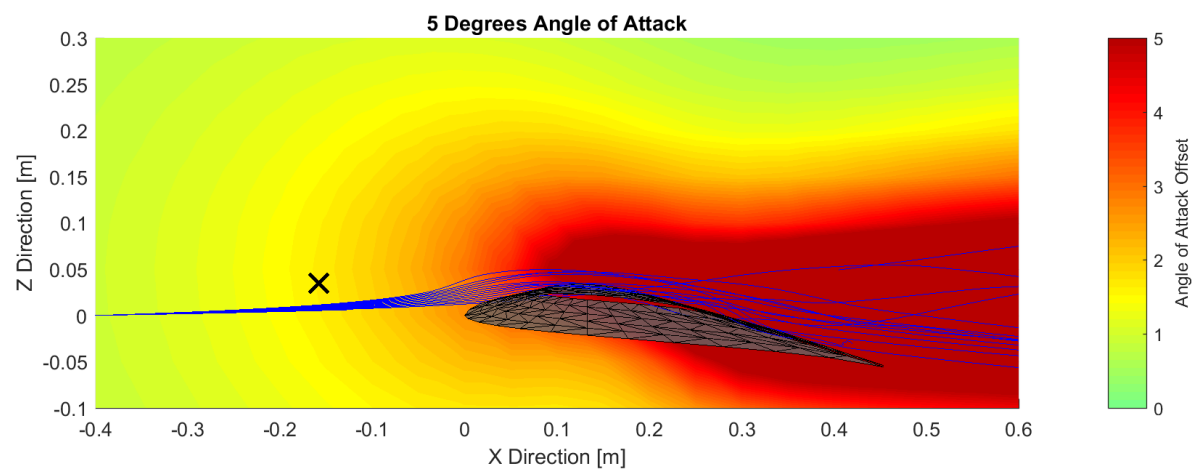

(a) XZ plane.

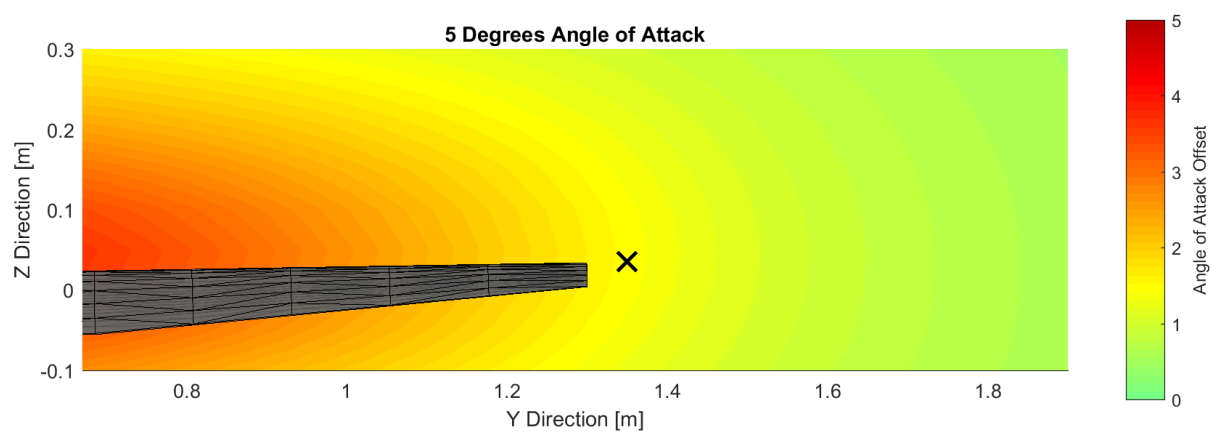

(b) YZ plane.

Figure 2.25: Predicted angle of attack measurement offset at 5 degrees angle of attack. 


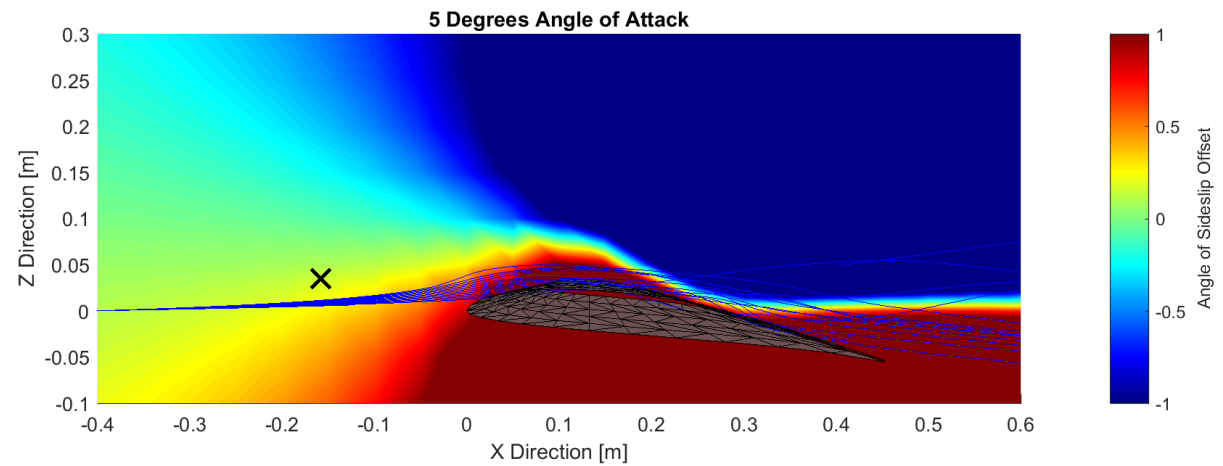

(a) XZ plane.

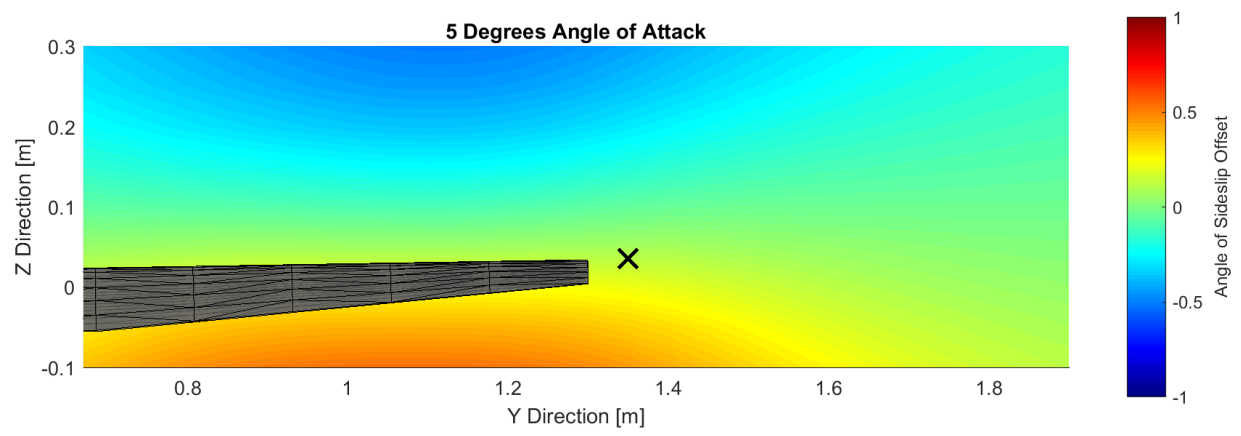

(b) YZ plane.

Figure 2.26: Predicted angle of sideslip measurement offset at 5 degrees angle of attack.

Fig. 2.25 and Fig. 2.26 show the predicted offset values of the five-hole probe in angle of attack and angle of sideslip measurements. The finalize probe location is represented by the black cross marker. Fig 2.25a shows the flow field on the XZ plane where the probe is located. The figure illustrates the effect of the upwash represented by the red colour surrounding the wing cross section and placing the air-data probe in that region should be avoided. Fig. 2.26b shows the lateral flow field on the YZ plane and captures the effect of the wingtip vortices: air flowing outboard under the wing and inboard above the wing. To minimized the measurement offset of angle of sideslip, the probe is placed along the spanwise axis of the wing to minimize the crossflow effect.

Finally the analysis was repeated across various angles of attack (Fig 2.27) and the measurement offset of the angle of sideslip stays relatively constant while the offset in angle of attack increases. Hence, the flight experiments are conducted with the aircraft flying at $16 \mathrm{~m} / \mathrm{s}$ or above. In steady level flight, the lift coefficient at 5 degrees angle of attack is equal to 0.45 according to the potential flow analysis. 
Cruising at speed greater than $16 \mathrm{~m} / \mathrm{s}$ should allow the aircraft to fly at the angle of attack below 5 degrees to minimize this source of error. Additionally, the results from this analysis can be used to correct the wind measurement data in post-processing to improve the measurement accuracy.

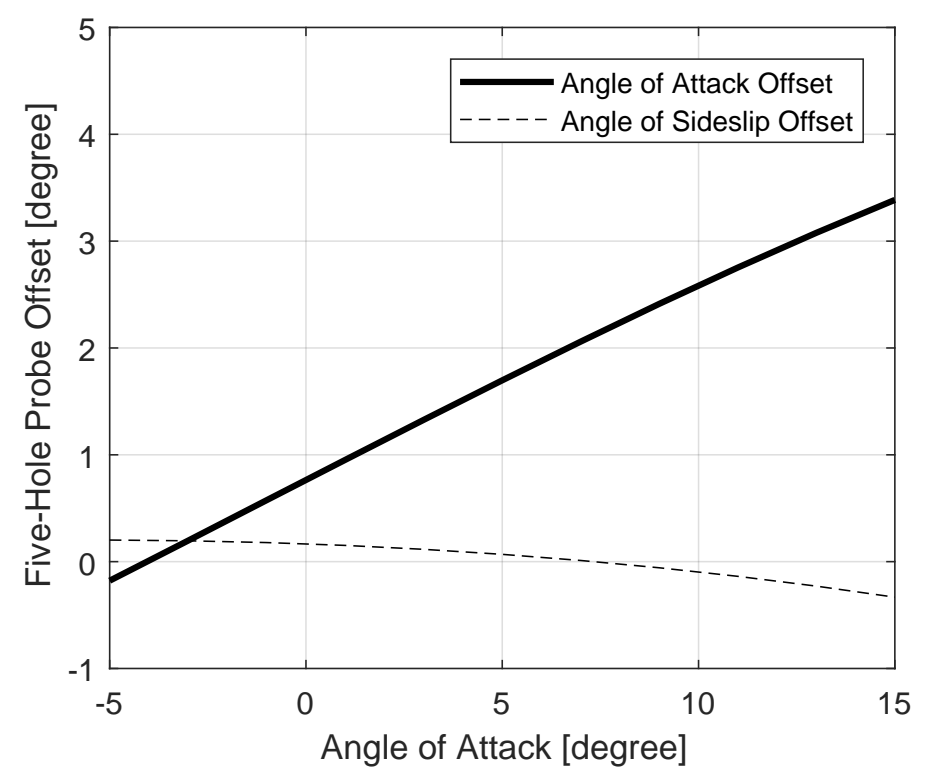

Figure 2.27: Angle of attack and angle of sideslip measurement offset acorss various angles of attack.

\subsubsection{Inertial Measurement Unit}

The Aventech AIMMS-30 main circuit board holds an inertial measurement unit. The inertial measurement unit includes a tri-axis accelerometer and a tri-axis gyroscope to measure the accelerations and angular rates of the aircraft during flight. Along with a navigation processor, this type of inertial navigation system can integrate and output position, velocity, and attitude solution of the vehicle at a high-bandwidth $(100 \mathrm{~Hz})$ and have relatively low short-term noise 45]. However, any errors in the inertial navigation solution can grow with time as successive sensor errors are summed. Low cost, small size, and light mass inertial measurement units are often used on small UAVs including GustAV. These inertial measurement units are manufactured using micro-electromechanical systems (MEMS) technology which are small in size and have high shock tolerance, their performance is relatively poor compared 
to higher-cost, larger gyroscope designs. To reduce the measurement error, an error-state Kalman filter is incorporated by Aventech Research Inc. in the AIMMS-30 real-time and post-processing algorithms. The architecture of the IMU/GNSS integrated system is shown in (Fig. 2.20). Note that the Kalman filter error state correction runs at $1 \mathrm{~Hz}$ when GNSS solution is available. The Kalman filter estimates the state errors of the IMU by time-marching the kinematic equations of motions along with GNSS velocities and compares to the integral solutions of IMU acceleration and angular rate measurements at $100 \mathrm{~Hz}$.

\subsubsection{Global Navigation Satellite System}

The air-data system requires velocity and position measurements from the Global Navigation Satellite System (GNSS) in order to update the error state caused by the drift of the IMU kinematics solution. Although the air-data system setup on GustAV uses solely signals from the Global Positioning System (GPS) operated by the United States, the processing methodology is identical to using geolocation information that is provided by other systems [46]. Therefore, the term GNSS is used to include all available satellite navigation systems. The GNSS solutions provided by the receiver unit can provide horizontal position root-mean-square accuracy of $0.7 \mathrm{~m}$ by incorporated signals that the Wide Area Augmentation System (WAAS) broadcasts. WAAS is a satellite-based augmentation system (SBAS) that has ground stations located in North America to provide extra information about the GNSS correction signals, such as clock drift and ionospheric delay, which further improve the GNSS solutions [45].

The Global Navigation Satellite System (GNSS) setup consists of two receivers located on the main circuit board of the Aventech AIMMS-30 air-data system as shown in Fig. 2.19 The corresponding antennas are located on the left and right wing, approximately $2.5 \mathrm{~m}$ apart. This dual-antenna setup allows the GNSS system to determine the attitude of the vehicle by measuring the differential carrierphase between the two antennas. The datasheets of the GNSS receivers and antennas are included in Appendix 4 As shown in Fig. 2.28 with the distance between the antennas, $r_{a b}$, is fixed and known, the angle, $\theta$, between the plane of where the two antennas placed and the satellite line-of-sight can be solved using:

$$
\cos \theta=\Delta \rho_{a b} / r_{a b}
$$




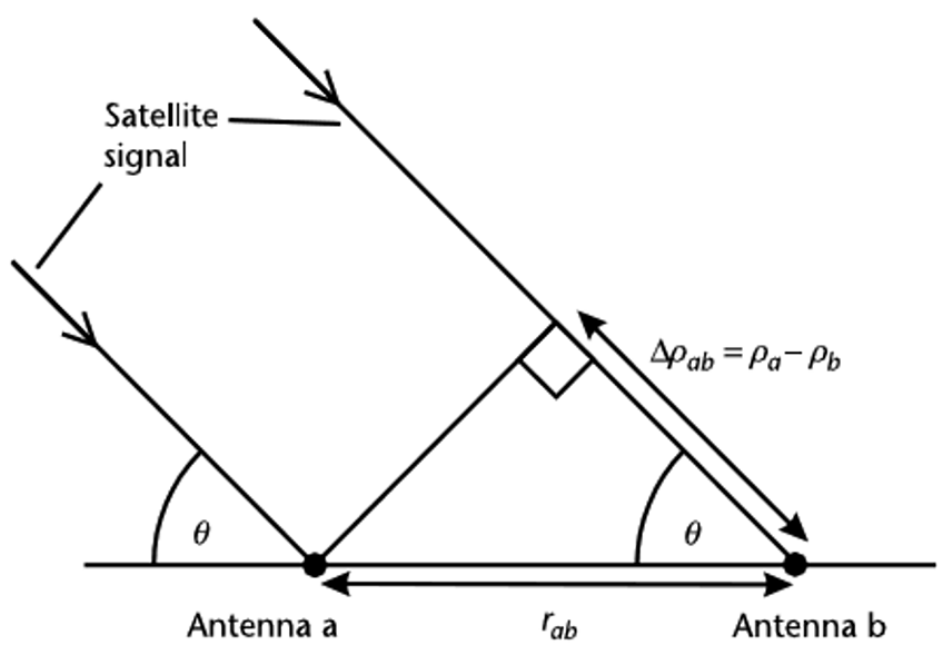

Figure 2.28: Schematic of GNSS attitude determination 45].

The relative range measurement, $\Delta \rho_{a b}$, is equal to the sum of the carrier-phase s that the two GNSS recievers measure and an unknown-multiple of wavelength. This is known as the carrier-phase integer ambiguity problem. To resolve the ambiguity, multiple differential carrier-phase signals from different satellites can be used. Fig. 2.29 shows the ambiguity solution can be found by a geometry technique. The attitude solution lies at the intersection of all four ambiguous range measurements 45].

Usually, magnetometers are used to determine the absolute yaw angle of the vehicle (aircraft's nose heading). However, they are prone to magnetic interference due to onboard avionics, power supply, and the electric motor. This causes measurement error in the aircraft positioning. By measuring the vehicle's attitude using the GNSS antenna pair will result in a better system robustness.

The attitude and velocity measurement are updated every second and sent to the Kalman filter estimation algorithm to correct the Inertial Measurement Unit (IMU) error drift (Fig. 2.20). This allows the unit onboard GustAV to achieve velocity accuracy of less than root-mean-square accuracy of $0.05 \mathrm{~m} / \mathrm{s}$ 46] for accurate gust measurements during the airborne experiment. 


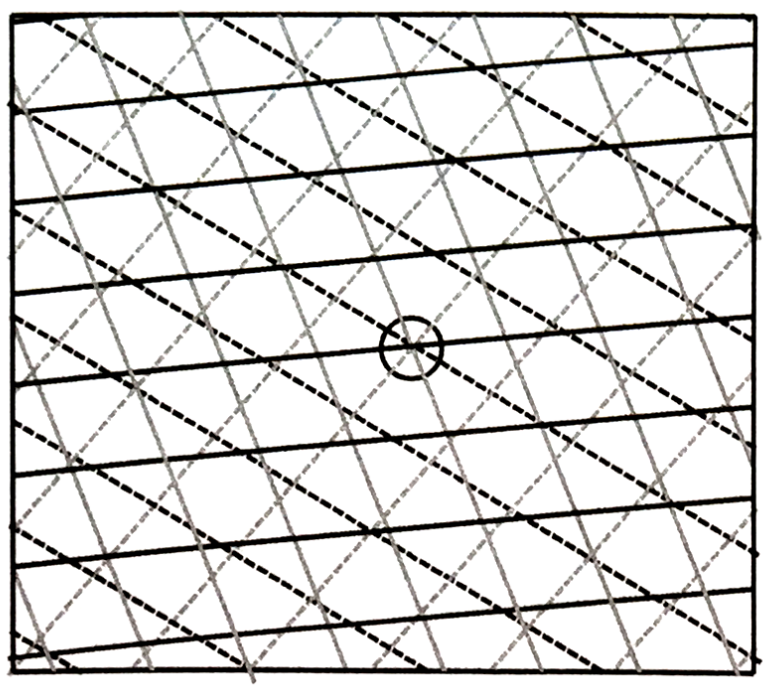

Figure 2.29: Intersection of the lines of position from ambiguous range measurements. 45.
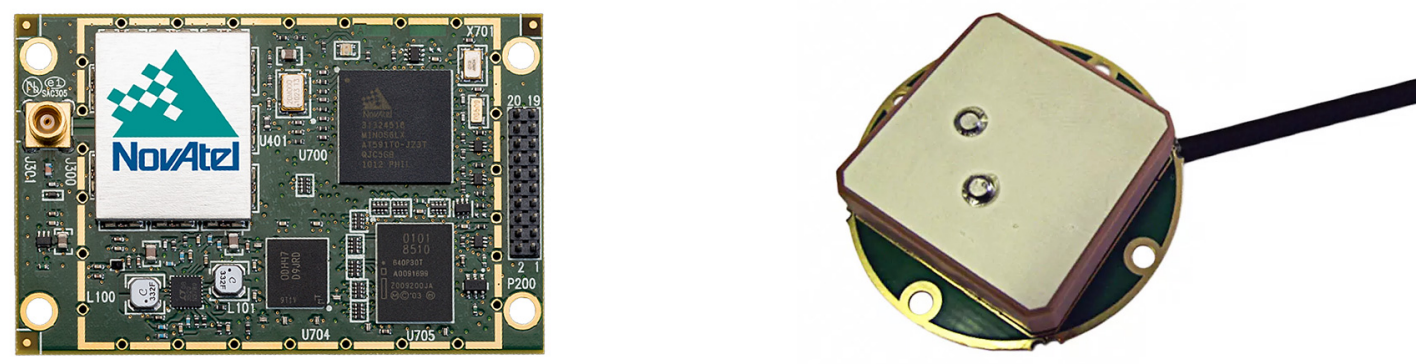
(a) OEMStar GNSS receiver 46.
(b) Tallysman TW1422 GNSS patch antenna 47 .

Figure 2.30: GNSS receiver and antenna used on GustAV.

\subsection{Weather Ground Station}

Along the in-flight experiment with the unmanned aerial vehicle platform, the atmospheric properties such as wind speed, wind direction, and temperature have to be monitored by a ground based weather station in order to provide ground conditions during GustAV's flight tests. This conditions measured 
at the ground can be correlated with the data measured in flight during post processing. The weather station logs wind speed, wind direction, atmospheric pressure, relative humidity, and temperature. The weather station consists of commercially available weather sensors and customized Arduino data logger setup to decode and record the parameters from each sensor. Data logger and the general setup of the weather station are shown in Fig. 2.31 Fig. 2.32 shows the weather station during one of the flight tests at TEMAC's field. This setup can provide useful real-time wind measurement for operational purposes. The weather data records were kept for every flight test for providing weather data at ground level for comparison with in-flight data captured in the air by GustAV.

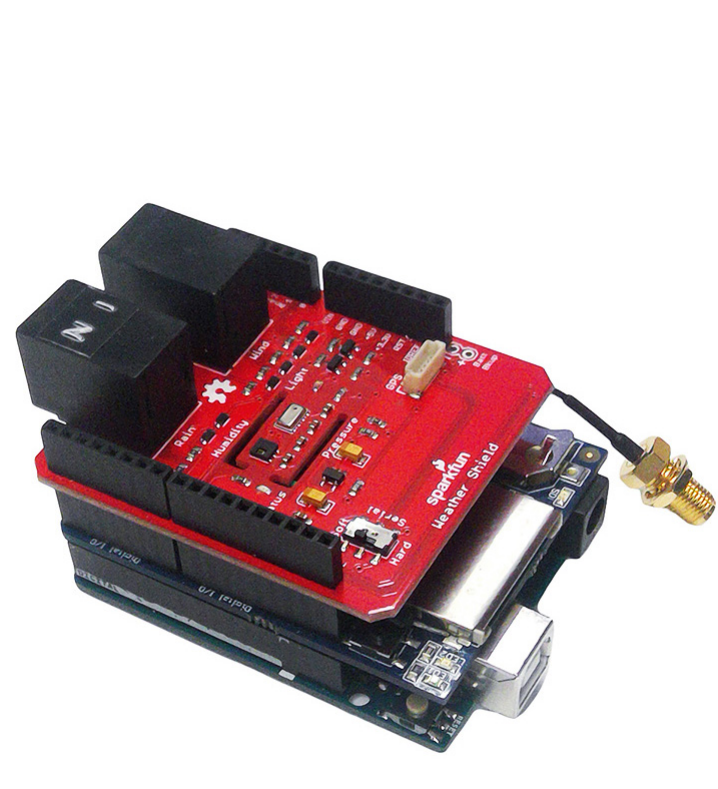

(a) Weather station data logger.

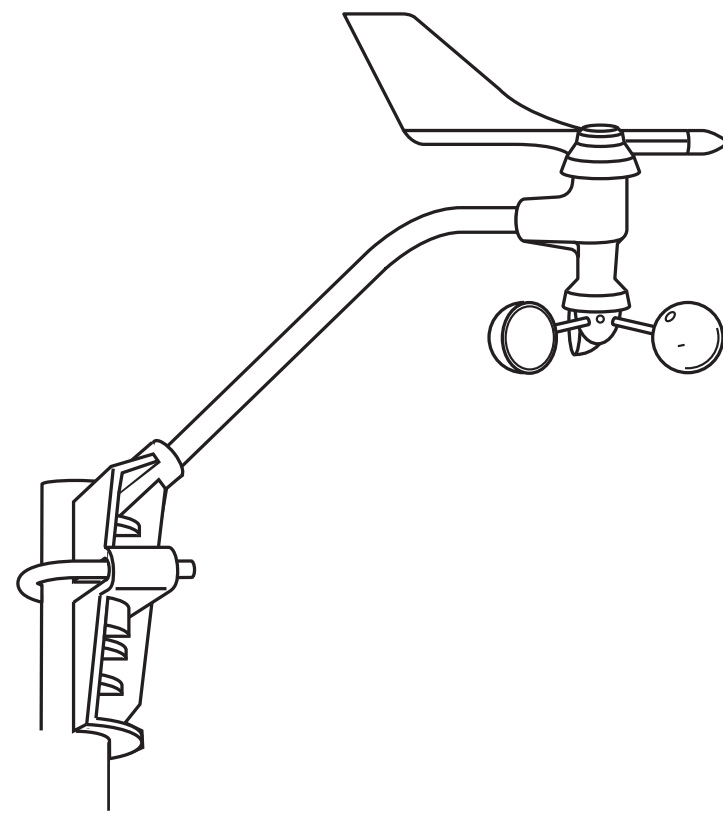

(b) Cup anemometer and wind vane 48 .

Figure 2.31: Components of the weather ground station.

The main component of the weather ground station is the DS6410 anemometer and wind vane manufactured by Davis Instruments. The cup anemometer can measure wind speed up to $89 \mathrm{~m} / \mathrm{s}$ and the wind vane can measure the wind direction. They were both mounted $2 \mathrm{~m}$ off the ground on a metal tripod during the experiment at the flying field. This type of anemometer was selected because of its ease to use and reliability [49]. Bearings are used to ensure the wind cup shaft can rotate freely with minimal friction to reduce measurement error, especially under low wind speeds. At each rotation, the 


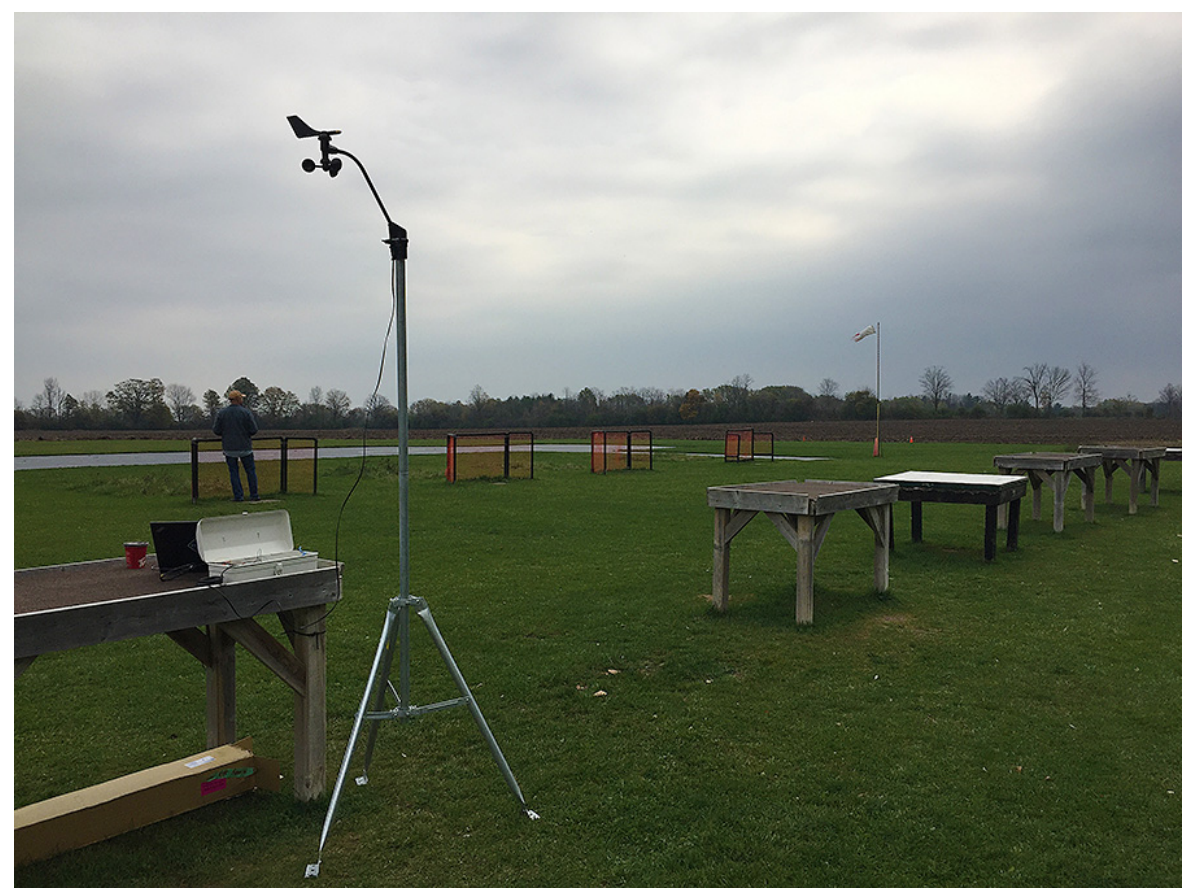

Figure 2.32: Weather ground station in operation at the flying field during experiment.

rotor activates the reed switch and send an electrical pulse signal to the Arduino data logger. The speed, at which the cup rotor is rotating at is correlated to the wind speed. In the datasheet provided by Davis Instruments, that is included in Appendix 4. The anemometer readings were verified using the windtunnel at Ryerson University to wind speeds up to $20 \mathrm{~m} / \mathrm{s}$ (Fig. 2.33 Although cup anemometers were used in previous gust measurement and produced fair results [50], wind-shear profile can cause unsteady motion of the cup rotor and produce measurements that oscilate, but are not related to atmospheric gusts 51]. In this experiment, the measurement using the cup anemometer was solely used to determine the mean-wind speed at ground level.

The direction of the wind is measured with the wind vane. A $20 k \Omega$ potentiometer is attached under the vane to measure its position. It acts as a voltage divider with $5 \mathrm{~V}$ supplied from the Arduino data logger. The analog signal of the wind vane position is then converted to bearing angle of the wind direction using the variable resistance of $0-20 k \Omega$ with the half-way point $(10 k \Omega)$ aligns to the south. The zero angle position of the wind vane needs to be aligned to the magnetic north with the use of a compass at the flying field. The magnetic declination of the flying field is added $\left(-10.1979^{\circ}\right)$ to convert 


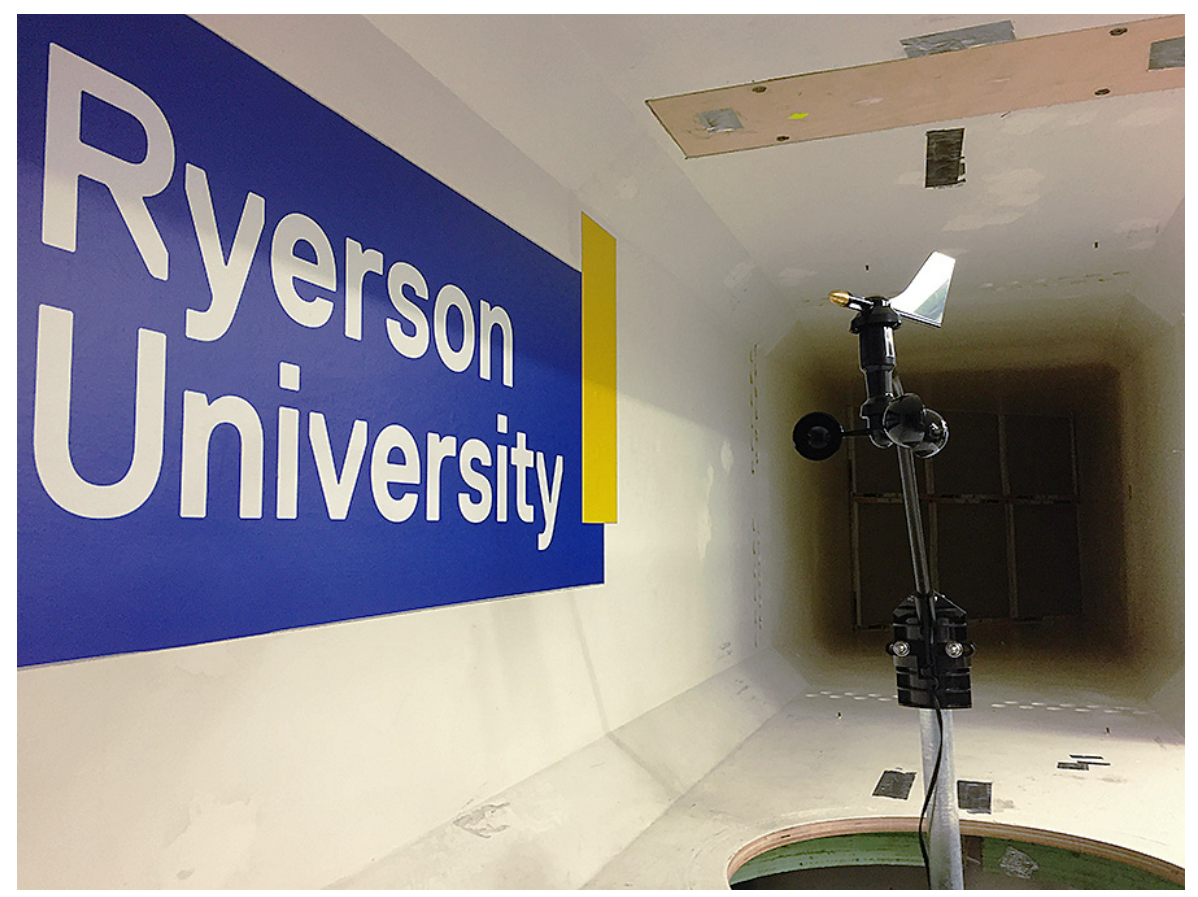

Figure 2.33: The cup anemometer and wind vane calibration setup in wind-tunnel at Ryerson University.

Table 2.2: Weather station sensor specifications.

\begin{tabular}{|c|c|c|c|}
\hline & Range & Resolution & Accuracy \\
\hline Cup anemometer 48 ] & 0.5 to $89 \mathrm{~m} / \mathrm{s}$ & $0.001 \mathrm{~m} / \mathrm{s}$ & $\pm 1 \mathrm{~m} / \mathrm{s}$ \\
\hline Wind vane 48 & 0 to $359^{\circ}$ & $1^{\circ}$ & $\pm 3^{\circ}$ \\
\hline Barometer 52 & 50 to $110 \mathrm{kPa}$ & $0.25 \mathrm{~Pa}$ & $\pm 0.4 \mathrm{kPa}$ \\
\hline Temperature Sensor 53 & 0 to $100 \%$ & $0.0625^{\circ} \mathrm{C}$ & $\pm 0.3^{\circ} \mathrm{C}$ \\
\hline Humidity Sensor 53 & 0 to $100 \%$ & $0.025 \%$ & $\pm 2 \%$ \\
\hline
\end{tabular}

the wind direction to the true north heading to match the data collected by the air-data system on GustAV.

The Arduino data logger includes a SparkFun Weather Shield, which utilizes the Si7021 humidity/temperature sensor and the MPL3115A2 barometric pressure sensor. The measurements are fetched by the Arduino data logger every second and being recorded to the SD card. The weather shield also contains two RJ11 connectors as an interface between the Arduino data logger and the Davis Instruments anemometer and wind vane. Table 2.2 presents the specifications of the sensors on the weather ground station. 


\subsection{Testing Site}

All field tests of this research were performed at TEMAC Field that the Toronto Electric Model Aviation Club operates near Stouffville, Ontario, about $40 \mathrm{~km}$ north of Toronto, Ontario, Canada. The flying field consists of a paved runway and a flying zone over a farm field that measures approximately 300 meters by 400 meters. As part of the planning of the experiments, a digital elevation model was obtained from the government of Ontario and the terrain surrounding of the flying field was studied. The elevation of the runway is 243 meters above the sea level and the farm field has variation of no more than 5 meters in elevation as shown in Fig. 2.34 .

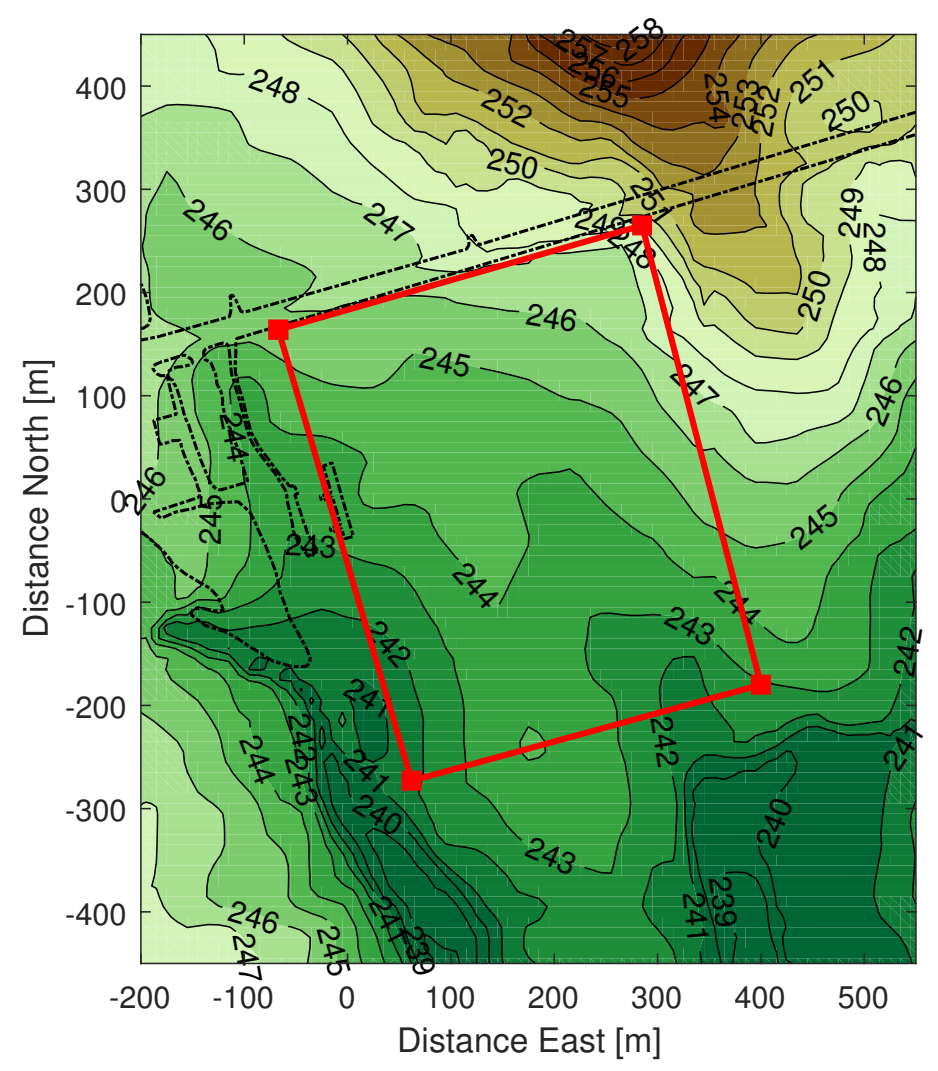

Figure 2.34: Elevation contour map of GustAV flight testing region at TEMAC field. 


\section{Chapter 3}

\section{Wind Tunnel and In-Flight Experiments}

In order to develop GustAV and measure atmospheric data using the Aventech air-data system, ground and flight tests were required. For example, wind-tunnel tests were preformed in the wind tunnel of Ryerson University. Furthermore, flight tests were performed at the Toronto Electric Model Aviation Club (TEMAC) in Stouffville, Ontario. The objectives, significant events, and the results of the tests performed are categorized and discussed in this chapter.

\subsection{Wind Tunnel Test}

The goal of the wind tunnel experiment was to quantify the sensitivity of the pressure transducers and the response of the five-hole probe changes in angle of attack. The Ryerson's large wind-tunnel was used to conduct the tests and its configuration is shown in Fig. 3.1. The closed circuit wind-tunnel has a $91.4 \mathrm{~cm}$ by $91.4 \mathrm{~cm}$ square test section. The turning vanes, screens, and flow nacelle are installed in the tunnel to reduce the turbulence level and improved the flow quality. Previous experiment performed by Barcelos has shown the wind tunnel used in this experiment has a turbulence intensity slight less than $0.29 \%$ 54. The low turbulence level is preferable to determine the sensitivity of the pressure transducers. 


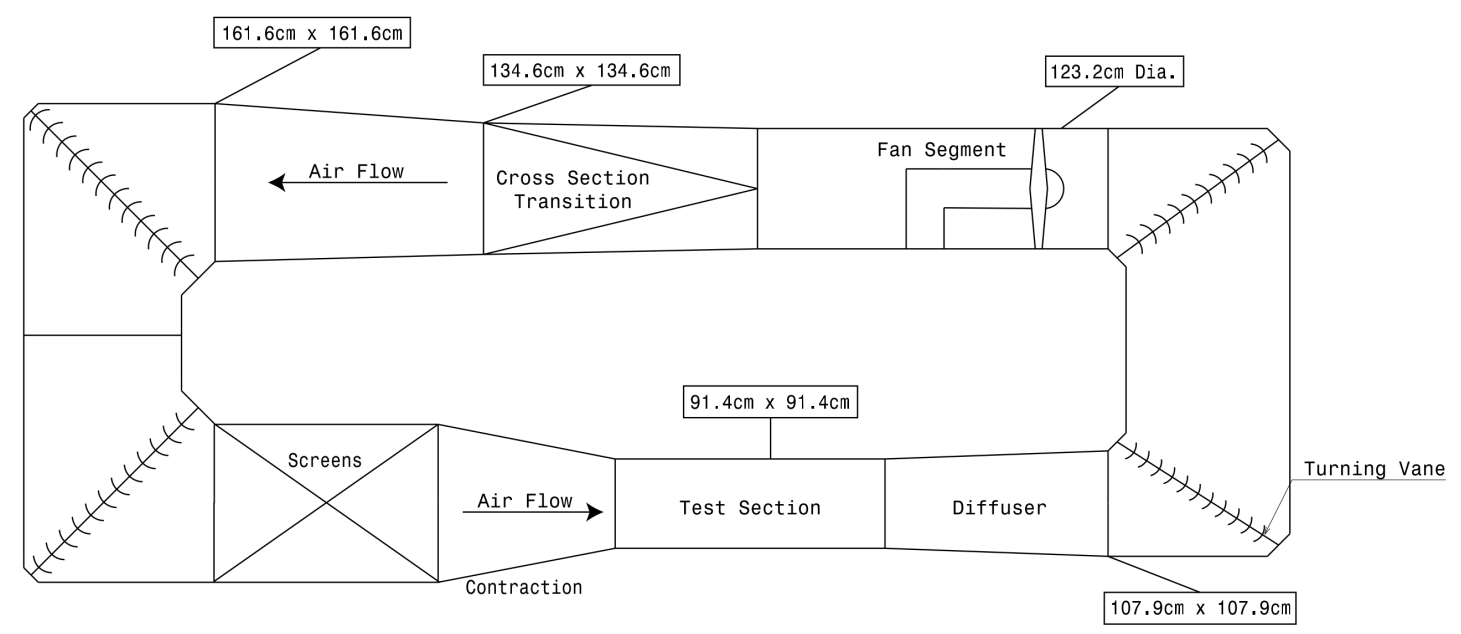

Figure 3.1: Ryerson University large wind tunnel [54].

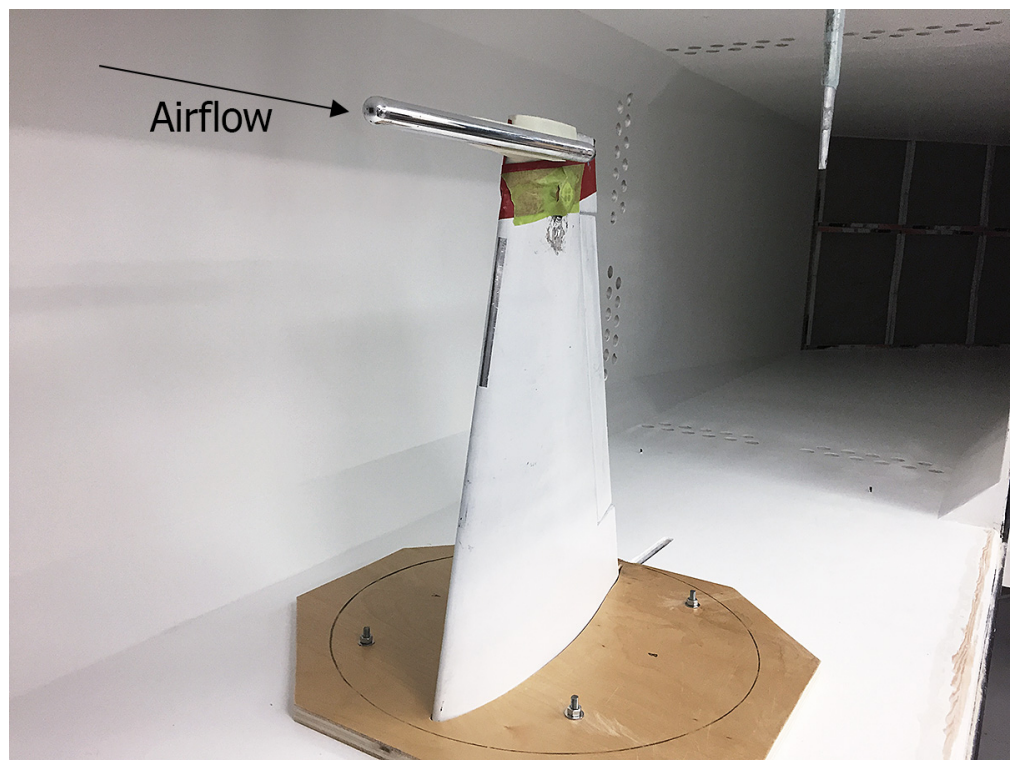

Figure 3.2: Five-hole probe experiment setup in the large wind tunnel at Ryerson University.

The five-hole probe was attached to the wing of GustAV and tested at freestream velocities of $10 \mathrm{~m} / \mathrm{s}$, $15 \mathrm{~m} / \mathrm{s}$, and $20 \mathrm{~m} / \mathrm{s}$. The tests were conducted at $-2.5^{\circ}, 2.5^{\circ}$, and $7.5^{\circ}$ angles of attack. The experimental setup is shown in Fig. 3.2 . The halfspan of the wing was mounted through the floor of the turn table in the wind tunnel with the five-hole probe located near the center line of the test section. The data acquisition was acquired using the Aventech AIMMS-30 air-data system which is the same hardware 


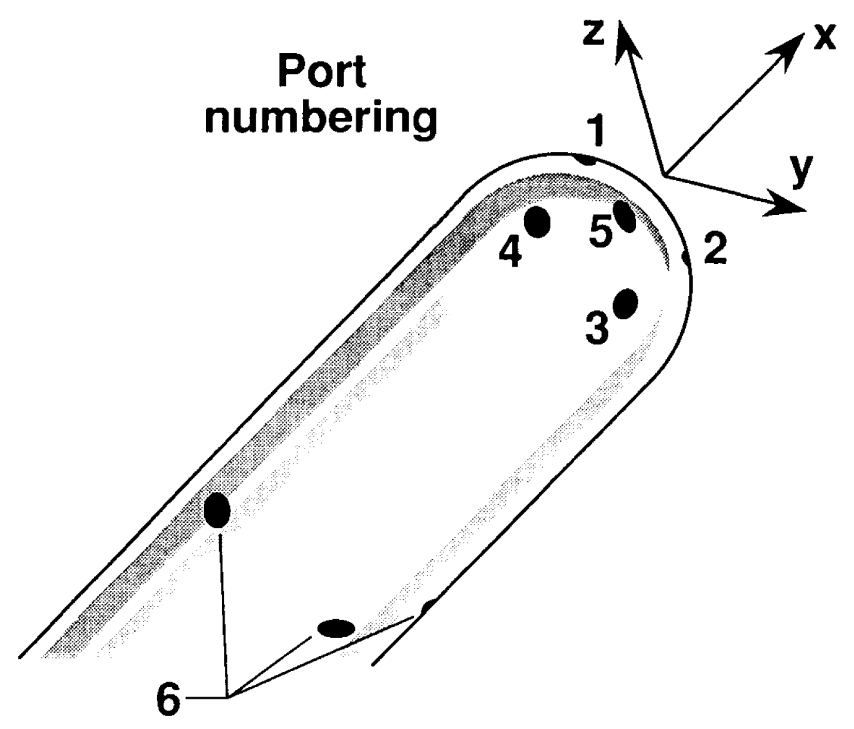

Figure 3.3: Pressure port convention of the Aventech five-hole probe, modified from 39 .

that is onboard GustAV.

The data logging device recorded the angle of attack differential pressure $\left(p_{3}-p_{1}\right)$, the angle of sideslip differential pressure $\left(p_{4}-p_{2}\right)$, the dynamic pressure $\left(p_{5}-p_{6}\right)$, and the static pressure $p_{6}$. The numbering convention of the pressure ports on the five-hole probe is shown in Fig. 3.3. The pressure measurements were recorded at all three angle of attack settings at three different speeds of the freestream flow. At each setting, 2000 samples were recorded at 50 samples per second. The results are shown in Fig. 3.4 The goal is to gather pressure measurements at a constant airspeed in the wind tunnel and determine the standard deviations of the pressure measured by the sensors. This information is important since the signal noise of the pressure transducers determines the smallest perturbation of wind speed that can be detected by this air-data instrument setup. Based on these measurements, the smallest wind-speed perturbation that the five-hole probe can detect is $0.10 \mathrm{~m} / \mathrm{s}$. 


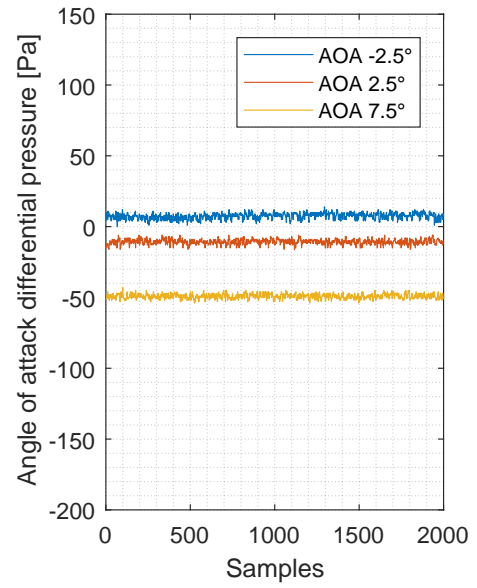

(a) Freestream flow of $10 \mathrm{~m} / \mathrm{s}$.

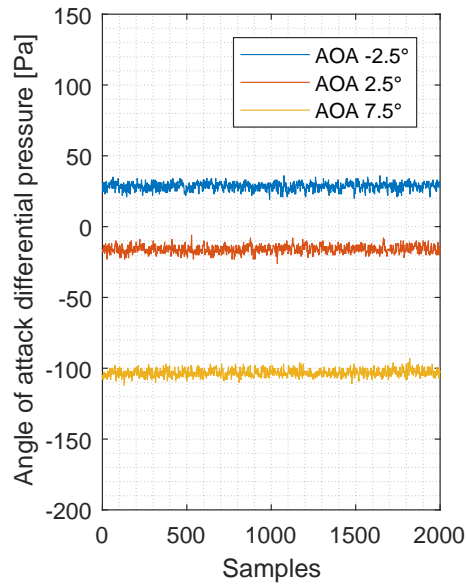

(b) Freestream flow of $15 \mathrm{~m} / \mathrm{s}$.

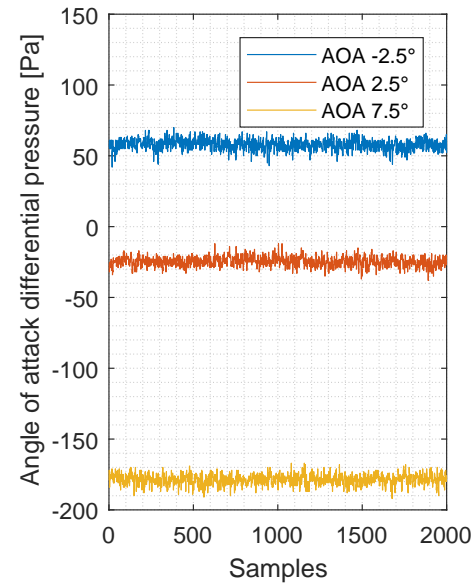

(c) Freestream flow of $20 \mathrm{~m} / \mathrm{s}$.

Figure 3.4: The measured differential pressure $\left(p_{3}-p_{1}\right)$ at various speeds of freestream flow.

The angle of attack, $\alpha$, can be derived from the difference of the angle of attack pressure ports $\left(p_{3}-p_{1}\right)$ using Eq. 3.1 .

$$
\alpha=-a_{0}+a_{\alpha} \frac{p_{3}-p_{1}}{p_{5}-p_{6}}
$$

The calibration coefficients are provided by the manufacturer where the angle of attack calibration offset, $a_{0}$, is 0 degrees, and the angle of attack calibration coefficient, $a_{\alpha}$, is 12.7 degrees.

The velocity of the wind gust can be computed using the change in angle of attack and mean freestream velocity by rearranging Eq. 1.5 .

$$
U=V_{\infty} \tan (\Delta \alpha)
$$




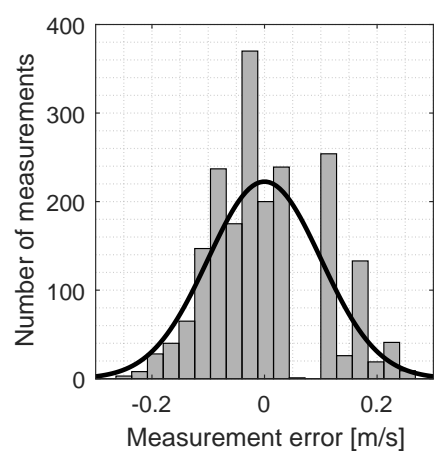

(a) Angle of attack of $-2.5^{\circ}$ at freesteam flow of $10 \mathrm{~m} / \mathrm{s}$.

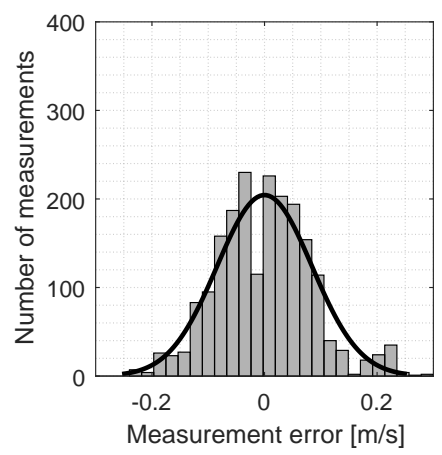

(d) Angle of attack of $2.5^{\circ}$ at freesteam flow of $10 \mathrm{~m} / \mathrm{s}$.

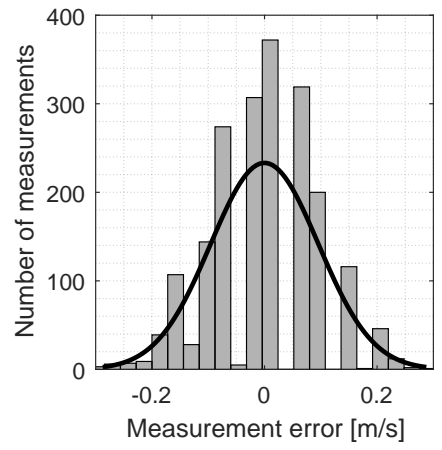

(g) Angle of attack of $7.5^{\circ}$ at freesteam flow of $10 \mathrm{~m} / \mathrm{s}$.

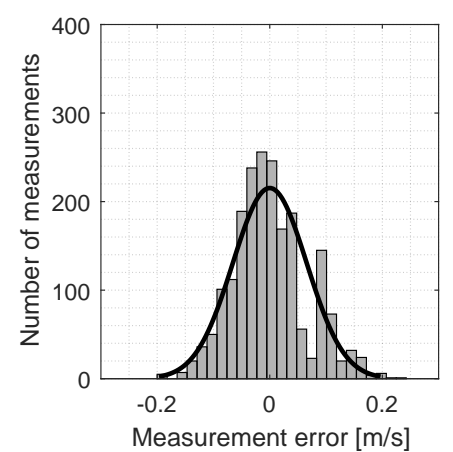

(b) Angle of attack of $-2.5^{\circ}$ at freesteam flow of $15 \mathrm{~m} / \mathrm{s}$.

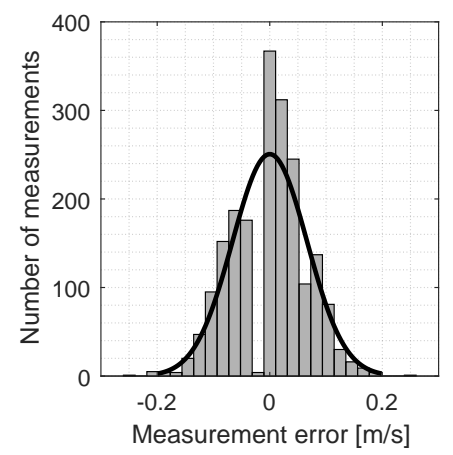

(e) Angle of attack of $2.5^{\circ}$ at freesteam flow of $15 \mathrm{~m} / \mathrm{s}$.

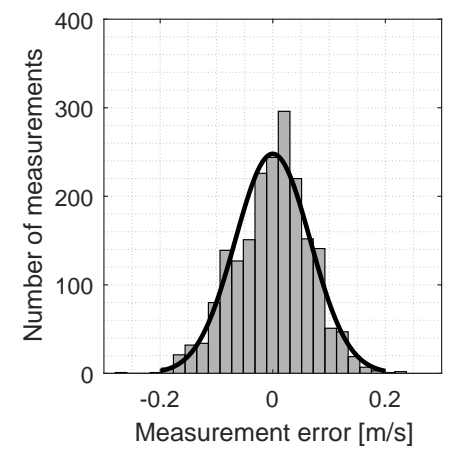

(h) Angle of attack of $7.5^{\circ}$ at freesteam flow of $15 \mathrm{~m} / \mathrm{s}$.

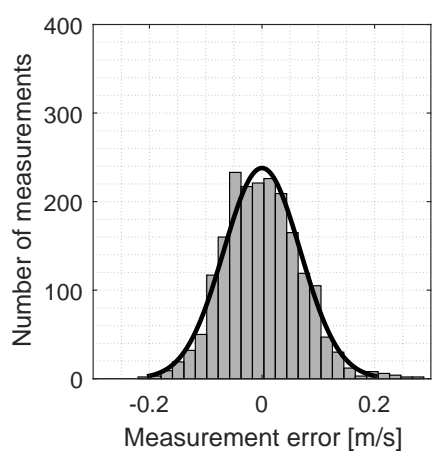

(c) Angle of attack of $-2.5^{\circ}$ at freesteam flow of $20 \mathrm{~m} / \mathrm{s}$.

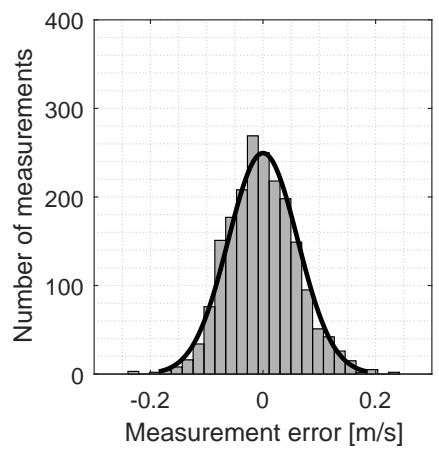

(f) Angle of attack of $2.5^{\circ}$ at freesteam flow of $20 \mathrm{~m} / \mathrm{s}$.

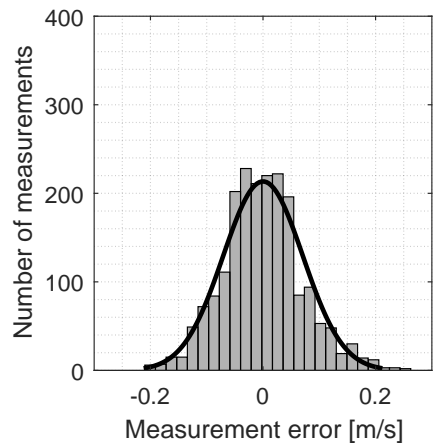

(i) Angle of attack of $7.5^{\circ}$ at freesteam flow of $20 \mathrm{~m} / \mathrm{s}$.

Figure 3.5: The distribution of the signal noise at various freestream velocities and angles of attack with normal distribution fits. 
Table 3.1: Root-mean-square values of the five-hole probe sample error.

\begin{tabular}{ccc}
\hline Angle of attack & Airspeed & Root-mean-square error \\
\hline$-2.5^{\circ}$ & $10 \mathrm{~m} / \mathrm{s}$ & $0.1004 \mathrm{~m} / \mathrm{s}$ \\
& $15 \mathrm{~m} / \mathrm{s}$ & $0.0656 \mathrm{~m} / \mathrm{s}$ \\
$20 \mathrm{~m} / \mathrm{s}$ & $0.0681 \mathrm{~m} / \mathrm{s}$ \\
\hline $2.5^{\circ}$ & $10 \mathrm{~m} / \mathrm{s}$ & $0.0843 \mathrm{~m} / \mathrm{s}$ \\
& $15 \mathrm{~m} / \mathrm{s}$ & $0.0662 \mathrm{~m} / \mathrm{s}$ \\
& $20 \mathrm{~m} / \mathrm{s}$ & $0.0617 \mathrm{~m} / \mathrm{s}$ \\
\hline $7.5^{\circ}$ & $10 \mathrm{~m} / \mathrm{s}$ & $0.0958 \mathrm{~m} / \mathrm{s}$ \\
& $15 \mathrm{~m} / \mathrm{s}$ & $0.0666 \mathrm{~m} / \mathrm{s}$ \\
& $20 \mathrm{~m} / \mathrm{s}$ & $0.0707 \mathrm{~m} / \mathrm{s}$ \\
\hline
\end{tabular}

The wind tunnel used in this experiment has a low turbulence intensity slight less than $0.29 \%$ [54]. The turbulence intensity can also be described as the root mean square (RMS) or the standard devation of the flow velocity. Hence, the lower turbulence intensity is the result of fewer fluctuations in the flow velocity measurements. When comparing the wind tunnel to environment within the earth's atmospheric boundary layer where the turbulence intensity can reach $30 \%$ or higher [11], the turbulence found in the wind tunnel is extremely low. Therefore, for the purpose of analyzing the noise level of the air-data system, it is fair to assume the speed of air flowing past the wind tunnel cross section is constant and fluctuations in pressure measured by the transducers are signal noise. The distribution of the signal noise at various freestream velocities and angles of attack are plotted with normal distribution fits in Fig 3.5. The root-mean-square values of the five-hole probe sample error are summerized in Table 3.1 . The sensor performed similarly at airspeeds of $15 \mathrm{~m} / \mathrm{s}$ and $20 \mathrm{~m} / \mathrm{s}$. The pressure transducers have a precision of $1 \mathrm{~Pa}$ which explains the relatively poorer performance at lower pressure values at $10 \mathrm{~m} / \mathrm{s}$ (Fig. 3.5a). In conclusion, the gust measurement should be performed at airspeed faster than $15 \mathrm{~m} / \mathrm{s}$ in order to take advantage of the better performance of the five-hole probe at the higher pressures. 


\subsection{UAV Platform}

During the development of the GustAV platform, flight tests were performed to determine the performance and realibility of the vehicle. These tests include tuning the autopilot control system to achieve autonomous flight before the air-data system was mounted. The tables in Appendix 1 are showing the flight $\log$ of the flight vehicles, GustAV and Bix3, with the date and elapsed time of each flight. The maximum altitudes and speeds achieved during each flight are also included in the tables.

\subsubsection{First Flight}

On February 6, 2016, GustAV flew smoothly during its first flight. That flight was a short exploration of the flight characteristics of GustAV that lasted for 3 minutes. The aircraft had only its essential systems in order to reduce the complexity of the setup. The pilot performed the flight entirely in manual mode to retain full control and ensure safety before the autopilot system was fully tested in later flights.

During the first flight a tail-mounted camera revealed excessive upward bending of the wing. In Fig. 3.6, two frames from the camera footage were superimposed to show the amount of wing bending under aerodynamic load. The original wing design of GustAV used a balsa wood for the internal structure and Monokote, a plastic shrink wrap film material, for the wing skin. This method produced a strong and light-weight design which can be found on most model aircraft. However, it appeared that the original wing design did not provide sufficient structural rigidity. Since the five-hole probe mounted on the wing tip is sensitive to the vertical motion of the probe relative to the inertial measurement unit mounted in the aircraft's fuselage.

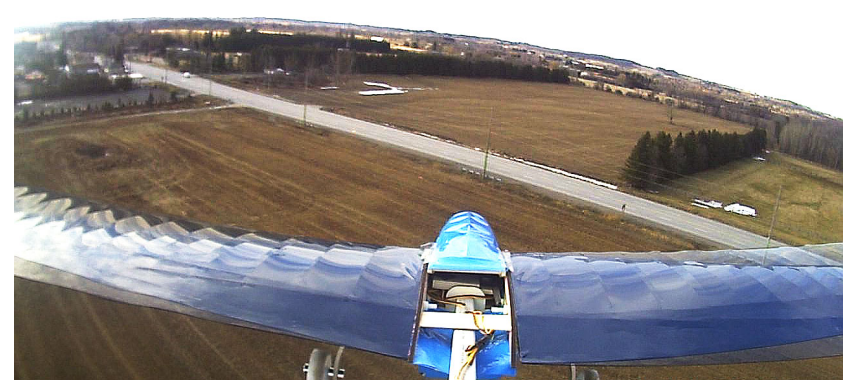

Figure 3.6: Wing bending under aerodynamic load.

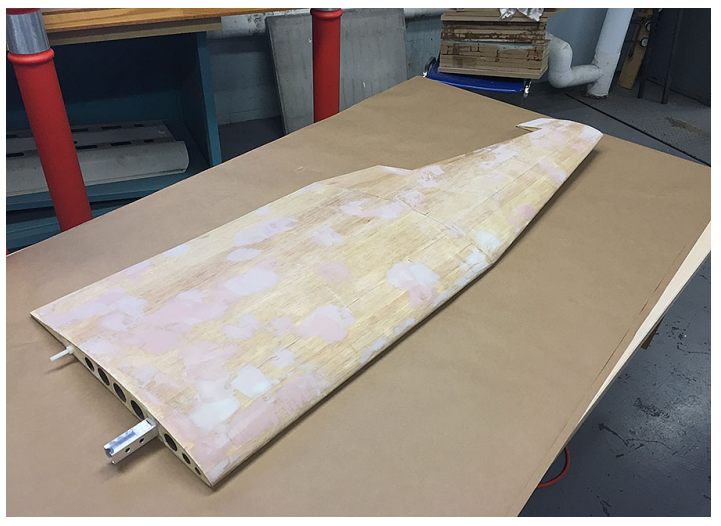

Figure 3.7: Balsa and fiberglass wing skin. 
The bending of the wing induces extra motion to the five-hole probe and causes sensor errors. Stiffer wing was required to mitigate this problem. Thus, the Monokote skin was replaced by thin balsa sheet reinforced with fiberglass to stiffen the wing structure as shown in Fig. 3.7. The extra rigidity reduced wing bending and enhanced the accuracy of the air-data system. It came, however, with the penalty of $1 \mathrm{~kg}$ of extra mass and reduced the aircraft's endurance but the action was nessesary to ensure the measurement accuracy of the experiment.

\subsubsection{Aircraft Performance, Stability, and Control}

Several modifications were made related to the aerodynamics of the aircraft. On the seventh flight, GustAV exhibited instabilities while rolling that caused the aircraft to yaw drastically then entered a stall. Fortunately, the pilot was able to recover from the stall and landed the aircraft safely. A snippet of the flight recording shows that large aileron deflections caused significant amounts of adverse yaw, especially during relatively slow flight at high angles of attack. The relatively large angles and angular rates would then lead to one wing entering stall as pointed out in Fig. 3.8 at the 581 seconds mark. 

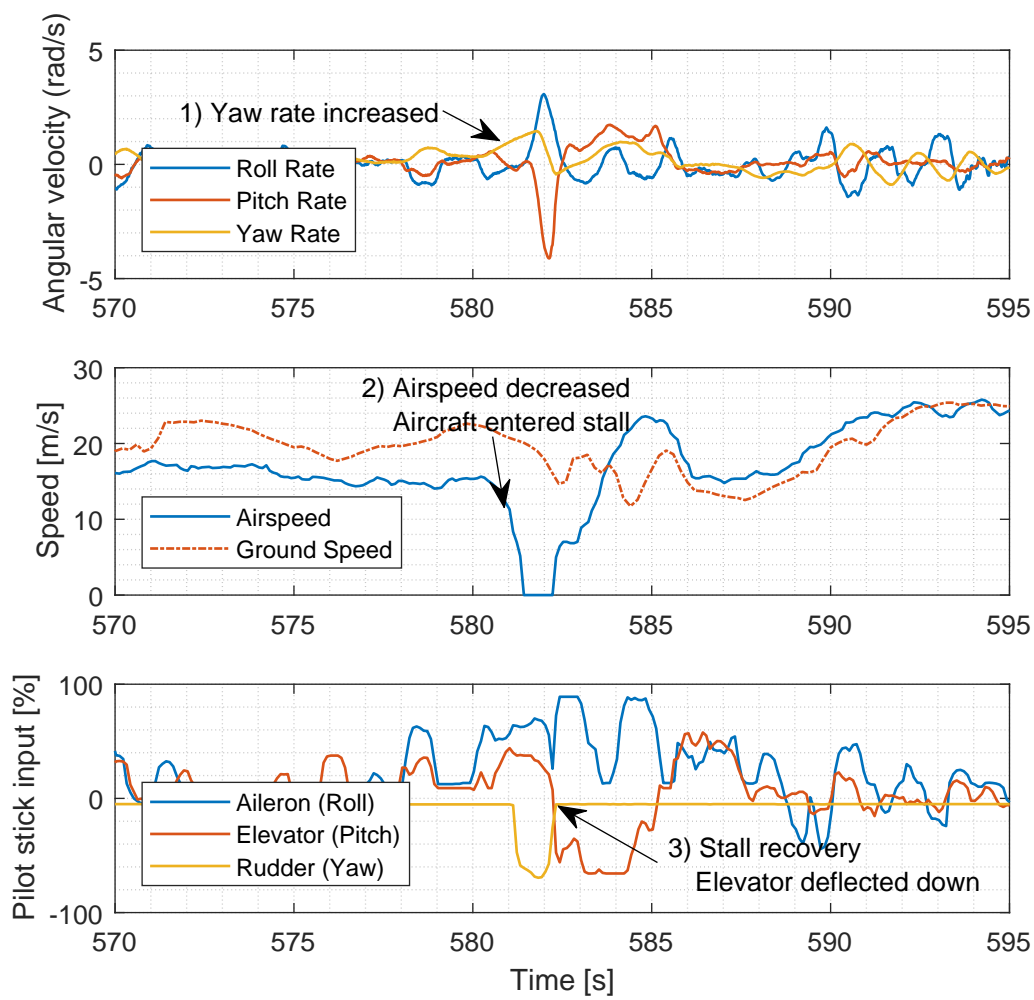

Figure 3.8: Flight log showing GustAV experienced directional instabilities during flight 7.

After the incident, differential ailerons were setup to reduce adverse yaw. Furthermore, the original tail design did not provide sufficient directional stability. Thus, additional area was added to the vertical tail in order to increase directional stability of the aircraft. The tail was replaced with a new design with vertical stabilizer $40 \%$ larger than the original (Fig. 3.9). Also, the elevator was undersized on the original tail design and did not provide sufficient pitching control authority at low speeds which resulted in hard landings. Therefore, in addition to a new vertical tail design, the elevator chord was increased in order to provide sufficient longitudinal control response of the aircraft at low speeds during approach and landing. 


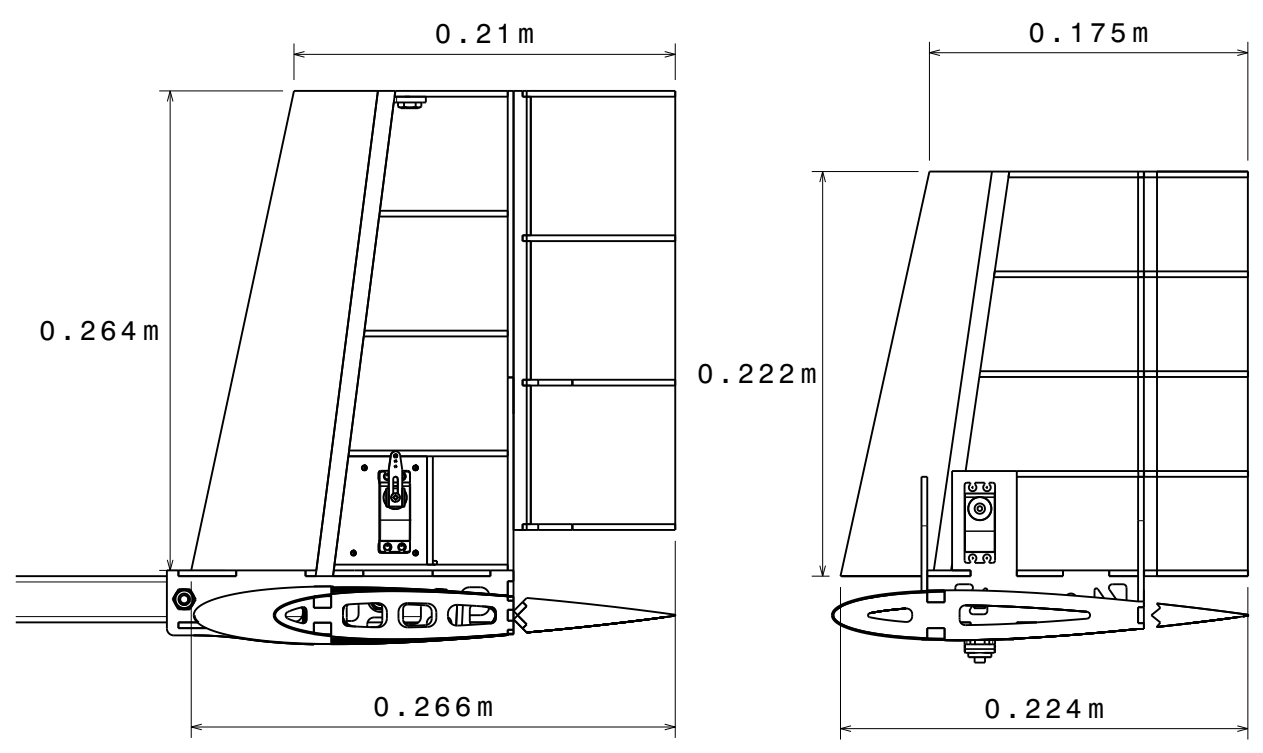

Figure 3.9: Dimensions of the new vertical stabilizer design on the left and the old design on the right.

\subsubsection{Autopilot System Tuning}

In order for GustAV to operate according to the flight mission and follow the programmed trajectory accurately, the autopilot system needed to be tuned. This was performed by changing the PID controller parameters of the autopilot system until the desired level of control system performance is achieved. The tuning is crucial for the flight control system to achieve autonomous mission following.

During the tuning process, the pilot commanded the aircraft to do a series of rapid consecutive rolling and pitching maneuvers. The onboard flight control system monitors the aircraft control surfaces actuation and the measured feedback of the aircraft dynamics. This process was repeated multiple times to allow the control system to gather sufficient flight data to perform the PID turning. At the end of this process, the demanded roll or pitch angle shown in the flight data log should closely match the achieved angle. This signifies the PID parameters are tuned to the correct values and the system is ready to perform autonomous flights. Fig. 3.10 shows the achieved roll and demanded roll measurement of a correctly tuned flight controller. The roll angle achieved by the aircraft had minimal lag and overshoot when compared to the demanded roll by the flight control system. 


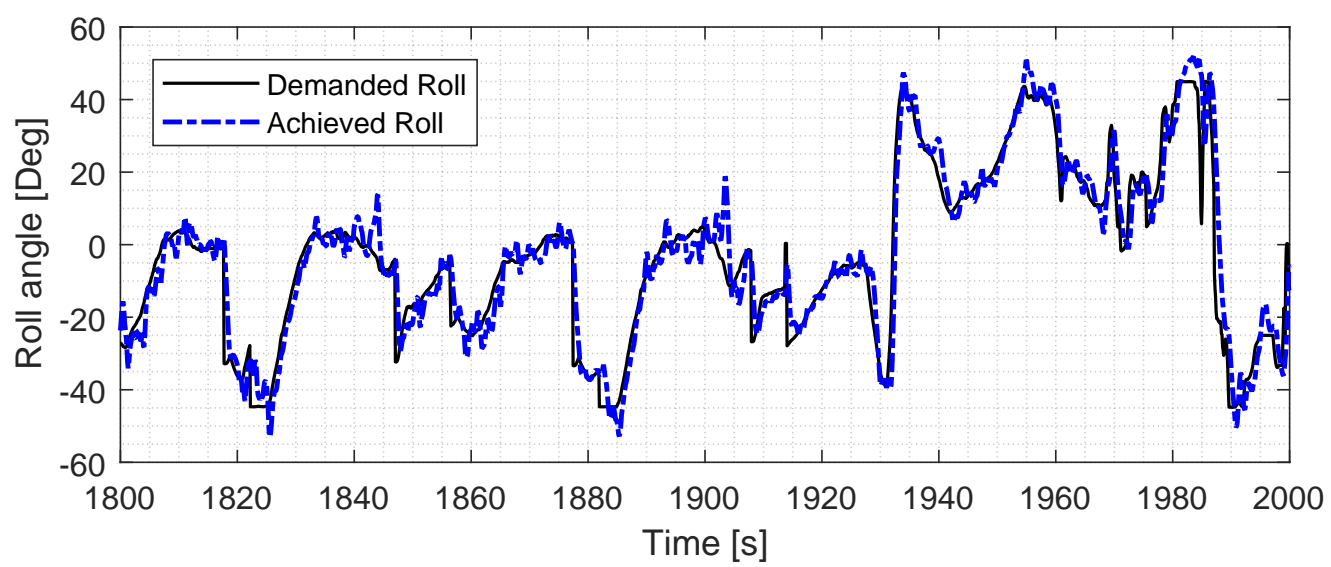

Figure 3.10: Demanded roll and achieved roll after the flight control system has been tuned.

\subsection{Gust Measurement}

\subsubsection{Air-Data System Integration}

Once the aircraft was able to perform autonomous flights and follow programmed flight paths. The focus of the flight testing shifted onto the air-data system integration. These test performed during flights 18 to 21 (see flight logs in Appendix 1) and the flew the 'racecourse' pattern around four waypoints (represented by diamond markers) shown in Fig. 3.11. These flights required the aircraft to fly straightand-level in two opposite directions and allow the air-data system to measure the wind coming from both directions of the aircraft. The aircraft also had to perform tight turns at the end of each straight segment where the GNSS receiver performance are tested since weaker signal strength is expected when the aircraft is banking and hence reduces the accuracy of the air-data system. Through out these flight tests, shielding was added to the main circuit board of the AIMMS-30 system and low bandwidth GNSS antennas were replaced with high bandwidth antennas to improve the performance of the air-data system.

During flights 18 and 19, the GNSS receivers suffered from low signal strength. The air-data system was unable to obtain any positioning information during those flights. Aluminum foils were used to surround the GNSS receiver circuit boards to form a shield. The foil is grounded to the circuit board 
and reduce the electro-magnetic interference. Thus, through extensive ground testing, the GNSS signalto-noise level was improved by the aluminum shielding and the system performed well during flights 20 and 21.

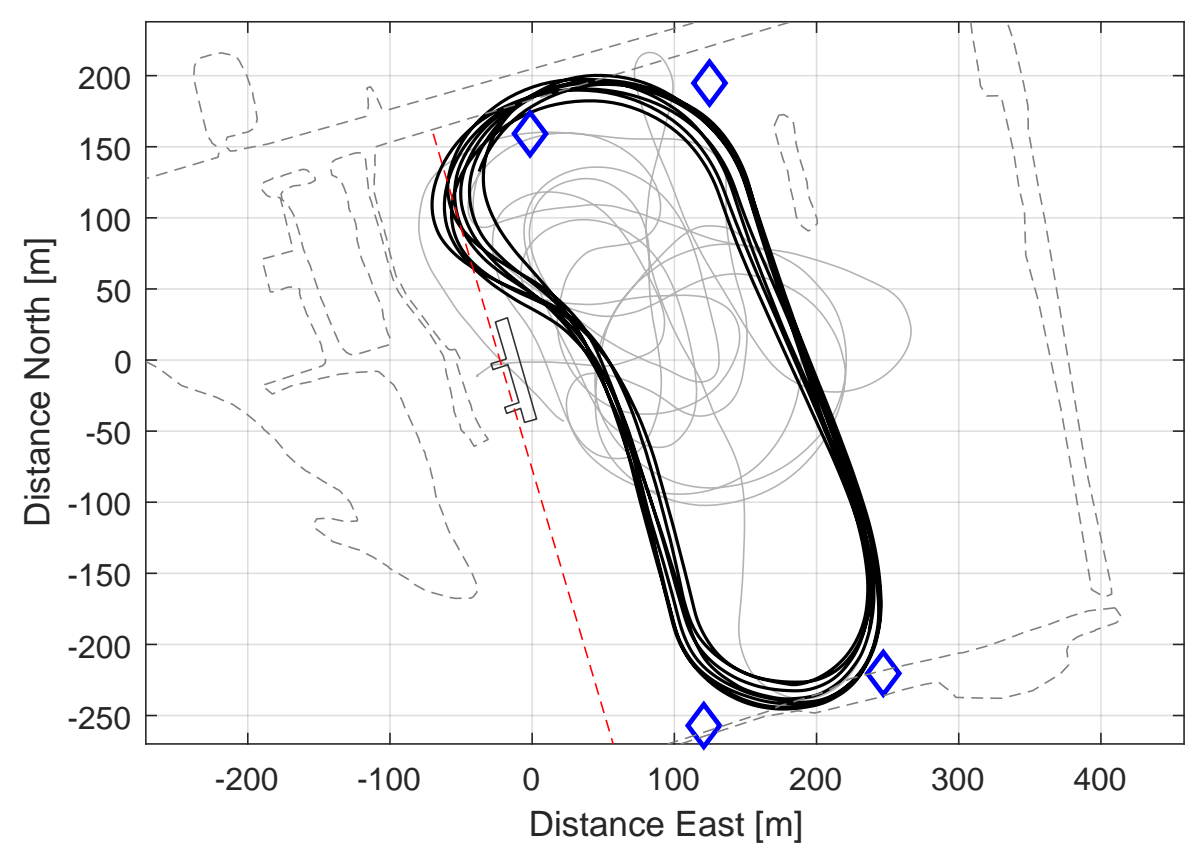

Figure 3.11: Flight path of the 'racecourse' circuit performed during flight 20. 

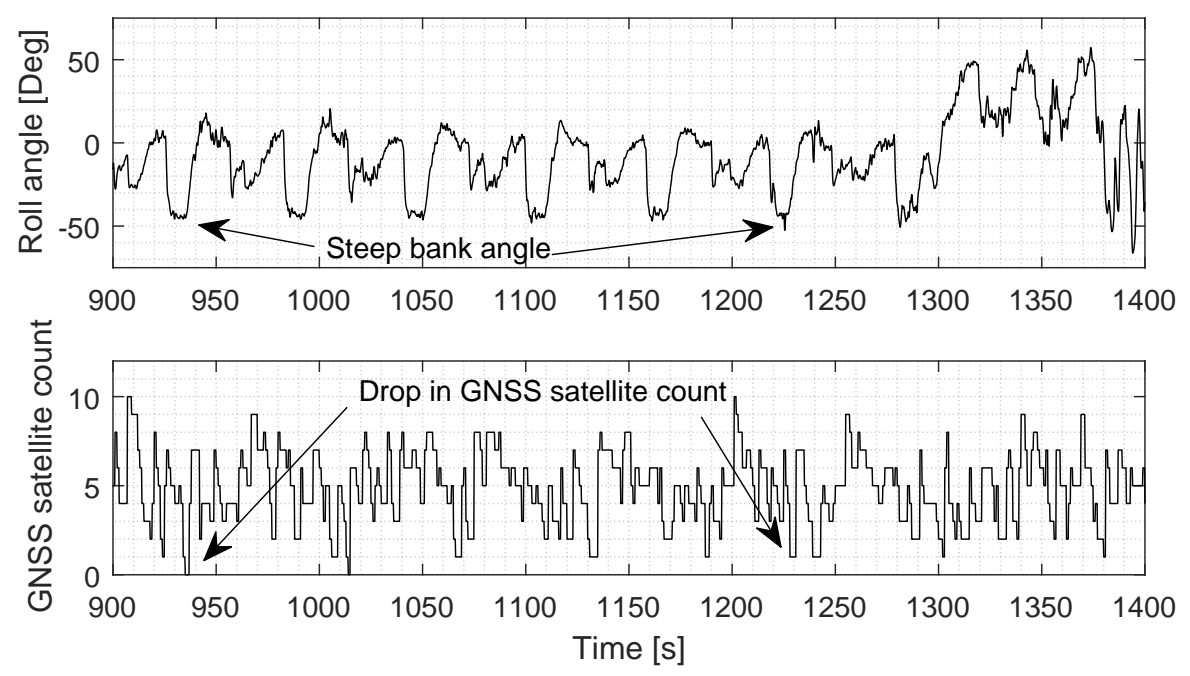

(a) Flight 20

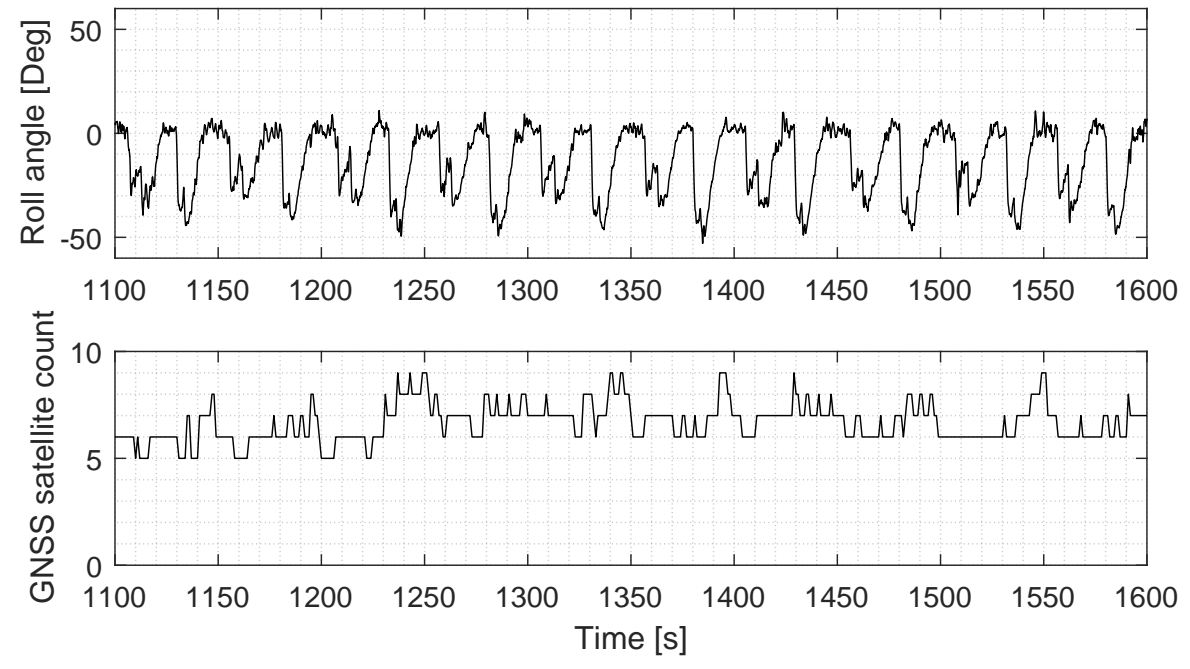

(b) Flight 23.

Figure 3.12: Roll angle of the aircraft and GNSS satellite count during flights 20 and 23.

The GNSS receiver performance is important for the gust measurements since the GNSS velocity solution is required for the correction of the inertial measurement unit. Furthermore, in order to measure the attitude of the aircraft using the differential carrier-phase, both GNSS receivers have to function at the same time. Although the signal performance was improved from previous flights using a better shielding, interruptions occurred while the aircraft was banking. Since the patch antennas on the wing 
of GustAV work best with signals coming directly overhead, and become less sensitive towards the horizon [47, banking the aircraft weakens the GNSS signal. The weak signal performance can be seen in Fig. 3.12a where the number of GNSS satellites detected was dropped every time when the aircraft banked. Since the GNSS receiver required a signal from at least four satellites, the results collected from flight 20 did not provide a good solution for the aircraft's velocity. Fig. $3.12 \mathrm{~b}$ shows a much improved GNSS signal reception during flight 23 with newly installed GNSS antennas. The new antenna, Tallyman TW1422 has a higher bandwidth and better off-zenith performance than the previously used antenna. GustAV performed an autonomous flight similar to flight 20 with rolling manuevers up to $50^{\circ}$ and the GNSS satellite count never dropped below five during those manuevers.

\subsubsection{Gust Measurement Experiment}

Atmospheric gusts were measured during flights 22 and 23 (3 June 2017) at TEMAC's field. Both flights lasted for 15 minutes and GustAV performed the 'racecourse' flight circuit at various altitudes (Fig. 3.13).

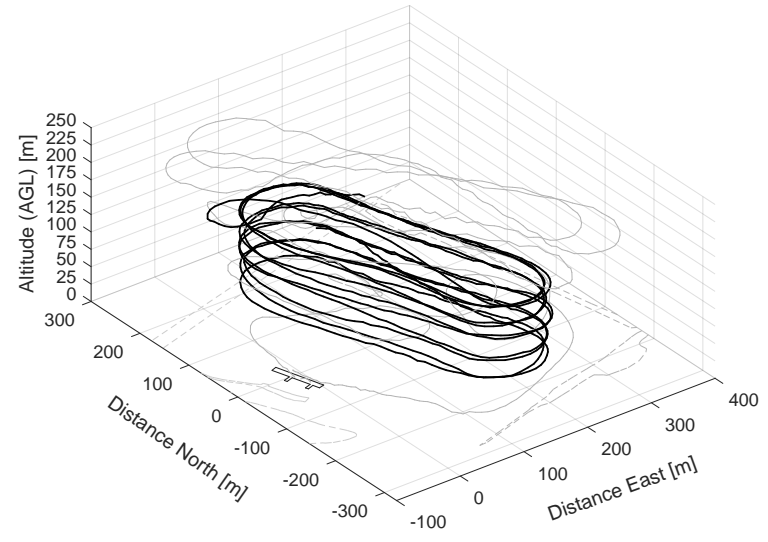

(a) Flight 22 .

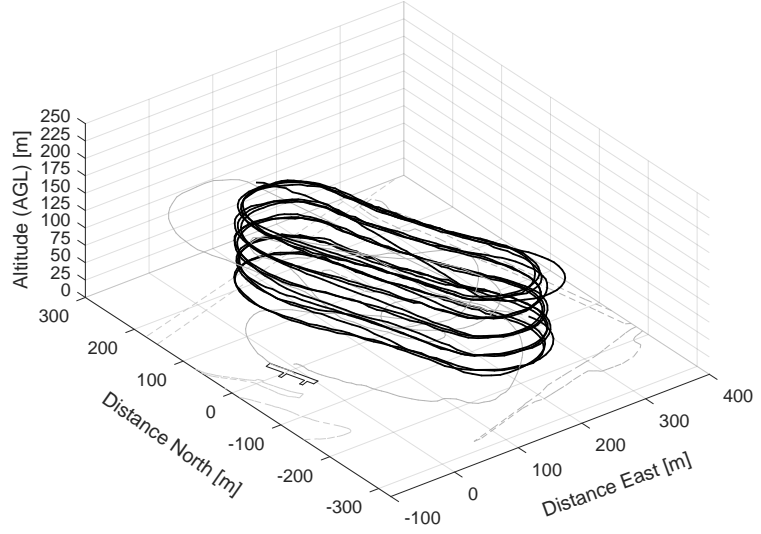

(b) Flight 23.

Figure 3.13: 'Racecourse' pattern performed in flights 22 and 23 to collect wind measruements.

The aircraft first climbed to the altitude of $150 \mathrm{~m}$ above the flying field and begin the flight mission. The aircraft maintained the altitude until two circuits were completed before descending down by $25 \mathrm{~m}$ in order to perform a circuit at the lower altitude. This flight profile continues until the aircraft had reached the altitude of $50 \mathrm{~m}$ above the field and the pilot regained control of the aircraft and proceed 
to land. The Aventech AIMMS-30 air-data system recorded the 3-D wind field data during the flights and data were synchronized with the measurement on the ground by the weather station. The gust measuring experiment began when the aircraft had reached the required altitude and maintaining stable flight for a few minutes. This was done in order to ensure that the Kalman filter estimator and GNSS receivers had been given sufficient time to have come to a converged solutions and, thus, improved the accuracy. The measured wind speeds were consistent when flying in opposite directions during the 'racecourse' patterns and Fig 3.14 shows the wind direction measured by the air-data system while the aircraft completes two laps of the 'racecourse' pattern. The airborne wind data is also showing good agreement with the weather ground station measurement (Fig 3.14). These results provided a high degree of confidence that the air-data system was functioning properly during these flights. This portion of the data collected was processed and compared with the von Kármán turbulence model in Chapter 4
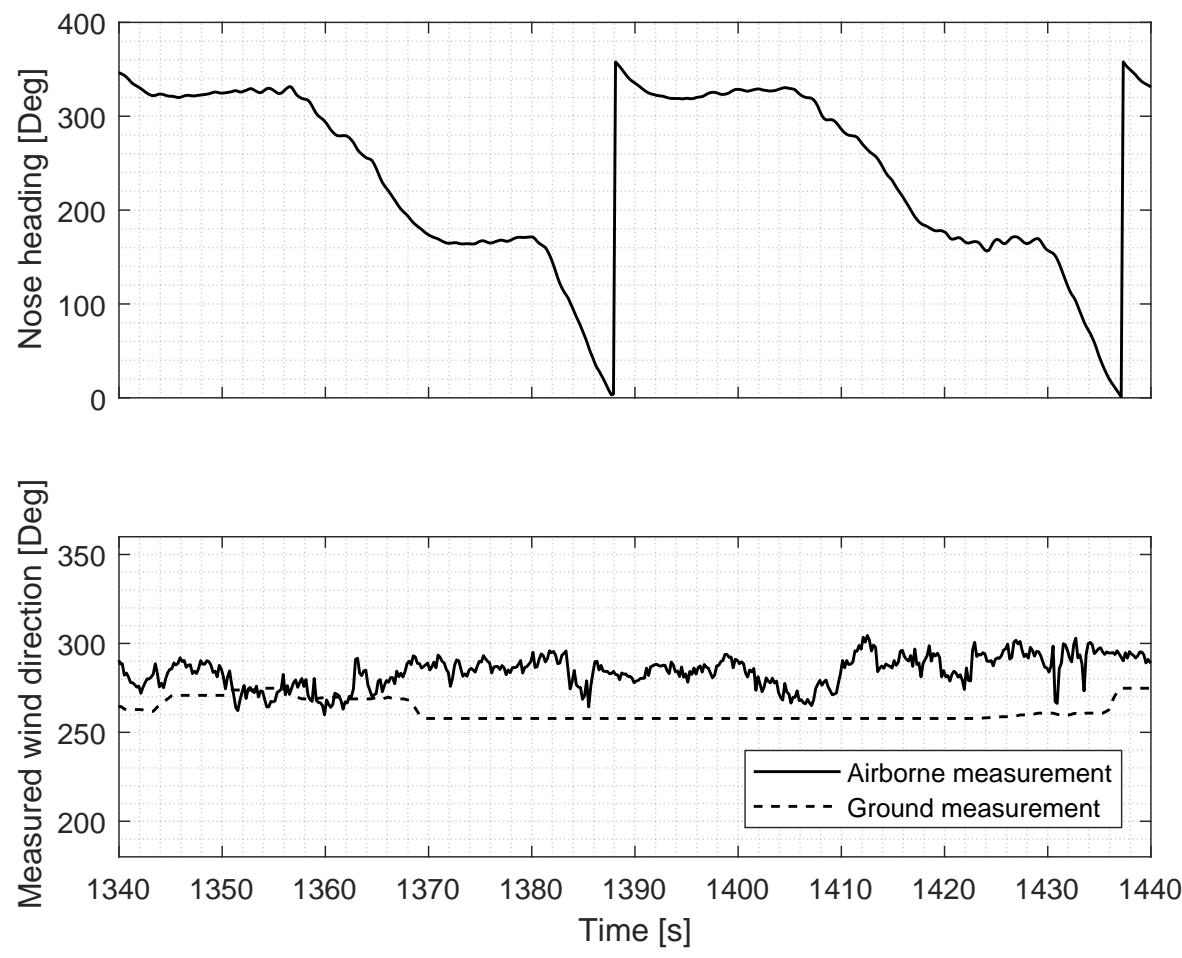

Figure 3.14: Flight path of the 'racecourse' circuit performed during flight 20. 


\section{Chapter 4}

\section{Results and Discussion of Inflight}

\section{Wind-Speed Measurements}

In this chapter, the wind data measured during flight 23 were analyzed and compared with the von Kármán model. Atmospheric wind was measured during flight 23 from timestamp 1250 s to timestamp $1750 \mathrm{~s}$ while GustAV performed the experiment at altitudes of $100 \mathrm{~m}, 75 \mathrm{~m}$, and $50 \mathrm{~m}$ above ground level (AGL) at TEMAC field as the 3D flight profile is shown in Fig. 4.1

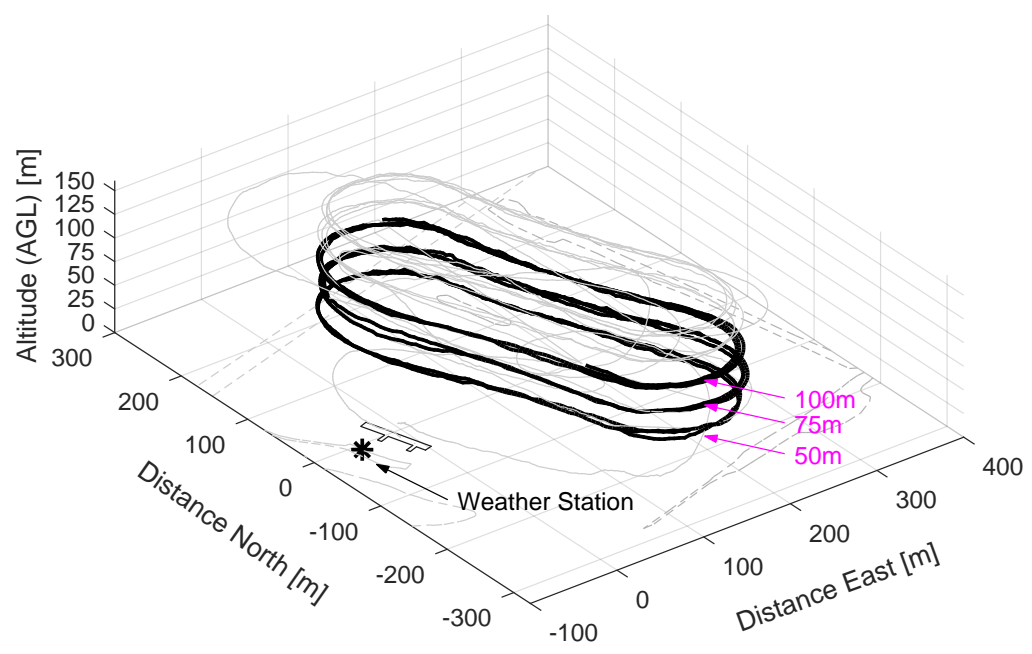

Figure 4.1: Flight test profile of flight 23 with gusts measurement segments highlighted and labeled. 


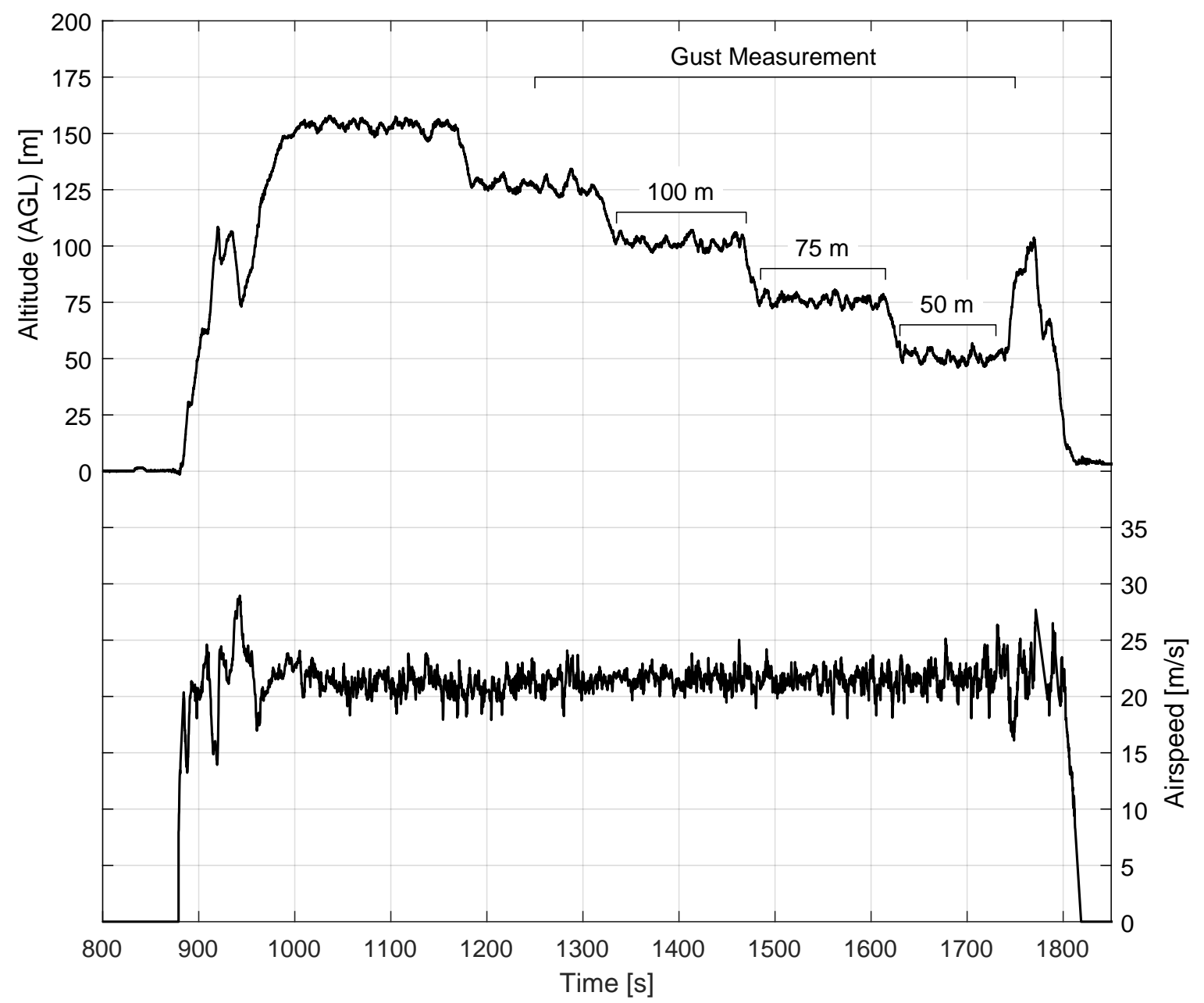

Figure 4.2: Altitude and airspeed profiles of flight 23. Atmospheric gusts were measure from timestamp $1250 \mathrm{~s}$ to timestamp $1750 \mathrm{~s}$.

According to literature and previous research discussed in Chapter 1 , gust properties are governed by the altitude above the ground. Also, the mean wind speed varies at different altitudes. Therefore, the measurements from the flight 23 were separated into three segments where the aircraft maintained altitudes of $100 \mathrm{~m}, 75 \mathrm{~m}$, and $50 \mathrm{~m}$ (Fig 4.2 ). The mean wind velocities at each altitude segments are $5.00 \mathrm{~m} / \mathrm{s}, 3.72 \mathrm{~m} / \mathrm{s}$, and $3.21 \mathrm{~m} / \mathrm{s}$ respectively. Summary of the data segments is included in Table 4.1 
Table 4.1: Summary of flight 23 with segments flown at $100 \mathrm{~m}, 75 \mathrm{~m}$, and $50 \mathrm{~m}$.

\begin{tabular}{cccccccr}
\hline $\begin{array}{c}\text { Reference } \\
\text { AGL }[\mathrm{m}]\end{array}$ & $\begin{array}{c}\text { Start } \\
\text { time }[\mathrm{s}]\end{array}$ & $\begin{array}{c}\text { End } \\
\text { time }[\mathrm{s}]\end{array}$ & $\begin{array}{c}\text { Altitude } \\
\text { range }[\mathrm{m}]\end{array}$ & $\begin{array}{c}\text { Mean wind } \\
\text { velocity }[\mathrm{m} / \mathrm{s}]\end{array}$ & $\begin{array}{c}\text { Mean wind } \\
\text { bearing }[\mathrm{deg}]\end{array}$ & $\begin{array}{c}\text { Mean } \\
\text { airspeed }[\mathrm{m} / \mathrm{s}]\end{array}$ & $\begin{array}{c}\text { Airspeed } \\
\text { range [m/s] }\end{array}$ \\
\hline $100 \mathrm{~m}$ & 1330 & 1460 & $96.7-107.1$ & 5.00 & 287.3 & 21.6 & $19.5-23.8$ \\
$75 \mathrm{~m}$ & 1485 & 1615 & $71.3-81.0$ & 3.72 & 284.2 & 21.5 & $18.0-24.2$ \\
$50 \mathrm{~m}$ & 1630 & 1730 & $46.0-56.9$ & 3.21 & 294.5 & 21.6 & $18.1-25.1$ \\
\hline
\end{tabular}

The wind data measured by the air-data system at during the flight 23 are shown in Fig. 4.3 along with the wind at the ground level measured by the weather station as a comparison. The wind measurements were transformed into the mean wind coordinate systems shown in Fig. 1.2 and the mean wind is subtracted from the result to compute the longitudinal, lateral, and vertical gusts. The gusts measured at the three different altitudes are separated into three directions and presented in Fig. 4.4 Fig. 4.5 and Fig. 4.6 .

The gust data from flight 23 were converted into power spectral density (PSD) using a fast Fourier transform (FFT) algorithm in MATLAB [55,56]. This provided the spectral results of the airborne gust data. The 3-D gust data, longitudinal, lateral, and vertical gust spectra, were separated into three altitudes and displayed in Fig. 4.7. The spectra were plotted in logarithmic scale and a $-5 / 3$ slope was included onto each plot. The result showed the spectra followed the $-5 / 3$ slope in the logarithmic scale at the high spatial frequencies $(\Omega)$ which matched the prediction provided by the von Kármán model as discussed in section 1.4.1. The knee of the power spatial density curve was observed at the spectral frequency of approximately $10^{-3}$ of each spectrum. This signifies the frequency range where the power special density tapers and remains constant. The position of the knee correlates to the altitude and the mean wind velocity of the location of interested. The measured spectra were compared to the von Kármán model using the turbulence intensities $(\sigma)$ and turbulence scale length $(L)$ as specified Military Handbook MIL-HDBK-1797 [30] (Eq. 1.14 to 1.17 ). 

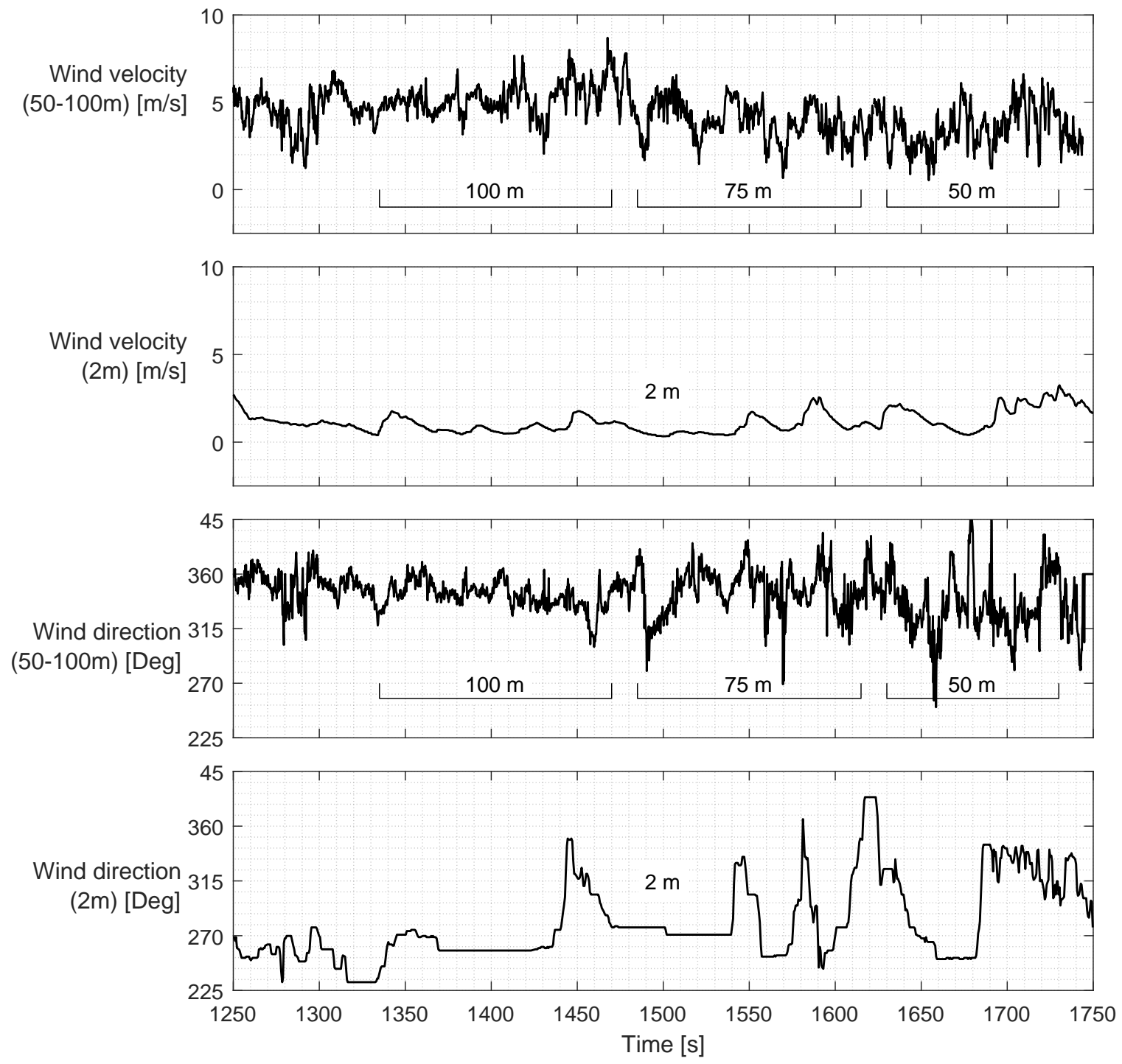

Figure 4.3: Wind speed and direction measured by GustAV $(50-100 \mathrm{~m})$ and weather ground station $(2 \mathrm{~m})$ from timestamp $1250 \mathrm{~s}$ to timestamp $1750 \mathrm{~s}$ during flight 23. 
Longitudinal Gust Velocity $[\mathrm{m} / \mathrm{s}]$

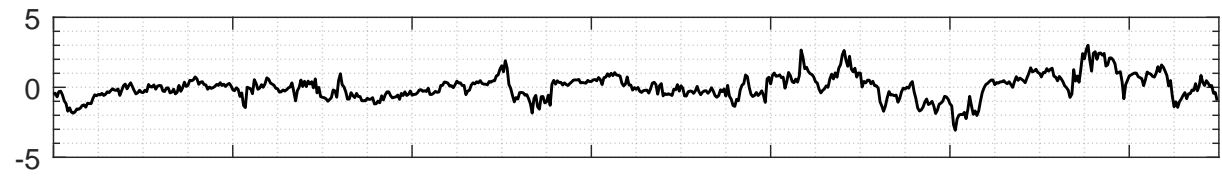

Lateral Gust Velocity $[\mathrm{m} / \mathrm{s}]$

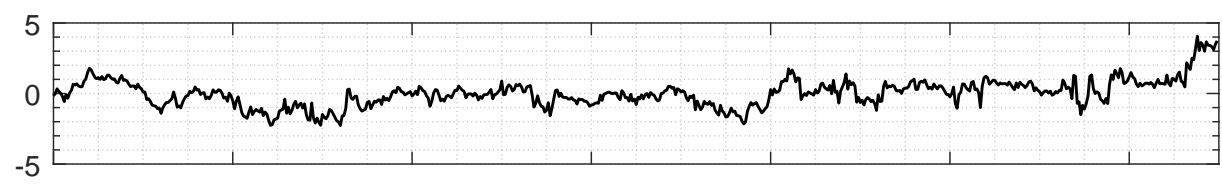

Vertical Gust Velocity $[\mathrm{m} / \mathrm{s}]$

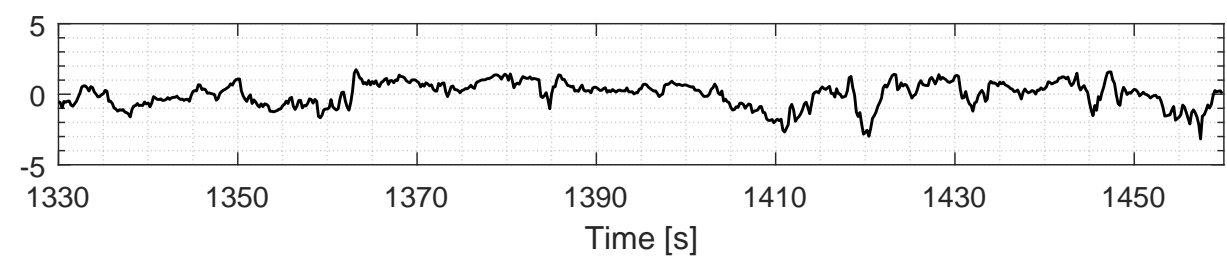

Figure 4.4: Gust measurements at altitude of $100 \mathrm{~m}$ from timestamp $1330 \mathrm{~s}$ to timestamp $1460 \mathrm{~s}$ during flight 23.

\section{Longitudinal Gust} Velocity $[\mathrm{m} / \mathrm{s}]$

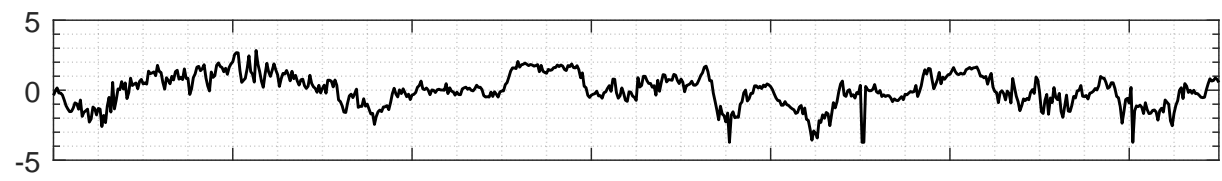

Lateral Gust Velocity $[\mathrm{m} / \mathrm{s}]$

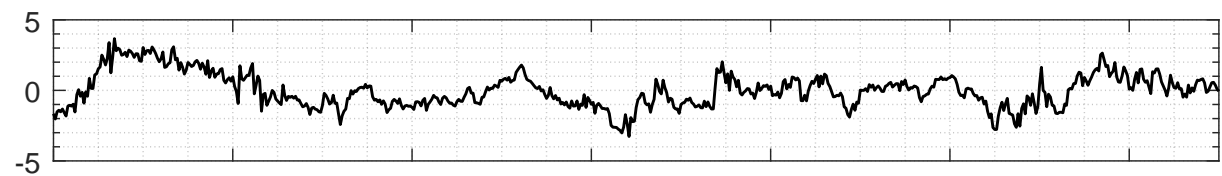

Vertical Gust Velocity $[\mathrm{m} / \mathrm{s}]$

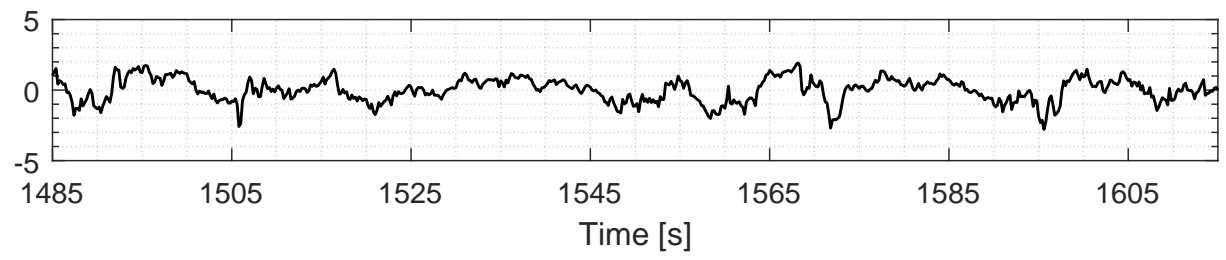

Figure 4.5: Gust measurements at altitude of $75 \mathrm{~m}$ from timestamp $1485 \mathrm{~s}$ to timestamp $1615 \mathrm{~s}$ during flight 23. 
Longitudinal Gust Velocity $[\mathrm{m} / \mathrm{s}]$
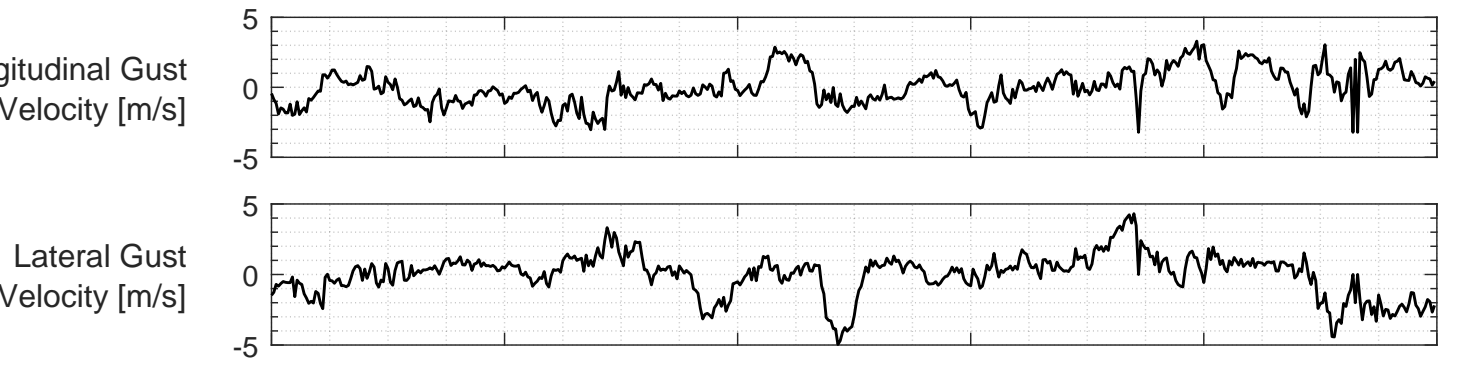
Velocity $[\mathrm{m} / \mathrm{s}]$

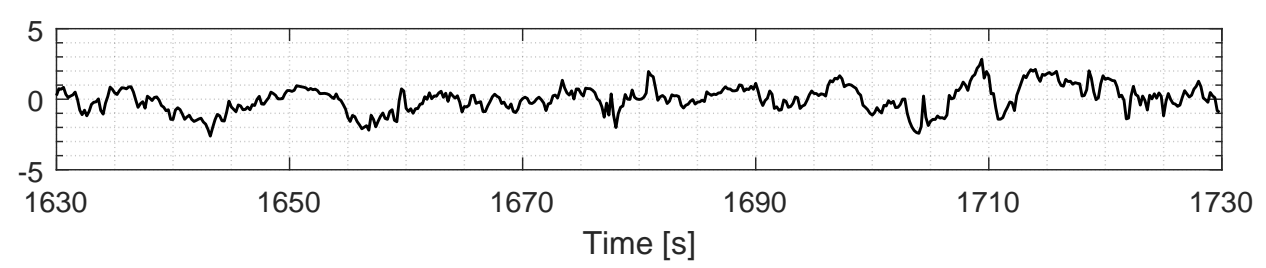

Figure 4.6: Gust measurements at altitude of $50 \mathrm{~m}$ from timestamp $1630 \mathrm{~s}$ to timestamp $1730 \mathrm{~s}$ during flight 23.

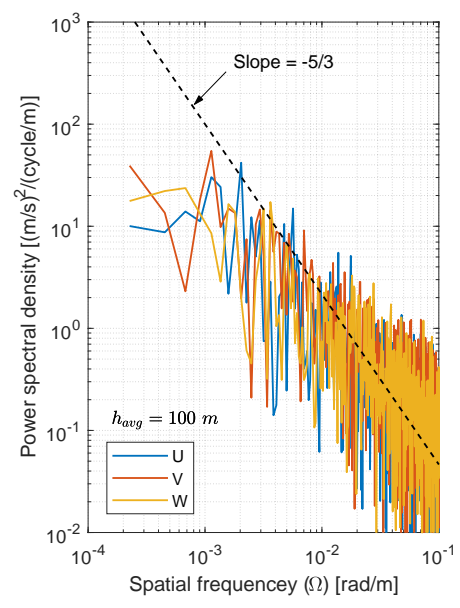

(a) Gust spectra at $100 \mathrm{~m}$.

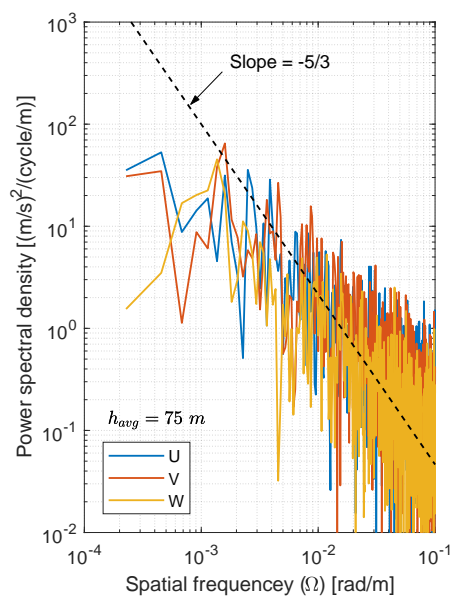

(b) Gust spectra at $75 \mathrm{~m}$.

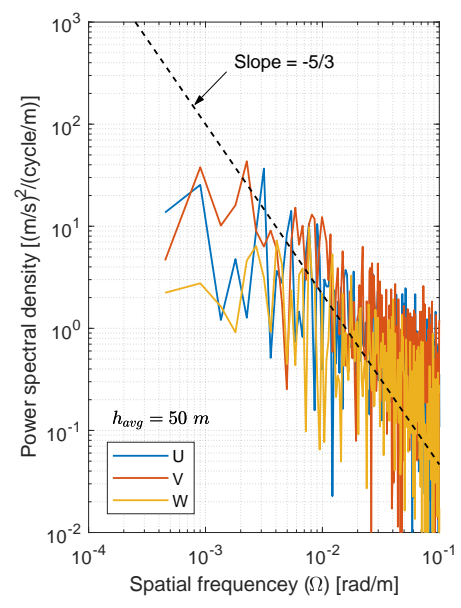

(c) Gust spectra at $50 \mathrm{~m}$.

Figure 4.7: Gust spectra at altitudes of $100 \mathrm{~m}, 75 \mathrm{~m}$, and $50 \mathrm{~m}$ measured during flight 23. 
To obtain the turbulence intensities $(\sigma)$ of the von Kármán turbulence model for comparison, Eq.1.14 provided by the Military Handbook MIL-HDBK-1797 was used 30. The equation requires an input of wind speed measured at the height of 20 feet $(6 \mathrm{~m})$. However, this measurement was not obtained during the flight experiment as there was no anemometer set up at that height. The wind speed at 20 feet was estimated by combining the wind measured by the air-data system at the flight altitude $(50 \mathrm{~m}-100 \mathrm{~m})$ and the weather ground station $(2 \mathrm{~m})$ using the wind profile power law provided in literature [57]:

$$
U\left(z_{g 1}\right)=U\left(z_{g 2}\right)\left(\frac{z_{g 1}}{z_{g 2}}\right)^{\alpha}
$$

where $\alpha$ is an exponent depended upon the roughness of terrain and $z_{g 1}$ and $z_{g 2}$ denote the altitudes above ground. A list of roughness exponents can be found in the same literature 57] while in this case, it is found by fitting the power law to two known wind speeds at height of $2 \mathrm{~m}$ and $100 \mathrm{~m}$. The exponent was calculated to be 0.44 and the wind speed power curve was plotted along with the wind speed measured at various altitudes in 4.8 . Fig. 4.8 shows the resultant curve along with the instantaneous wind speed measured at various altitudes during flight 23 shown as scattered dots. The result predicted by the wind power law showed a close relationship with the measured wind speed from the altitude of $100 \mathrm{~m}$ all the way down to the ground surface. Using this method, the wind speed at the height of 20 feet $(6 \mathrm{~m})$ was calculated to be $1.46 \mathrm{~m} / \mathrm{s}$ during the flight experiment.

The turbulence intensities $\left(\sigma_{u}, \sigma_{v}, \sigma_{w}\right)$ and scale length parameters $\left(L_{u}, L_{v}, L_{w}\right)$ for the von Kármán model were calculated using Eq. 1.14 to 1.17 and the results are listed in Table 4.2

Table 4.2: Calculated parameters for von Kármán turbulence model of flight 23.

\begin{tabular}{|c|c|c|c|c|c|c|}
\hline \multirow{2}{*}{$\begin{array}{l}\text { Reference } \\
\text { Altitude }\end{array}$} & \multicolumn{2}{|c|}{ Longitudinal gust } & \multicolumn{2}{|c|}{ Lateral gust } & \multicolumn{2}{|c|}{ Vertical gust } \\
\hline & Scale length & Intensity & Scale length & Intensity & Scale length & Intensity \\
\hline$(\mathrm{AGL})[\mathrm{m}]$ & $L_{u}[\mathrm{~m}]$ & $\sigma_{u}[\mathrm{~m} / \mathrm{s}]$ & $L_{v}[\mathrm{~m}]$ & $\sigma_{v}[\mathrm{~m} / \mathrm{s}]$ & $L_{w}[\mathrm{~m}]$ & $\sigma_{w}[\mathrm{~m} / \mathrm{s}]$ \\
\hline $100 \mathrm{~m}$ & 505.17 & 0.21 & 252.58 & 0.21 & 50.0 & 0.15 \\
\hline $75 \mathrm{~m}$ & 418.39 & 0.21 & 209.2 & 0.21 & 37.5 & 0.14 \\
\hline $50 \mathrm{~m}$ & 310.79 & 0.32 & 155.39 & 0.32 & 25.0 & 0.20 \\
\hline
\end{tabular}




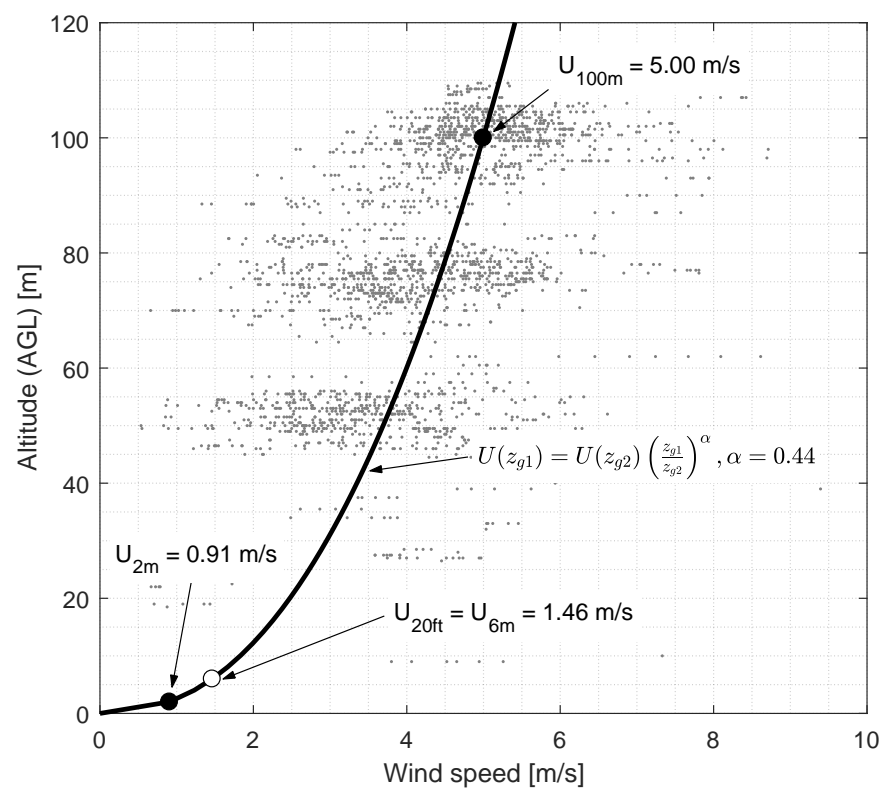

Figure 4.8: Wind speed estimation curve provided by wind power law and instantaneous wind speed measured at various altitudes during flight 23.

The parameters calculated using the MIL-HDBK-1797 method are shown in Table 4.2. These parameters were applied to the von Kármán turbulence model (Eq. 1.11 and Eq1.12) in order to generate the power special density curve. The predicted curves are shown as the magenta line over the experimental spectra measured by GustAV during flight 23 (Fig. 4.9. Fig. 4.10, and Fig. 4.11). Curve fitting were performed on the flight data to create a separate set of intensities and scale lengths to compare to the von Kármán prediction. The curve fit models are shown as green dotted lines in the power special density plots. When compared against the von Kármán model, longitudinal and lateral gust spectra measured during the flight are shown matching mostly across the spatial frequencies between $10^{-3}$ to $10^{-1} \mathrm{rad} / \mathrm{m}$ with a slight shift to the right. This reflects a higher turbulence intensities were measured during the flight test, especially along the longitudinal direction. This suggests a less stable atmosphere was observed while the measurements were taken. Larger deviations from the model were observed in the vertical gust measurements as the power special density did not taper at frequency of $10^{-2}$ which is shown as the knee on the von Kármán model predictions using the parameters provided by the MIL-HDBK-1797 (Fig. 4.9c 4.10c, and 4.11c). 


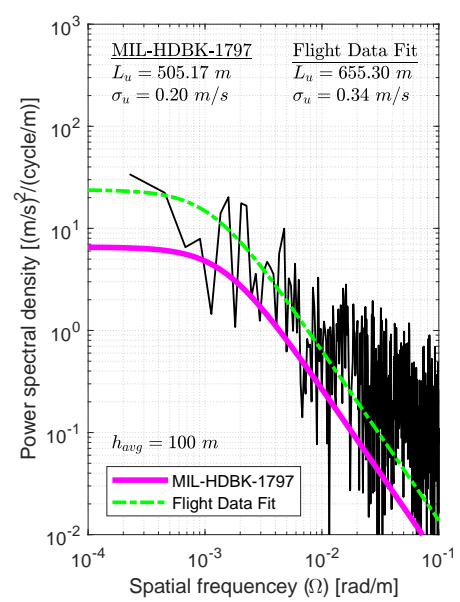

(a) Longitudinal gust spectrum.

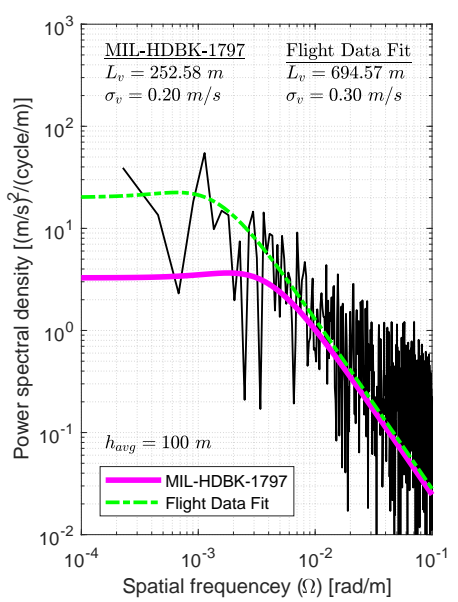

(b) Lateral gust spectrum.

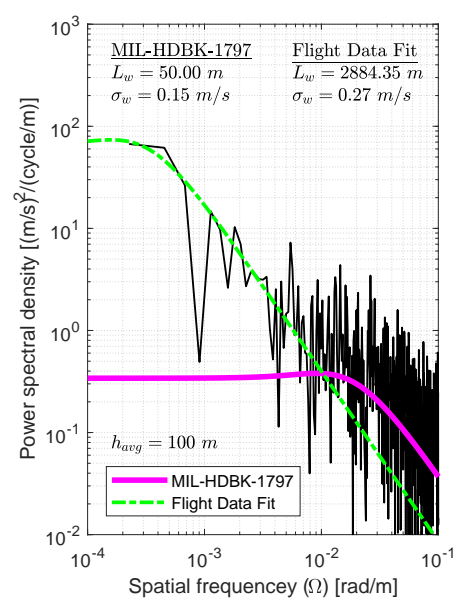

(c) Vertical gust spectrum.

Figure 4.9: Gust spectra measured at altitudes of $100 \mathrm{~m}$ during flight 23 and the von Kármán models.

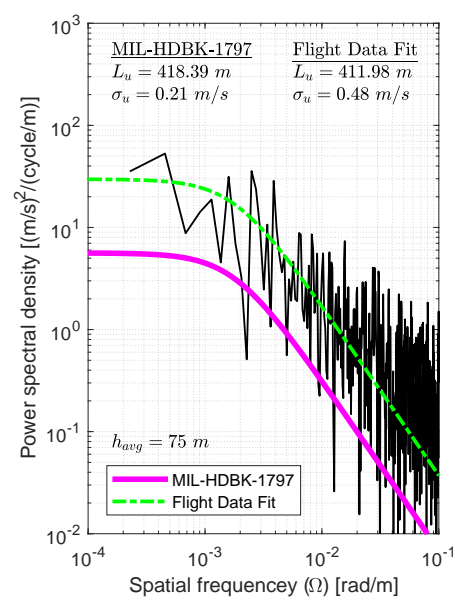

(a) Longitudinal gust spectrum.

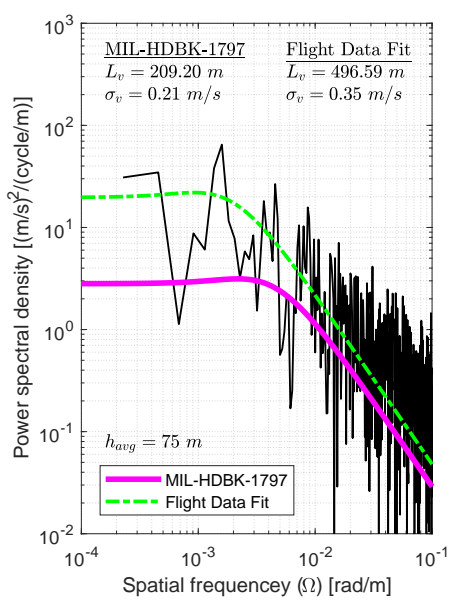

(b) Lateral gust spectrum.

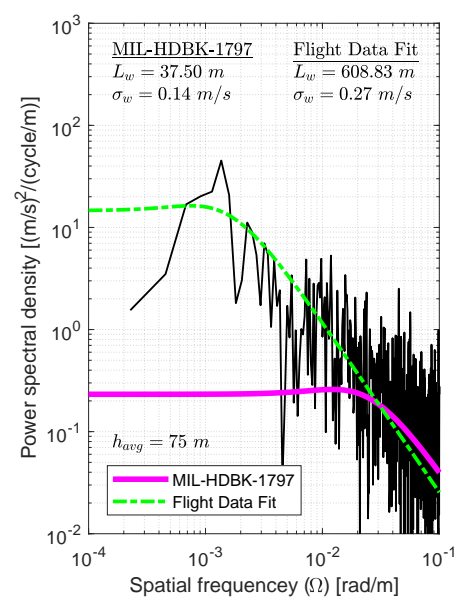

(c) Vertical gust spectrum.

Figure 4.10: Gust spectra measured at altitudes of $75 \mathrm{~m}$ during flight 23 and the von Kármán models. 


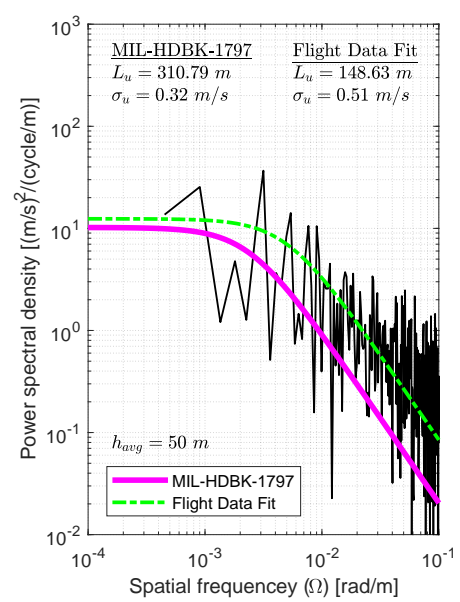

(a) Longitudinal gust spectrum.

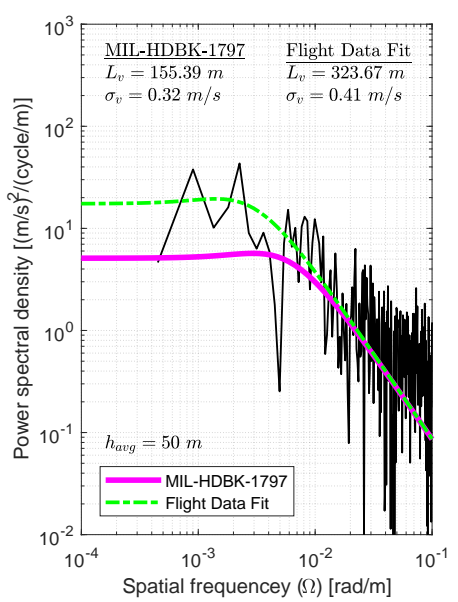

(b) Lateral gust spectrum.

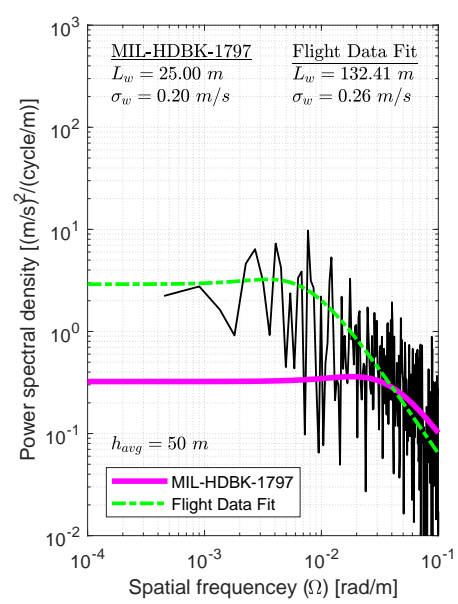

(c) Vertical gust spectrum.

Figure 4.11: Gust spectra measured at altitudes of $50 \mathrm{~m}$ during flight 23 and the von Kármán models.

Table 4.3: Turbulence intensities and scale length parameters parameters calculated using non-linear curve fitting.

\begin{tabular}{ccccccc}
\hline Reference & \multicolumn{2}{c}{ Longitudinal gust } & \multicolumn{2}{c}{ Lateral gust } & \multicolumn{2}{c}{ Vertical gust } \\
Altitude & Scale length & Intensity & Scale length & Intensity & Scale length & Intensity \\
$(\mathrm{AGL})[\mathrm{m}]$ & $L_{u}[\mathrm{~m}]$ & $\sigma_{u}[\mathrm{~m} / \mathrm{s}]$ & $L_{v}[\mathrm{~m}]$ & $\sigma_{v}[\mathrm{~m} / \mathrm{s}]$ & $L_{w}[\mathrm{~m}]$ & $\sigma_{w}[\mathrm{~m} / \mathrm{s}]$ \\
\hline $100 \mathrm{~m}$ & 655.30 & 0.34 & 694.57 & 0.30 & 1033.49 & 0.23 \\
$75 \mathrm{~m}$ & 411.98 & 0.48 & 496.59 & 0.35 & 608.83 & 0.27 \\
$50 \mathrm{~m}$ & 148.63 & 0.51 & 323.67 & 0.41 & 132.41 & 0.26 \\
\hline
\end{tabular}




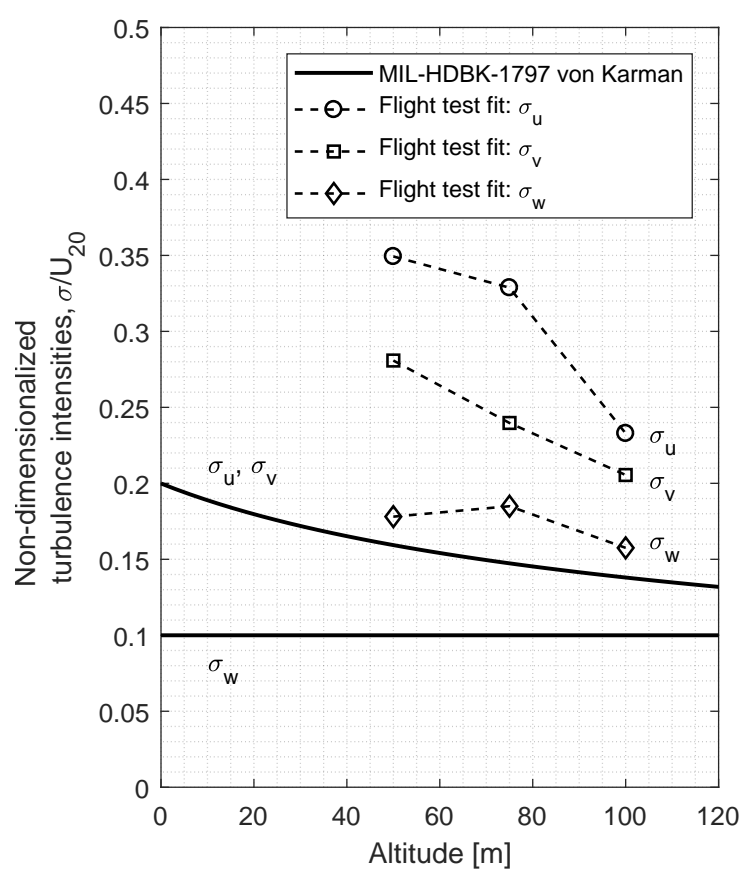

(a) Turbulence intensities.

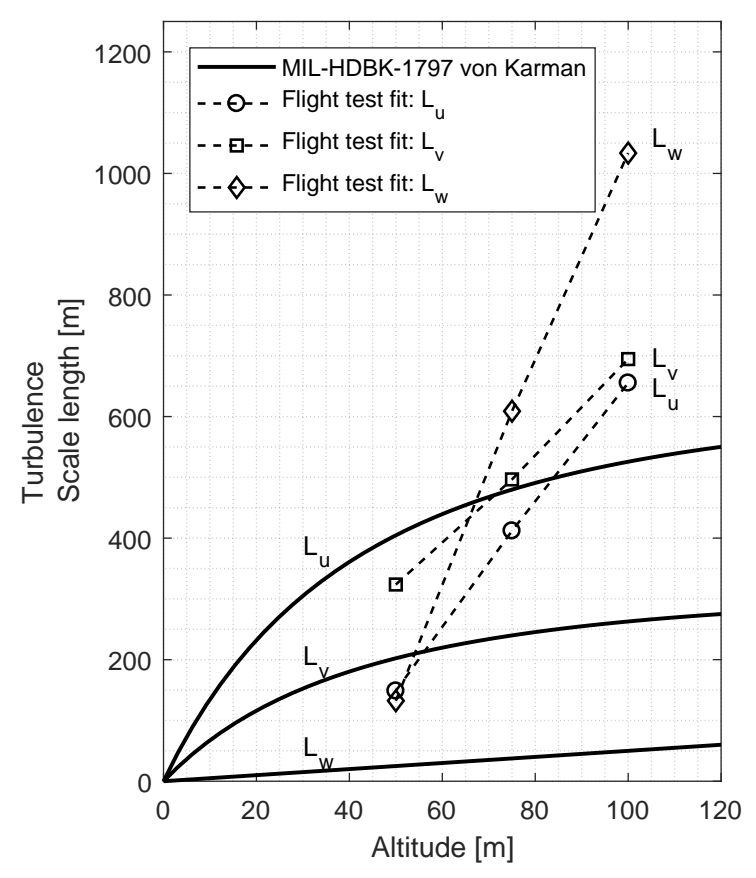

(b) Turbulence scale length.

Figure 4.12: Turbulence intensities and scale length parameters derived from gust measurements and the comparison against the von Kármán models from MIL-HDBK-1797.

Finally, the turbulence intensities values and scale length values calculated from the gust measurements were compared to the MIL-HDBK-1797 von Kármán model. With flight data only available from three altitudes on the same day, it was difficult to draw a distinctive conclusion. However, the comparison shows some promising results such as the turbulence intensities along the three directions (Fig 4.12a within the atmospheric boundary layer followed the relationship of $\sigma_{u}>\sigma_{v}>\sigma_{w}$ suggested by Etkin 22 . The intensities derived from the flight results also follow a similar downward slope towards the higher altitudes. However, the flight data derived scale length values increased at a greater rate along the altitude scale 'than the model predicted by the MIL-HDBK-1797. This is caused by a higher intensity gusts recorded by GustAV during the flight 23 than the literature model has predicted. Unfortunately, there are insufficient flight data to carry further analysis to determine whether the MIL-HDBK-1797 model differs from the gust intensities results measured during the flight.

In summary, the MIL-HDBK-1797 von Kármán turbulence model provided a good agreement to the longitudinal and lateral gusts observed by GustAV during flight 23 but the vertical gusts had been 
underpredicted as the resultant functions of the von Kármán model were shown below the measured gust spectra in all cases shown in Fig. 4.9 to Fig 4.11 . From the data gathered from flight 23, the gust intensity results from the data fit suggests the aircraft encounters stronger gust during the flight than predicted by the model. The derived turbulence intensities (Fig 4.12a) confirm the anisotropic air properties in the low-altitude environment within the atmospheric boundary layer. This indicates that there are shortfalls of the MIL-HDBK-1797 by assuming equal intensity values between the longitudinal and lateral directions (Eq. 1.15). Measuring the mean wind velocity at 20 feet above the ground instead of using the power law interpolation and reduce possible error in the empirical methods from the Military Handbook MIL-HDBK-1797. Improvement to the existing model can be done by measuring the gust above the same area of different weather and wind conditions. Regression analysis of measurements taken under different conditions can produce more accurate solutions to turbulence intensities and scale length parameters for that specific surface terrain. Large-scale surveying of a variety of terrain features will produce a more generalized model to enhance or replace the existing MIL-HDBK-1797 von Kármán model. 


\section{Chapter 5}

\section{Conclusion}

A gust measuring unmanned aerial vehicle, GustAV, was built and tested in order to conduct airborne atmospheric wind surveying at low-altitudes. GustAV demonstrated its ability to perform autonomous flight missions and carry out the atmospheric experiments. The supporting systems including the ground control station and the weather ground station have been thoroughly tested as well. The cost-effective unmanned aerial system provided better flexibility when compared to a fixed base measurement platform for low-altitude atmospheric surveying. The airborne system is capable of measuring the gust profile above land and water, and challenging terrain where the option of setting up tall tower structure is not feasible. Through out the experiments, the gust measurements gathered between $50 \mathrm{~m}$ to $100 \mathrm{~m}$ above a farm field near Stouffville, Ontario were analyzed and compared with the von Kármán model provided in the MIL-HDBK-1797. This comparison was a preliminary attempt to validate the published turbulence model at low-altitudes for unmanned aerial vehicles research and development. Although more data is still required in order to construct a generalized gust model, the preliminary results have shown a potential shortfall of the von Kármán model at underpredicting the low-frequency vertical gusts at the altitudes under $100 \mathrm{~m}$. The outcome is encouraging and suggests improvements that can be made to the existing gust models such as including anisotropic turbulence properties in different directions. The next step in this project is to perform tests over a longer period of time at various locations and under different mean wind conditions. In the current empirical model, only the altitude and the wind speed are used to correlate intensity and the scale length of the turbulence. The model can be improved by additional parameters such as terrain roughness and weather condition. These changes can produce 
a more sophisticated empirical method for the von Kármán model to incorporate with seasonal and geographical influences. The new model will be able to improve the fidelity of the gust model for small UAV development in the future. 


\section{Appendix 1}

\section{Flight Testing Summary}

\section{$1.1 \quad$ Bix3}

Table 1.1: Flight testing log of Bix3.

\begin{tabular}{lcccccc}
\hline & Flight & Start Time & $\begin{array}{c}\text { Duration } \\
{[\mathrm{mm}: \mathrm{ss}]}\end{array}$ & $\begin{array}{c}\text { Max. GS } \\
{[\mathrm{m} / \mathrm{s}]}\end{array}$ & $\begin{array}{c}\text { Max. IAS } \\
{[\mathrm{m} / \mathrm{s}]}\end{array}$ & $\begin{array}{c}\text { Max. AGL } \\
{[\mathrm{m}]}\end{array}$ \\
\hline $2016-05-07$ & 1 & $2: 17: 23 \mathrm{PM}$ & $01: 35$ & 26.79 & 1.44 & 70.8 \\
\hline $2016-05-14$ & 2 & $2: 35: 54 \mathrm{PM}$ & $05: 46$ & 34.46 & 0.00 & 109.0 \\
\hline $2016-05-28$ & 3 & $12: 44: 19 \mathrm{PM}$ & $12: 21$ & 23.79 & 0.00 & 80.0 \\
& 4 & $3: 02: 58 \mathrm{PM}$ & $08: 53$ & 24.63 & 24.93 & 50.1 \\
\hline $2016-06-04$ & 5 & $1: 14: 22 \mathrm{PM}$ & $11: 17$ & 22.82 & 22.10 & 84.9 \\
& 6 & $1: 46: 28 \mathrm{PM}$ & $08: 28$ & 24.98 & 24.29 & 79.7 \\
\hline $2016-06-11$ & 7 & $1: 57: 29 \mathrm{PM}$ & $10: 45$ & 30.04 & 24.71 & 109.4 \\
& 8 & $2: 30: 56 \mathrm{PM}$ & $05: 20$ & 27.75 & 24.74 & 77.6 \\
& 9 & $2: 49: 01 \mathrm{PM}$ & $05: 49$ & 30.71 & 23.48 & 79.8 \\
\hline
\end{tabular}




\subsection{GustAV}

Table 1.2: Flight testing log of GustAV.

\begin{tabular}{|c|c|c|c|c|c|c|}
\hline Date & Flight & Start Time & $\begin{array}{c}\text { Duration } \\
\text { [mm:ss] }\end{array}$ & $\begin{array}{c}\text { Max. GS } \\
{[\mathrm{m} / \mathrm{s}]}\end{array}$ & $\begin{array}{c}\text { Max. IAS } \\
{[\mathrm{m} / \mathrm{s}]}\end{array}$ & $\begin{array}{c}\text { Max. AGL } \\
{[\mathrm{m}]}\end{array}$ \\
\hline \multirow[t]{2}{*}{ 2016-02-06 } & 1 & 1:12:39 PM & 01:31 & 27.58 & $\mathrm{~N} / \mathrm{A}$ & 69.8 \\
\hline & 2 & $3: 25: 15 \mathrm{PM}$ & 01:39 & 25.51 & $\mathrm{~N} / \mathrm{A}$ & 54.4 \\
\hline \multirow[t]{2}{*}{ 2016-09-04 } & 3 & 1:06:05 PM & $01: 51$ & 32.14 & 26.58 & 54.1 \\
\hline & 4 & 1:59:25 PM & $04: 21$ & 32.47 & $\mathrm{~N} / \mathrm{A}$ & 56.1 \\
\hline \multirow[t]{2}{*}{ 2016-09-18 } & 5 & 10:38:50 AM & $03: 24$ & 30.76 & 26.93 & 66.8 \\
\hline & 6 & 11:11:16 AM & $01: 46$ & 30.15 & 24.57 & 123.6 \\
\hline 2016-10-29 & 7 & 11:45:29 AM & $02: 37$ & 29.33 & 25.79 & 128.4 \\
\hline \multirow[t]{3}{*}{ 2016-11-05 } & 8 & 1:30:37 PM & $03: 14$ & 31.75 & 26.51 & 70.0 \\
\hline & 9 & 2:01:06 PM & 04:30 & 28.20 & 26.11 & 105.9 \\
\hline & 10 & 2:35:54 PM & $06: 13$ & 30.41 & 25.95 & 184.1 \\
\hline \multirow[t]{2}{*}{ 2016-11-19 } & 11 & 1:41:14 PM & $06: 12$ & 28.79 & 0.00 & 121.9 \\
\hline & 12 & 1:59:00 PM & $\mathrm{N} / \mathrm{A}$ & $\mathrm{N} / \mathrm{A}$ & $\mathrm{N} / \mathrm{A}$ & $\mathrm{N} / \mathrm{A}$ \\
\hline \multirow[t]{2}{*}{$2016-12-03$} & 13 & 2:01:37 PM & 09:48 & 29.59 & 27.22 & 190.3 \\
\hline & 14 & 2:48:42 PM & $13: 35$ & 30.43 & 25.99 & 164.7 \\
\hline \multirow[t]{2}{*}{$2016-12-10$} & 15 & 12:48:00 PM & $02: 54$ & 26.43 & $\mathrm{~N} / \mathrm{A}$ & 91.9 \\
\hline & 16 & 1:00:13 PM & $02: 37$ & 26.08 & $\mathrm{~N} / \mathrm{A}$ & 49.0 \\
\hline \multirow[t]{3}{*}{ 2017-04-23 } & 17 & 11:40:48 AM & $02: 20$ & 33.97 & 29.34 & 83.6 \\
\hline & 18 & 11:55:20 AM & $07: 16$ & 33.34 & 28.43 & 299.3 \\
\hline & 19 & 12:44:55 PM & $18: 10$ & 31.82 & 27.62 & 169.7 \\
\hline \multirow[t]{2}{*}{ 2017-04-30 } & 20 & 10:26:09 AM & $13: 58$ & 33.77 & 24.76 & 162.9 \\
\hline & 21 & 11:14:06 AM & $17: 42$ & 32.91 & 27.66 & 185.7 \\
\hline \multirow[t]{2}{*}{ 2017-06-03 } & 22 & $11: 29: 26 \mathrm{AM}$ & $15: 49$ & 33.21 & 27.29 & 245.0 \\
\hline & 23 & 12:34:41 PM & $15: 39$ & 27.30 & 25.28 & 157.8 \\
\hline
\end{tabular}


Appendix 2

Flight Testing Log 


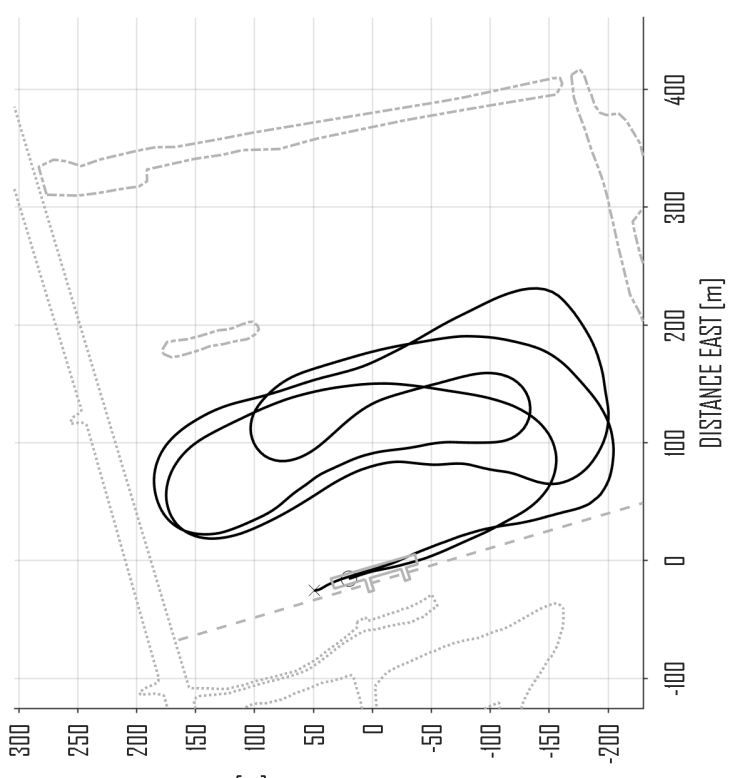

[山] HIdIN 3DNVISIO

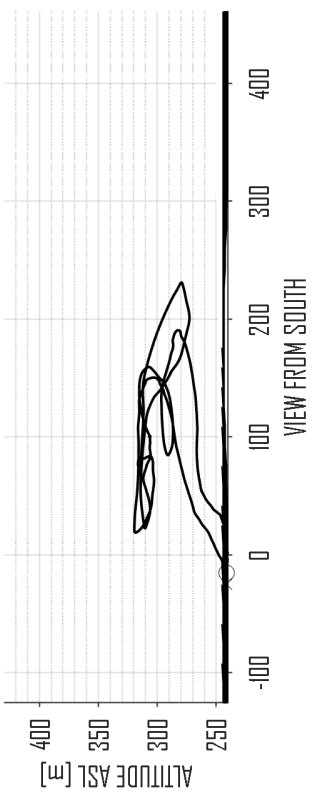

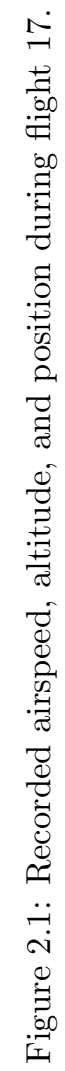
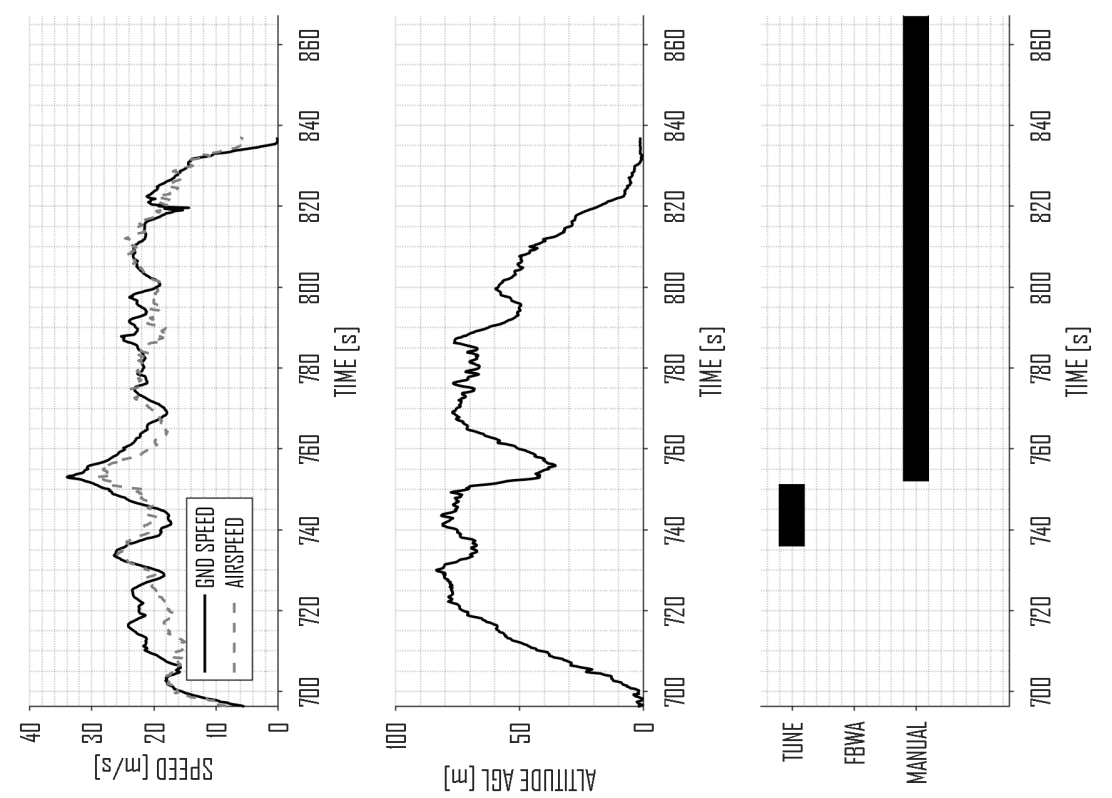

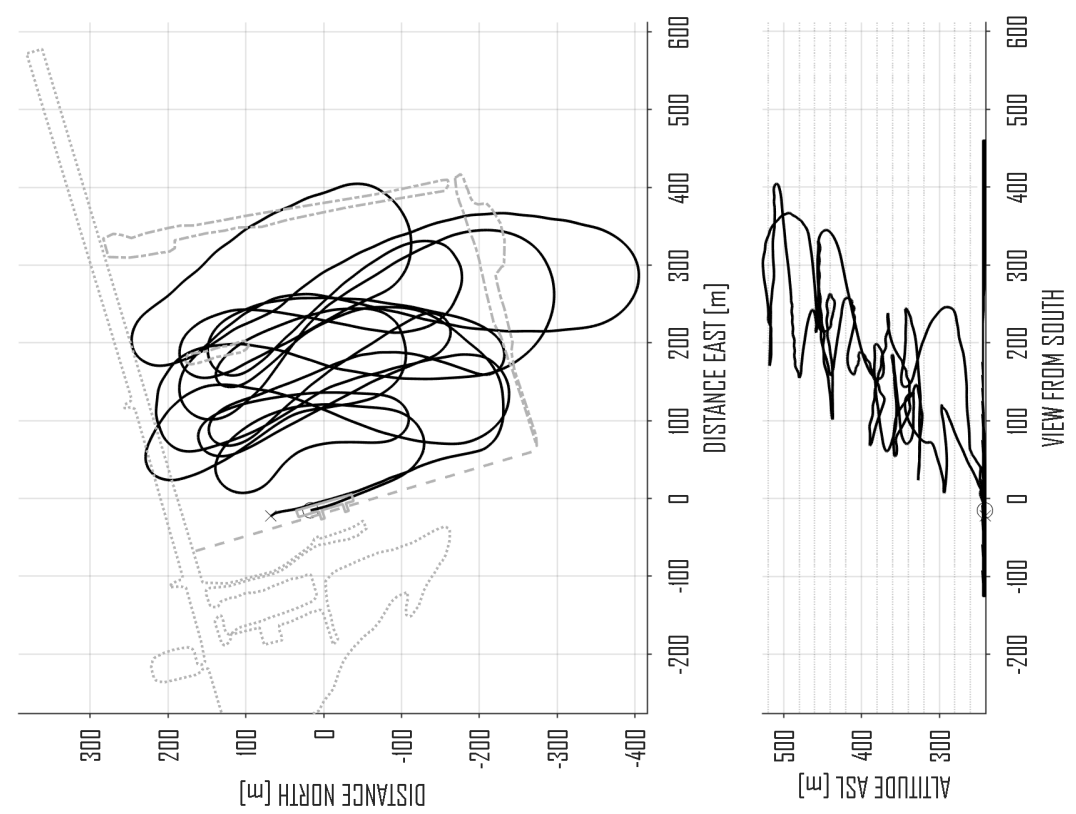

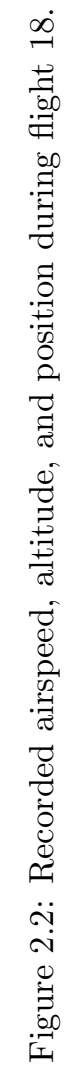
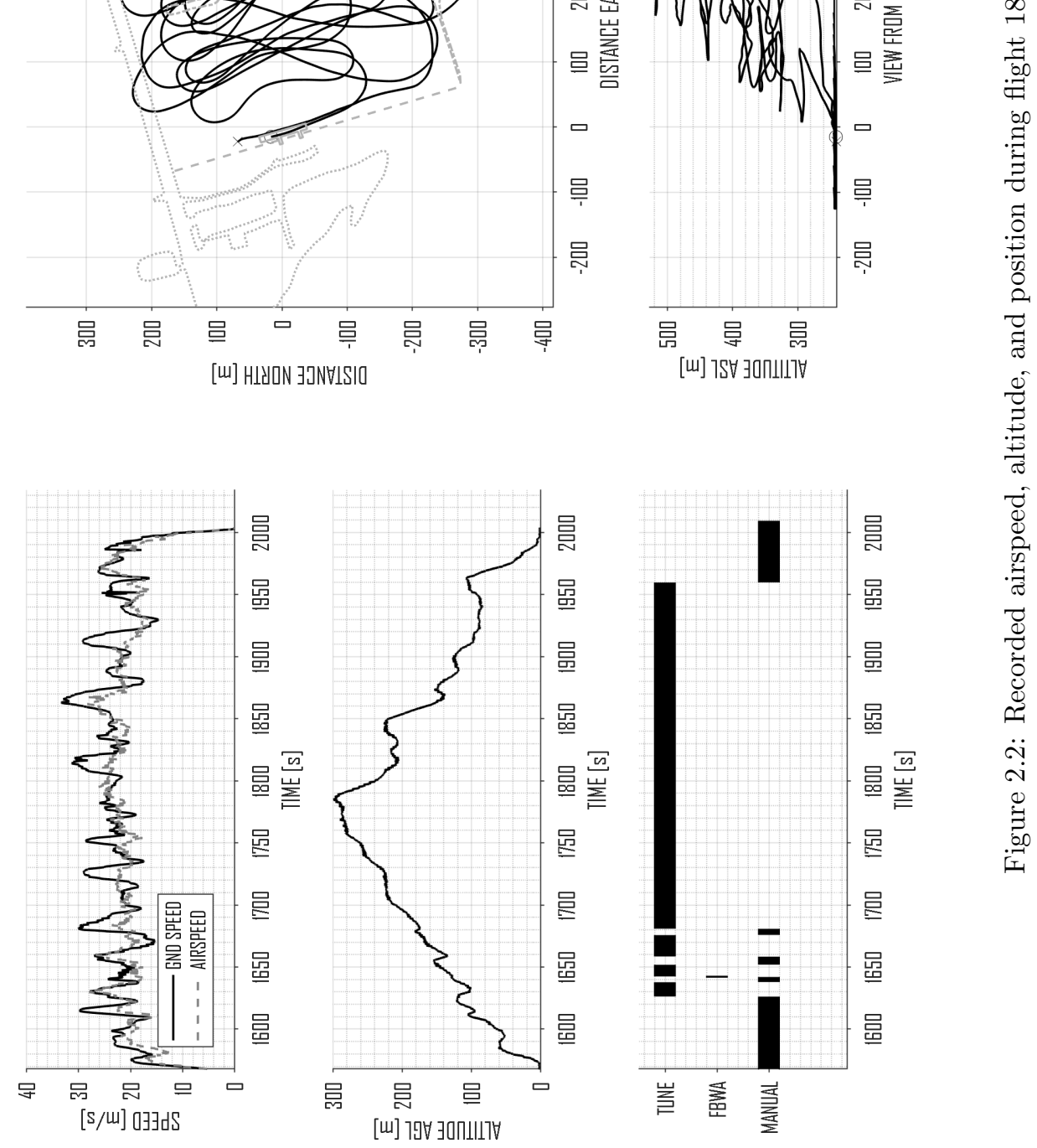


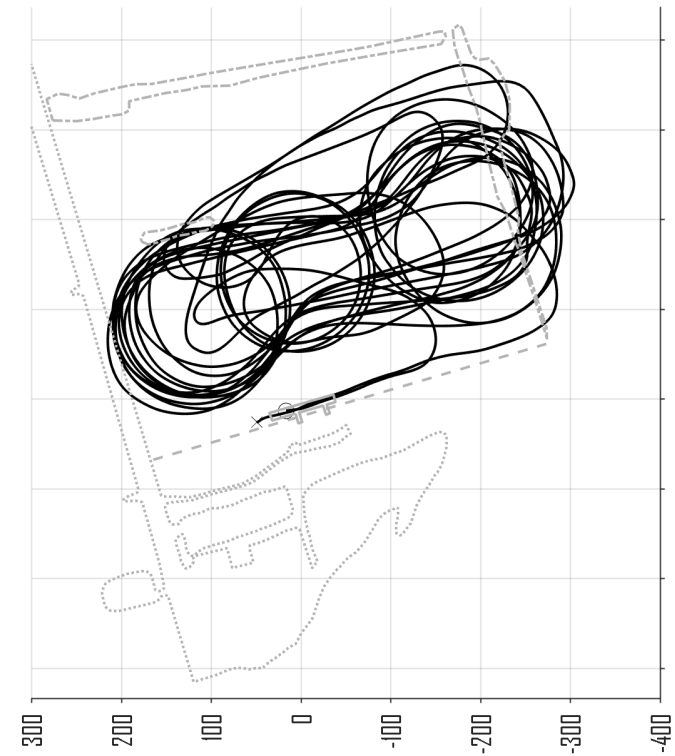

[W] HIJIN JINEISIC

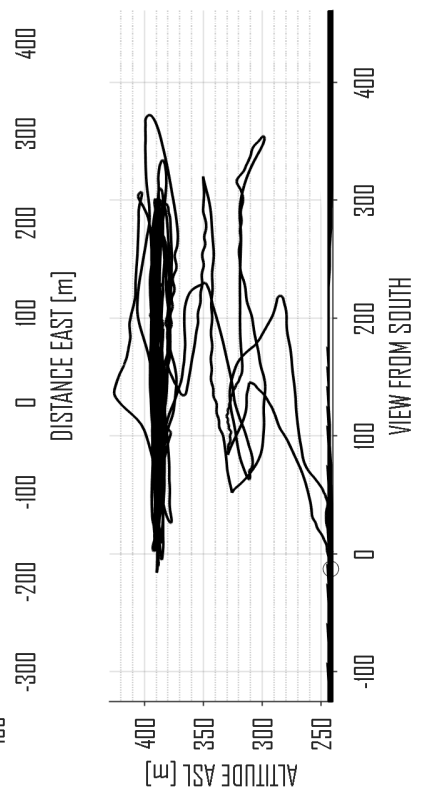

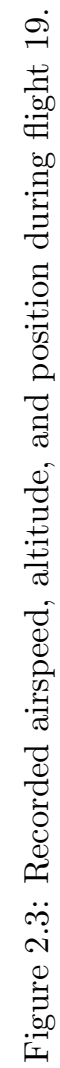
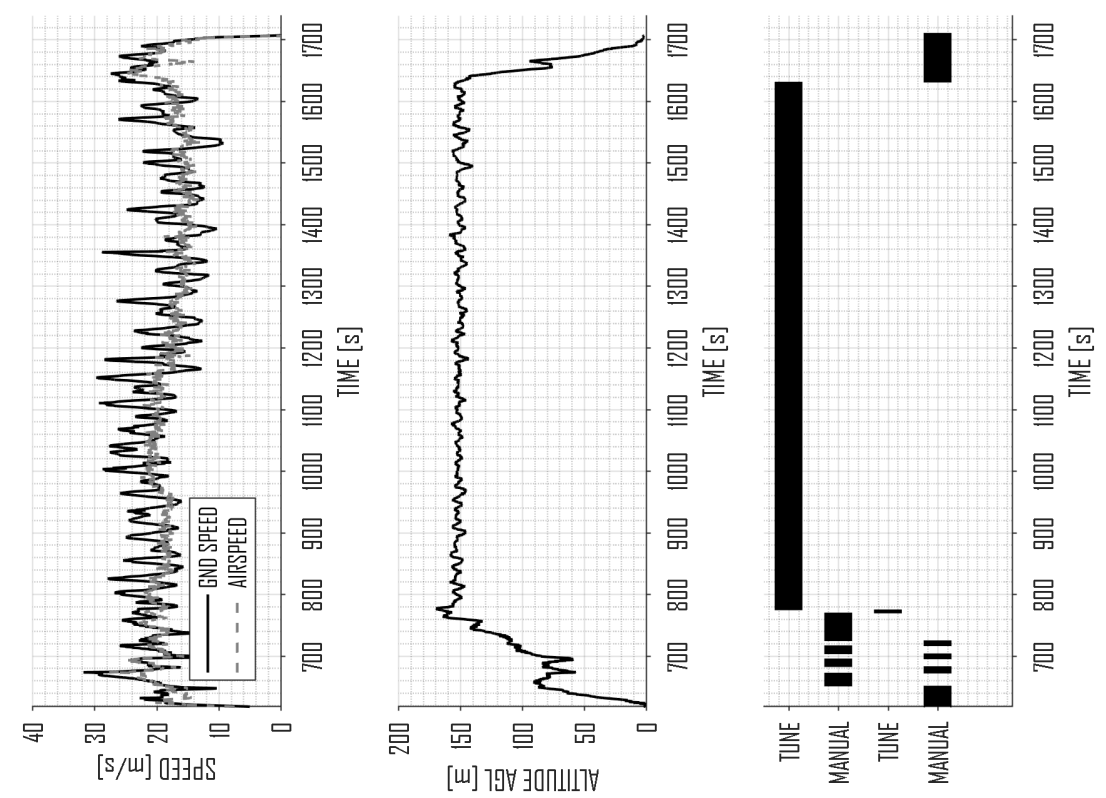


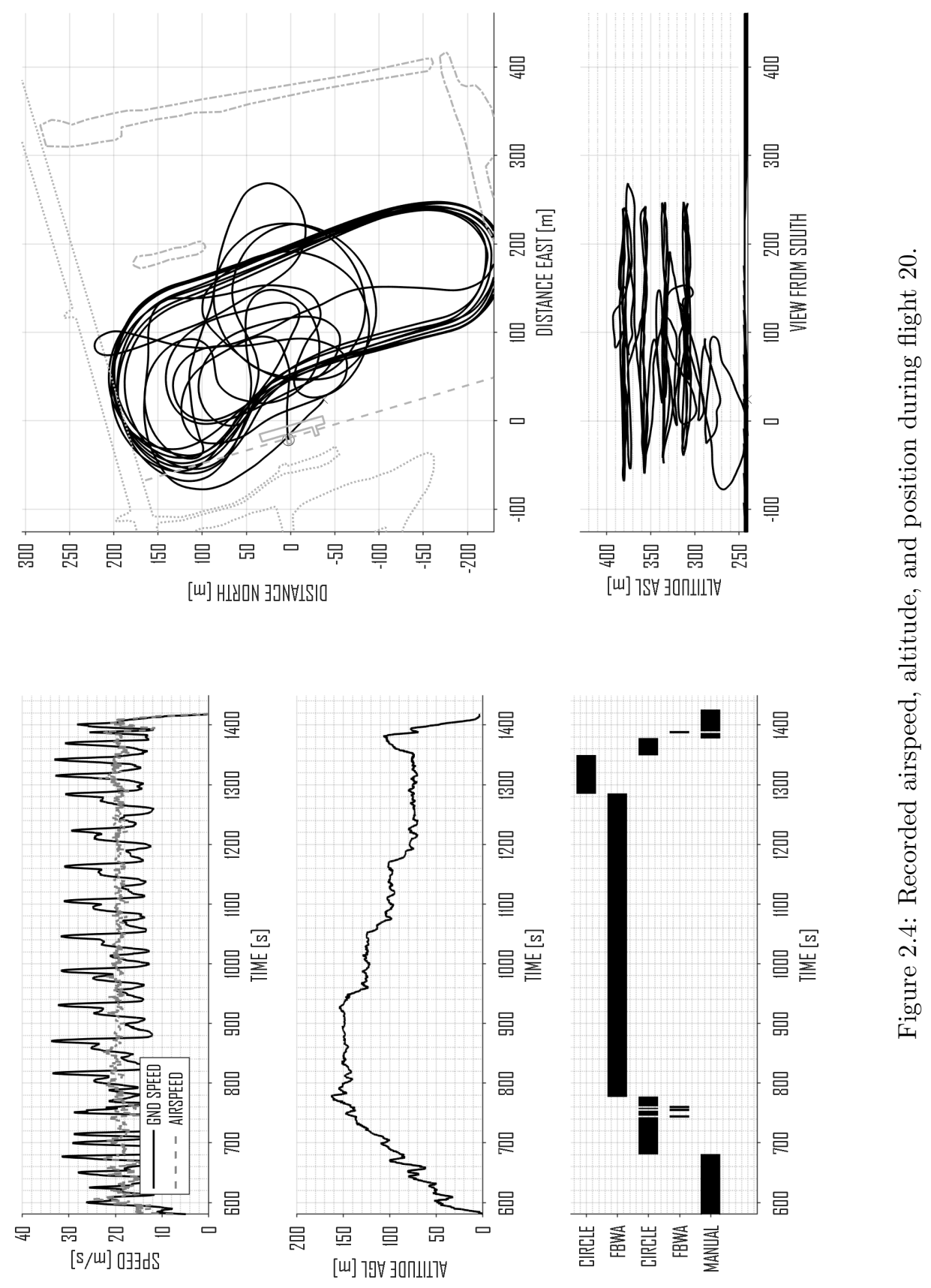




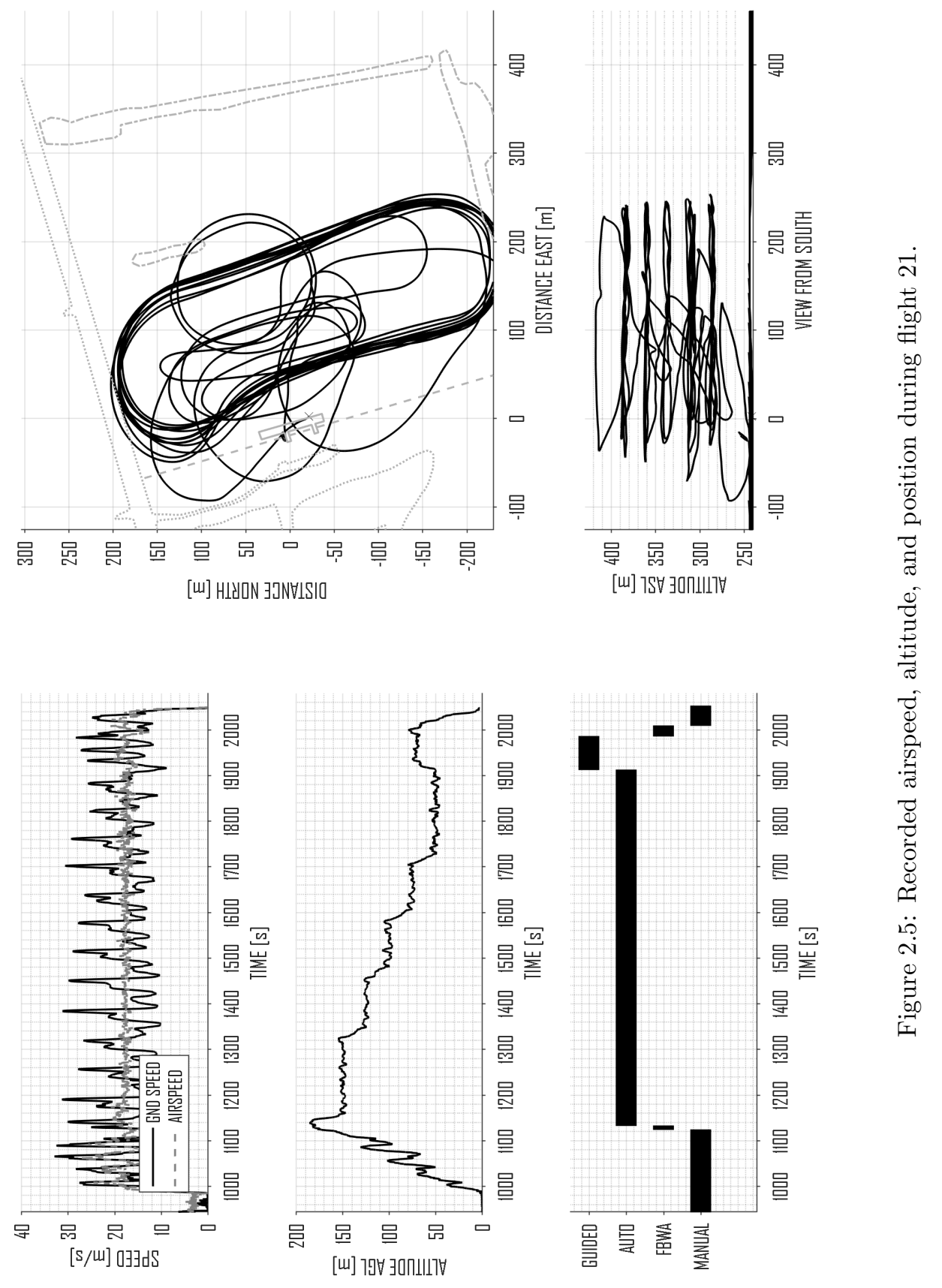




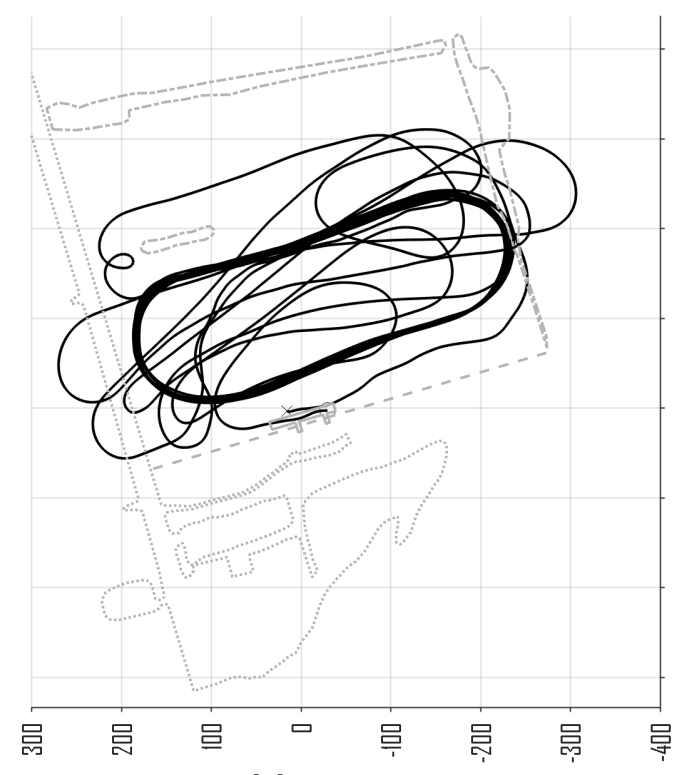

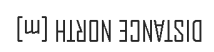

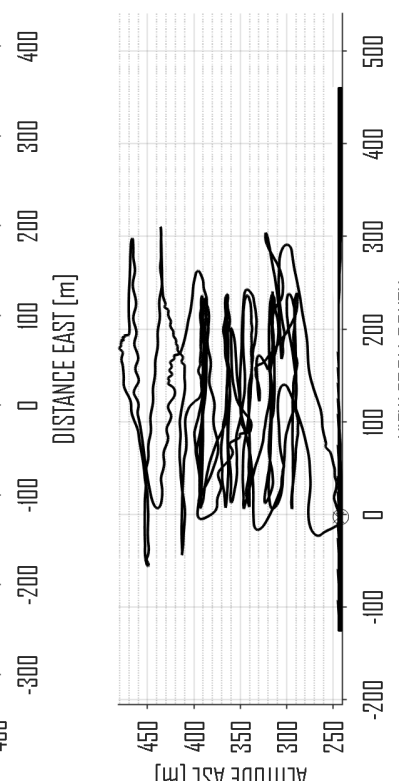

品

西
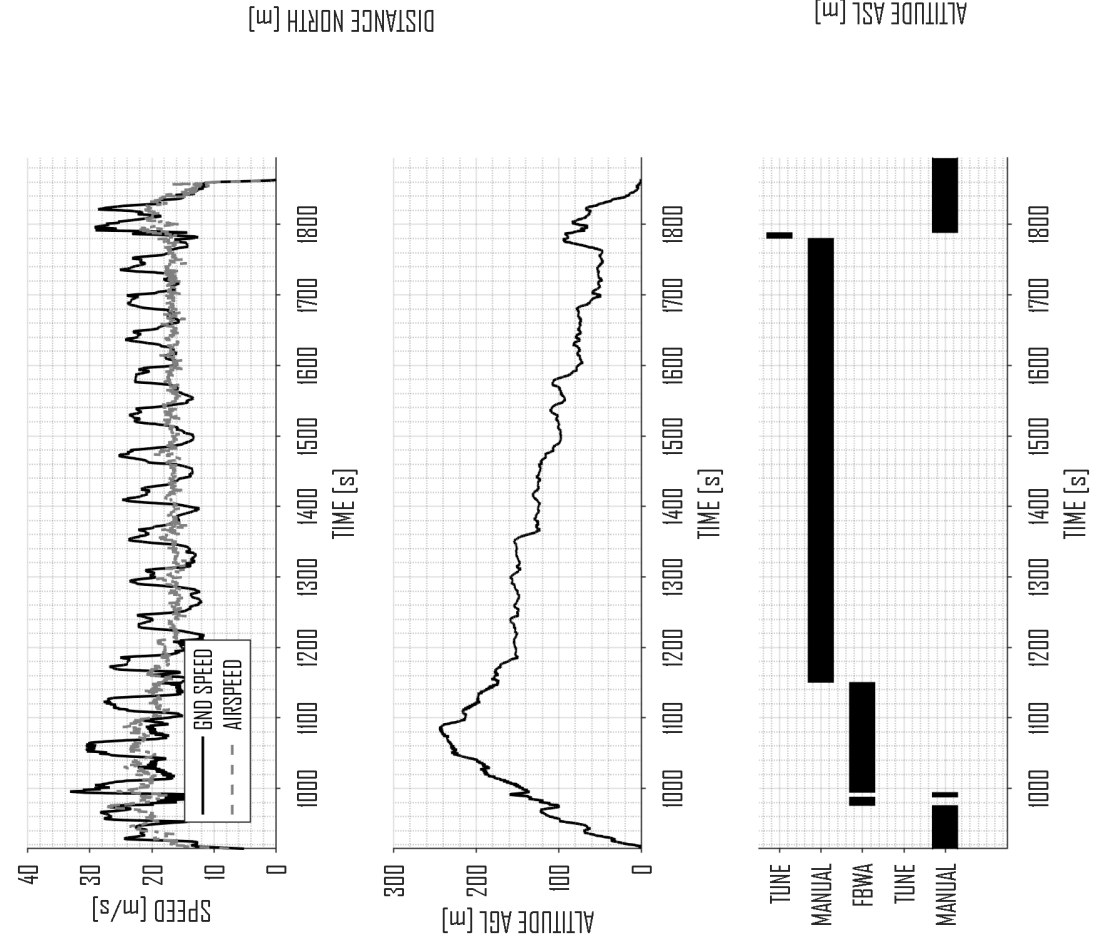

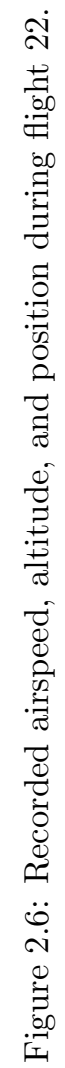



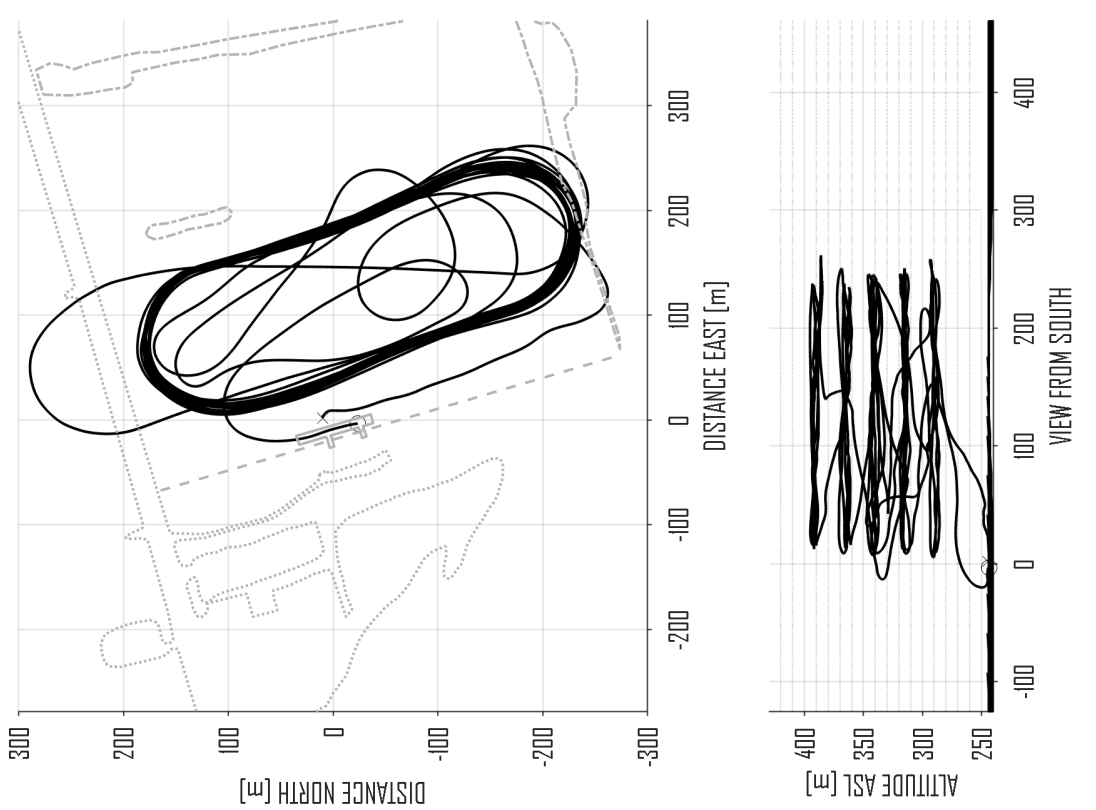

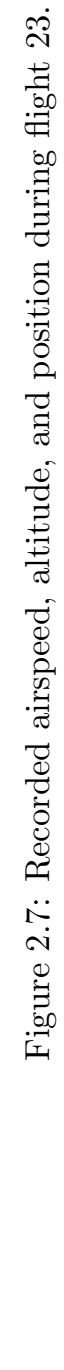
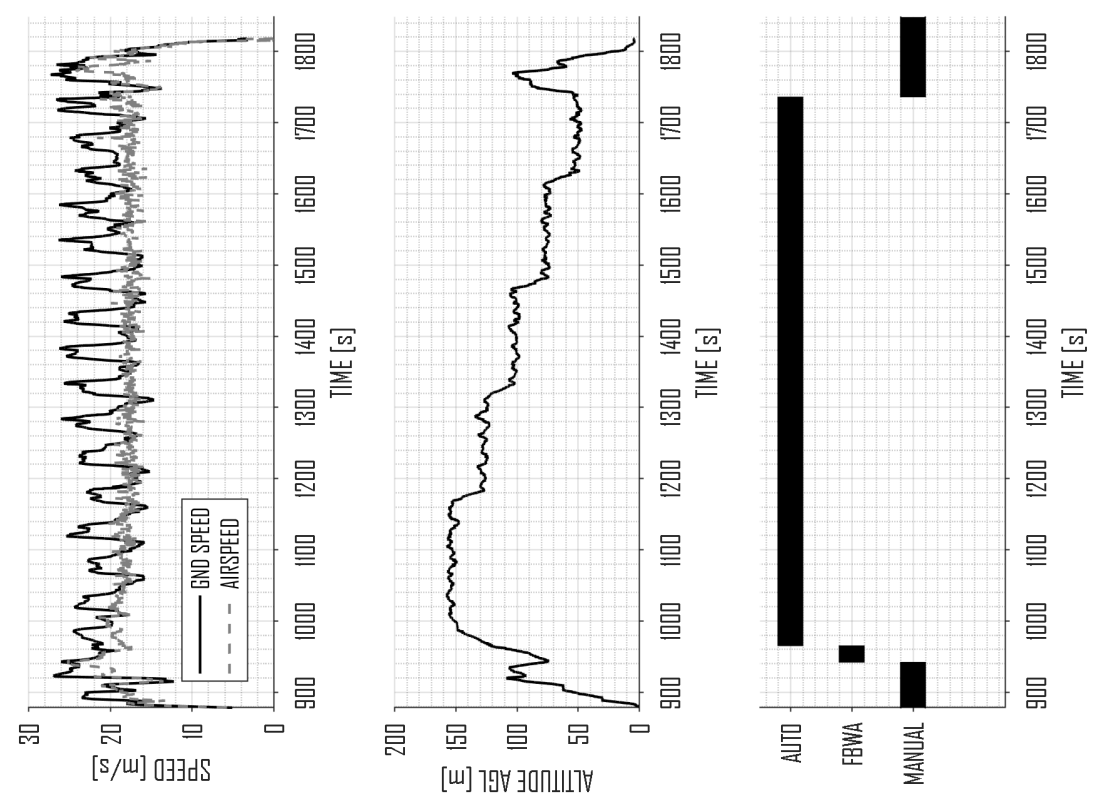


\section{Appendix 3}

\section{GustAV Performance Data}

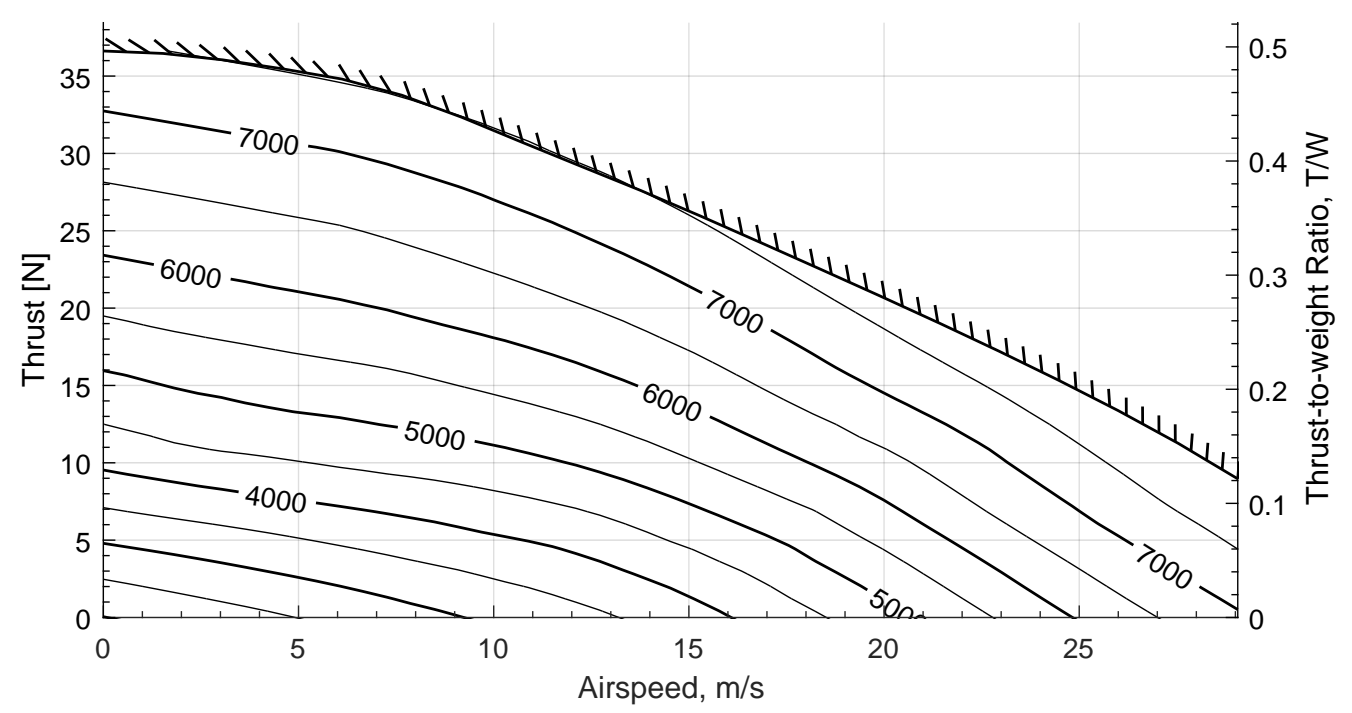

Figure 3.1: Thrust output as functions of airspeed and propeller RPM. 


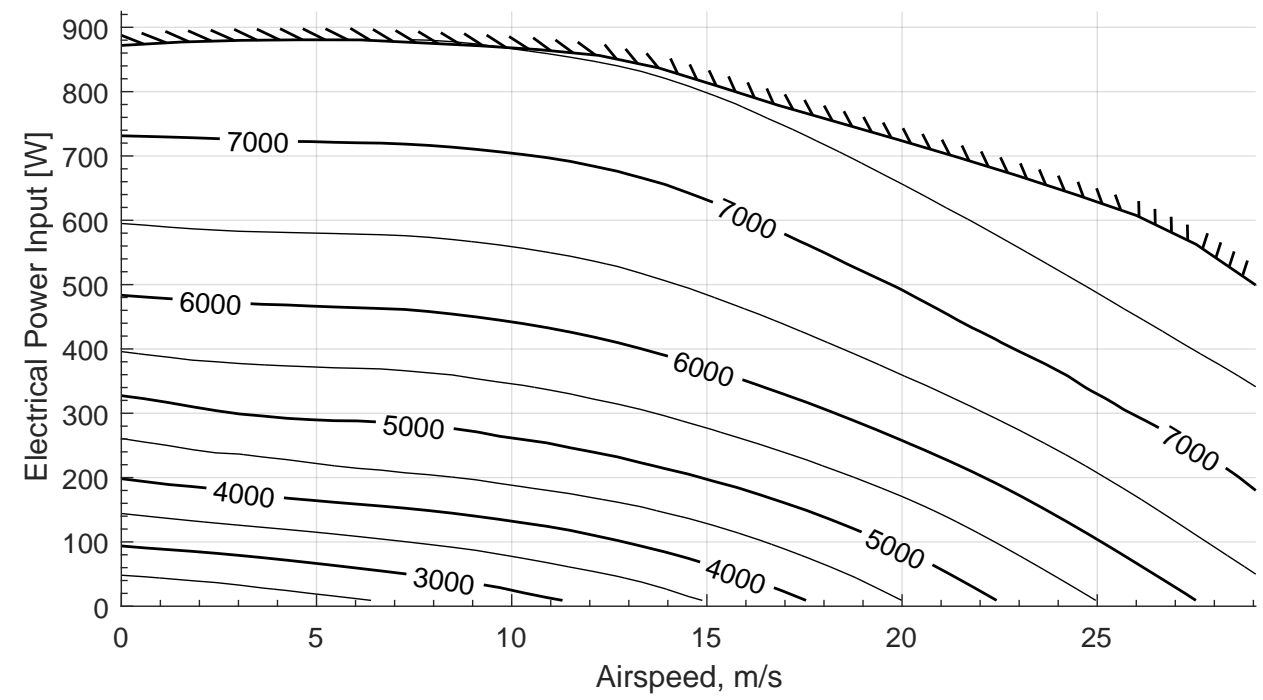

Figure 3.2: Electrical power input as functions of airspeed and propeller RPM.

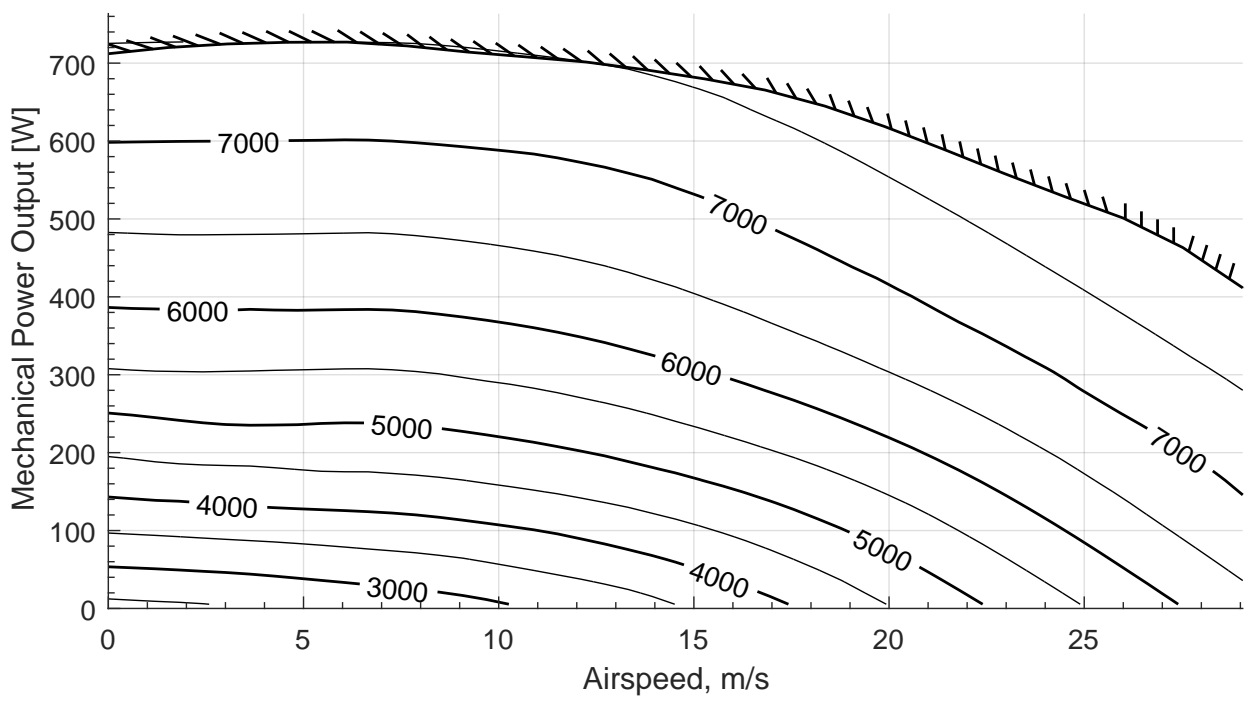

Figure 3.3: Mechanical power output as functions of airspeed and propeller RPM. 
Appendix 4

\section{Datasheets}




\section{PORTS}

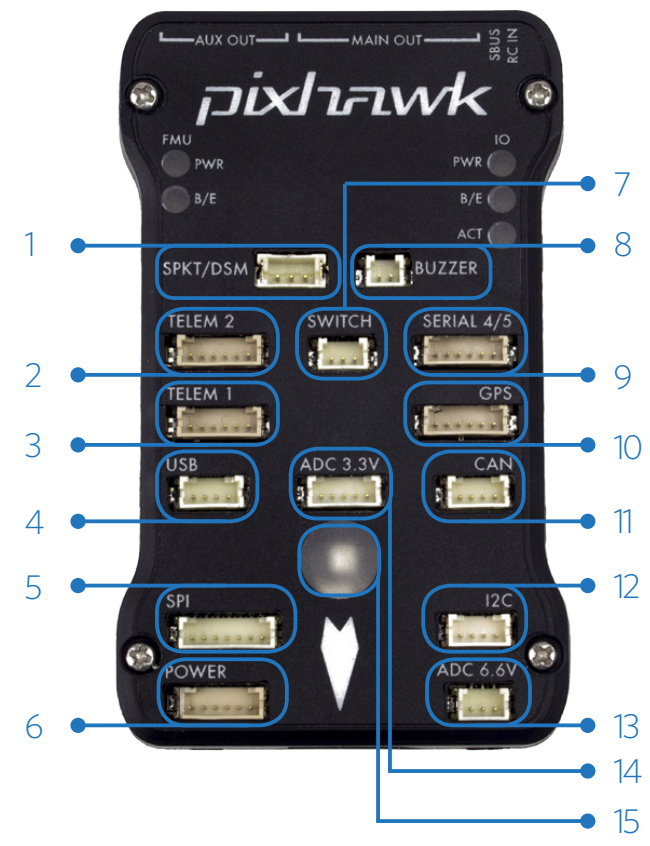

1 Spektrum DSM receiver

2 Telemetry (radio telemetry)

3 Telemetry (on-screen display)

4 USB

$5 \mathrm{SPI}$ (serial peripheral interface) bus

6 Power module

7 Safety switch button

8 Buzzer

9 Serial

10 GPS module

11 CAN (controller area network) bus

$12 \quad{ }^{2} \mathrm{C}$ splitter or compass module

13 Analog to digital converter $6.6 \mathrm{~V}$

14 Analog to digital converter $3.3 \mathrm{~V}$

15 LED indicator

\section{(ㄱ) 1}

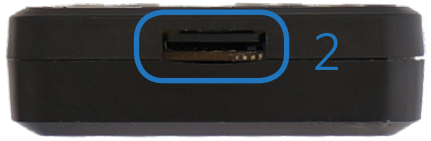

\section{7}

1 Input/output reset button

2 SD card

3 Flight management reset button

4 Micro-USB port

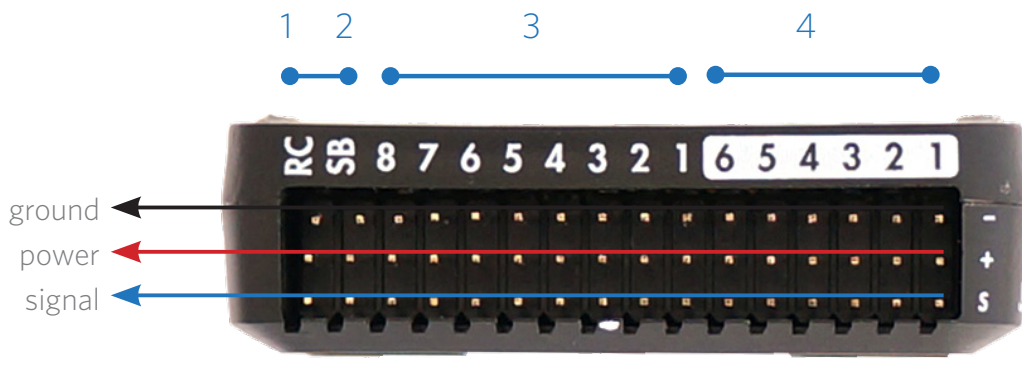

1 Radio control receiver input

2 S.Bus output

3 Main outputs

4 Auxiliary outputs 


\section{IMPORTANT NOTE}

Please note that these instructions describe basic setup for Pixhawk and do not represent the complete set of configuration procedures required to build a copter, plane, or rover.

For more information on ESC calibration, battery monitoring, failsafes, mode descriptions, and more, visit ardupilot.com. Do not operate your vehicle without a complete understanding of the online instructions.

\section{SPECIFICATIONS}

Processor

32-bit ARM Cortex M4 core with FPU

Dimensions

$168 \mathrm{Mhz} / 256 \mathrm{~KB}$ RAM/2 MB Flash

Weight $38 \mathrm{~g}(1.3 \mathrm{oz})$

32-bit failsafe co-processor

Width $50 \mathrm{~mm}\left(2.0^{\prime \prime}\right)$

Sensors

Height $15.5 \mathrm{~mm}\left(.6^{\prime \prime}\right)$

ST Micro 16-bit gyroscope

Length $81.5 \mathrm{~mm}\left(3.2^{\prime \prime}\right)$

ST Micro 14-bit accelerometer/magnetometer

MEAS barometer

MPU6000 accelerometer/magnetometer

Power

Ideal diode controller with automatic failover

Servo rail high-power ( $7 \mathrm{~V}$ ) and high-current ready

All peripheral outputs over-current protected, all

inputs ESC protected

Interfaces

$5 x$ UART serial ports, 1 high-power capable, $2 x$ with

HW flow control

Spektrum DSM/DSM2/DSM-X Satellite input

Futaba S.BUS input and output

PPM sum signal

RSSI (PWM or voltage) input

${ }^{2} \mathrm{C}, \mathrm{SPI}, 2 \times \mathrm{CAN}$, USB

3.3 and $6.6 \mathrm{ADC}$ inputs

\section{SUPPORT}

For more information about Pixhawk and other documentation, visit

3dr.com/learn. For more instruction on using APM firmware and

planner software, visit ardupilot.com.

For customer support, contact us at help@3dr.com or call our support line at +1 (858) 225-1414 Monday through Friday, 8 am to 5 pm, PST. 


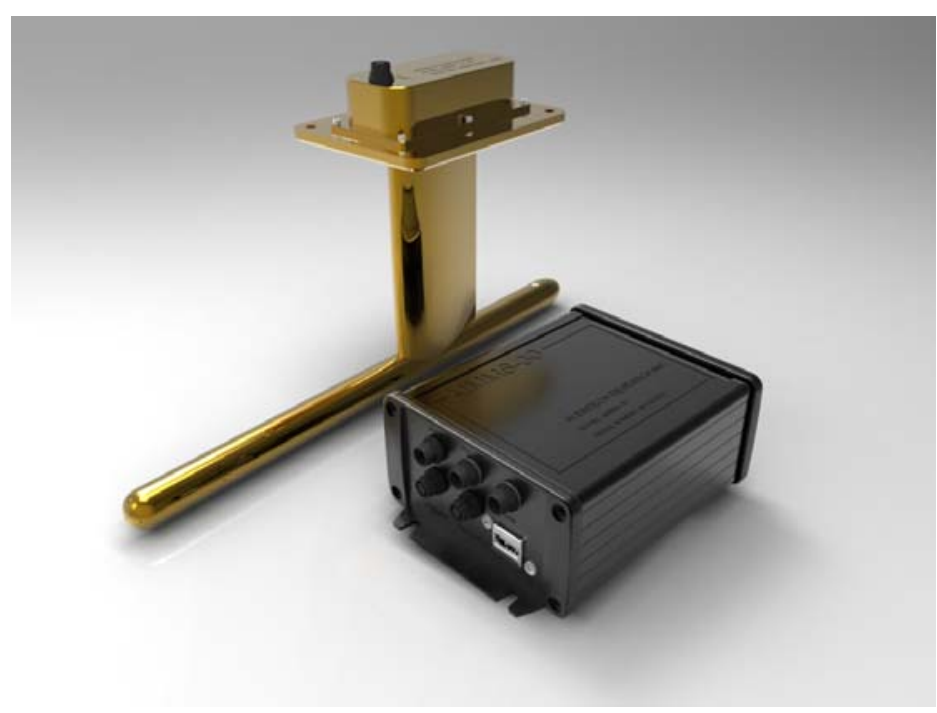

Accurate measurement of temperature, humidity, three-dimensional winds and turbulence on-board the aircraft at spray release height.

\section{Optimize Spray Deposition \\ Minimize Off-Target Drift}

\section{Document Meteorological Conditions to Prove} Due Diligence during Application

$\geqslant \mathrm{T}$

Third generation wind measurement technology.

Smaller, lighter and lower cost than previous second generation AIMMS-20 system.

AIMMS-30 system components include:

$$
\text { Air Data Probe (ADP) }
$$

Integrated Inertial / GPS Carrier Phase / Central Processing Module

Data available in real-time via serial broadcast, which can be utilized by GPS navigation systems for use in real-time spray drift models, or stored to an integrated USB FLASH memory drive for post-flight analysis.

Compatible with most major GPS navigation systems including:

$$
\begin{gathered}
\text { ADAPCO Wingman GX } \\
\text { AGNAV Guia } \\
\text { TracMap } \\
\text { AgJunction SATLOC G4 }
\end{gathered}
$$

Stand-alone operation capability with optional display module running Aventech MetTrack firmware.

Future MetTrack firmware versions to include spray drift modelling

DAventech

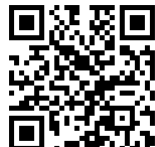

110 Anne Street South, Unit 23

Barrie, Ontario, Canada L4N 2E3

Tel: $\quad$ (705) $722-4288$

Toll: $\quad$ (705) 235-7766

Fax: $\quad$ (705) 722-9077

Web: www.aventech.com

E-mail: info@aventech.com

\section{TECHNICAL SPECIFICATIONS}

WIND SPEED ACCURACY:

Wind Components:

(North, East, Vertical)

\section{TEMPERATURE:}

Accuracy / Resolution:

\section{RELATIVE HUMIDITY:}

Accuracy / Resolution:

\section{ELECTRICAL:}

Operating Voltage:

Power:

Maximum Operating Current:

Digital Interfaces:

\section{ENVIRONMENTAL:}

Operating Temperature: Storage Temperature:

\section{PHYSICAL:}

\section{Dimensions:}

Air Data Probe (ADP):

Central Processing Module (CPM): (31.8cm L X $1.9 \mathrm{~cm}$ dia. boom, $12.7 \mathrm{~cm}$ pylon) $5.000 " \times 4.000 " \times 2.125 "$

\section{Weights:}

$\begin{array}{lll}\text { Air Data Probe (ADP): } & 1.39 \mathrm{lb} & 630 \mathrm{~g} \\ \text { Central Processing Module (CPM): } & 1.00 \mathrm{lb} & 455 \mathrm{~g}\end{array}$

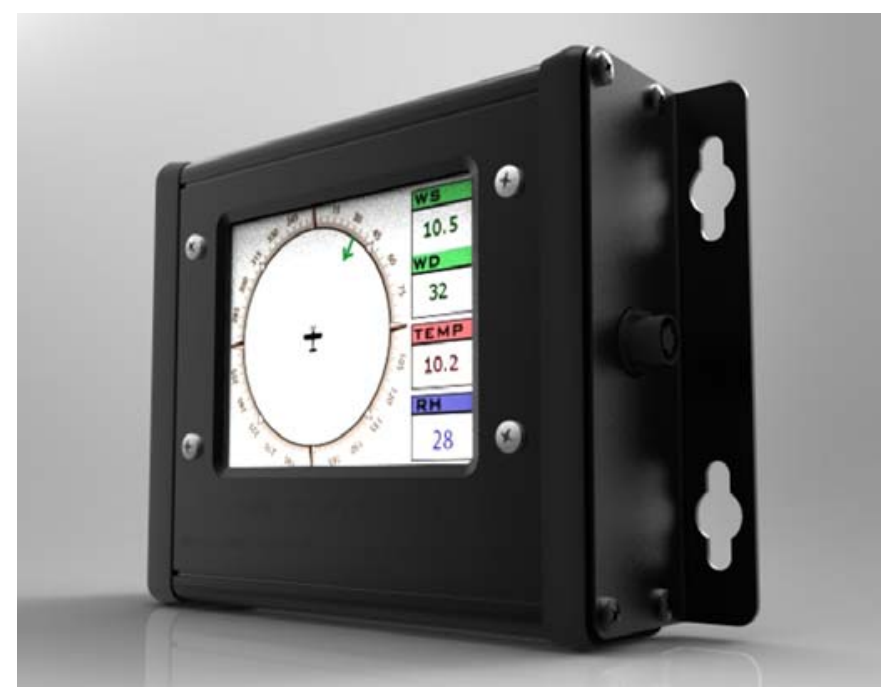

Optional 3.5" Sunlight Readable, Colour, Touch Screen Display Module Display:
3.5" Transreflective Colour TFT LCD Display $320 \times 240$ resolution
$64 \mathrm{~K}$ Colours
80 Nit LED Backlight for Night Viewing

Operating System:

MetTrack Firmware v1.0

Dimensions (WxHxD): $\quad 5.125 "$ X 4.000" X $1.125 "$

$(13.0 \mathrm{~cm} \times 10.2 \mathrm{~cm} \times 2.86 \mathrm{~cm})$

Weight:

$0.75 \mathrm{lb}$.

$340 \mathrm{~g}$ 


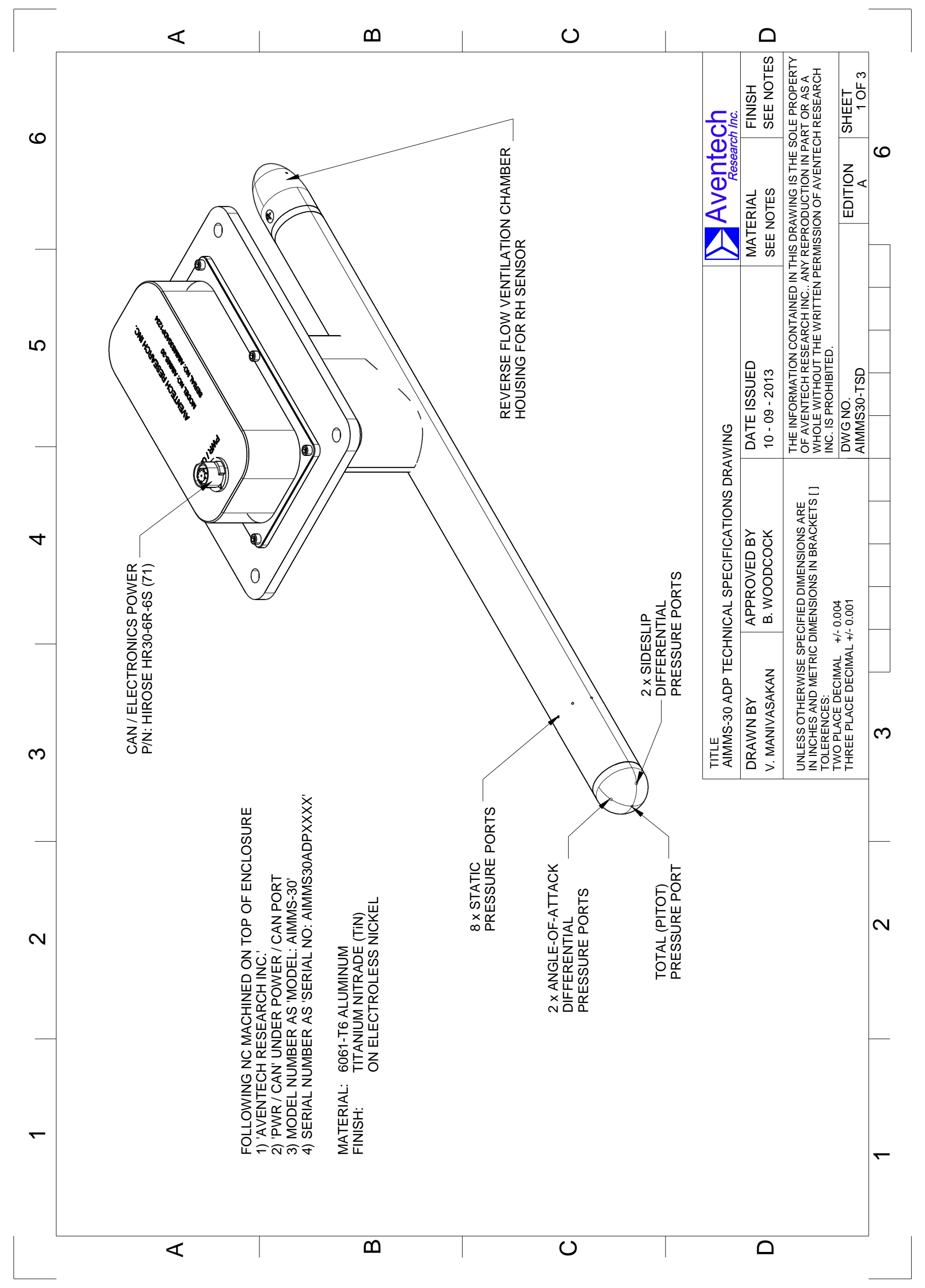




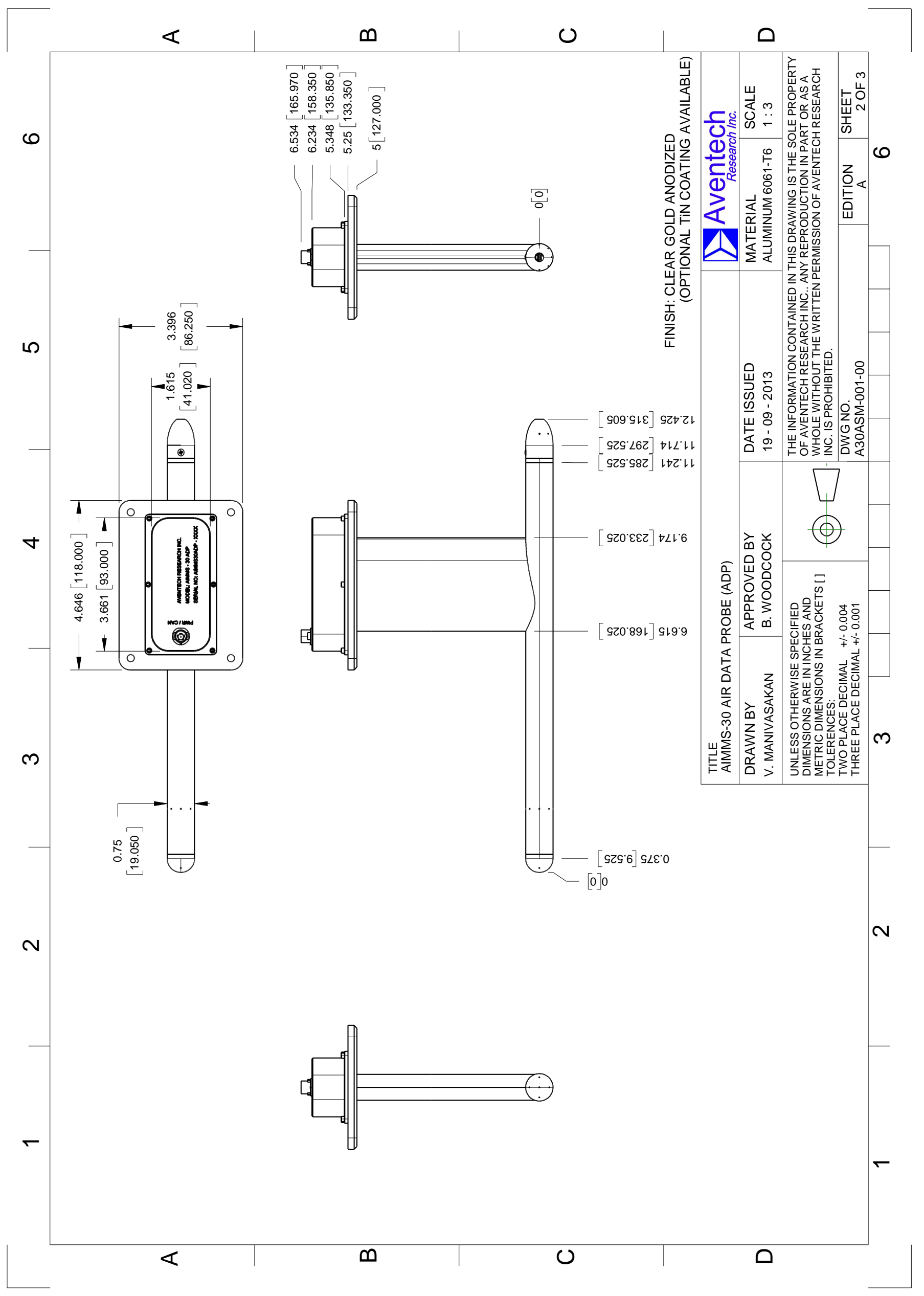




\section{OEMStar}

\section{PERFORMANCE ${ }^{1}$}

\section{Channel Configuration \\ 14 GPS L1 \\ 12 GPS L1 + 2 SBAS \\ 10 GPS L1 + 4 GLO L1 \\ 8 GPS L1 + 6 GLO L1 \\ 8 GPS L1 + 4 GLO L1 + 2 SBAS \\ 10 GPS L1 + 2 GLO L1 + 2 SBAS \\ 7 GPS L1 + 7 GLO L1 \\ 14 GLO L1}

Horizontal Position Accuracy (RMS)

Single point L1

SBAS $^{2}$

DGPS

$1.5 \mathrm{~m}$

$0.7 \mathrm{~m}$

$0.5 \mathrm{~m}$

Measurement Precision (RMS)

L1 C/A code GPS

L1 carrier phase

$5 \mathrm{~cm}$

GLO

Maximum Data Rate

Measurements

Position

$0.6 \mathrm{~mm}$

$35 \mathrm{~cm}$

$1.5 \mathrm{~mm}$

Time to First Fix

Cold start ${ }^{3}$

Hot start ${ }^{4}$

$10 \mathrm{~Hz}$

$10 \mathrm{~Hz}$

$65 \mathrm{~s}$

$35 \mathrm{~s}$

\section{Signal Reacquisition}

L1

$$
<1.0 \text { s (typical) }
$$

\section{Time Accuracy}

GPS 2,5

GLONASS 5,6

20 ns RMS

40 ns RMS

Velocity Accuracy

Velocity Limit ${ }^{7}$

$<0.05 \mathrm{~m} / \mathrm{s}$ RMS

$<515 \mathrm{~m} / \mathrm{s}$

\section{PHYSICAL AND ELECTRICAL ${ }^{8}$}

\begin{tabular}{lr}
\hline Dimensions & $46 \times 71 \times 13 \mathrm{~mm}$ \\
Weight & $18 \mathrm{~g}$
\end{tabular}

Power

Input voltage

+3.3 to 5.0 VDC $\pm 5 \%$

Power consumption ${ }^{9}$

$0.36 \mathrm{~W}$

Antenna LNA Power Output

Output voltage

Maximum current

$5 \mathrm{~V}$ nominal

\section{Connectors}

Main 20-pin dual row male header Antenna input MCX female

\section{COMMUNICATION PORTS}

2 LV-TTL 300 to 230,400 bps

1 USB 2.0

\section{ENVIRONMENTAL}

\section{Temperature}

Operating

Storage

Humidity

Vibration

Random

Sine

Shock

$-40^{\circ} \mathrm{C}$ to $+85^{\circ} \mathrm{C}$

$-45^{\circ} \mathrm{C}$ to $+90^{\circ} \mathrm{C}$

95\% non-condensing

MIL-STD $810 \mathrm{G}$

IEC 60068-2-6 (5 g)

MIL-STD $810 \mathrm{G}$

\section{FEATURES}

- Auxiliary strobe signals, including a configurable PPS output for time synchronization and a mark input

- Outputs to drive external LEDs

- Common, field-upgradeable software

\section{FIRMWARE OPTIONS}

- GLIDE

- API

- RAIM

\section{OPTIONAL ACCESSORIES}

- GPS-700 series antennas

- ANT series antennas

- RF cables-5, 10 and 30 m lengths

- Right angle RF connector

- Available in the FlexPak-G2 $2^{\mathrm{Tm}}$ enclosure
1. Typical values. Performance specifications subject to GPS system tropospheric conditions, satellite geometry, baseline length, multipat effects and the presence of intentional or unintentional interference sources.

2. GPS only. Clock aligned to GPS system time.

3. Typical value. No almanac or ephemerides. No approximate position or time.

4ypical value. Almanac and recent ephemerides saved and approximate position and time entered.

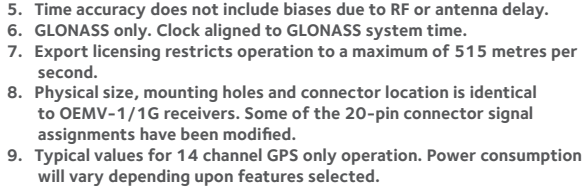

\section{NOVATEL CONNECTTM}

NovAtel Connect is an intuitive configuration and visualization tool suite allowing comprehensive control of the OEMStar product.

- Easy to use wizards guide you through positioning mode configuration and raw data collection

- Detailed graphical windows display comprehensive status information

- Plan view and playback files allow you to monitor the positioning and configuration history

- Remotely control and monitor the OEMStar over the internet

- Windows XP and Windows 7 platforms

For the most recent details of this product: www.novatel.com/products/gnss-receivers/ oem-receiver-boards/oemstar/

novatel.com

sales@novatel.com

1-800-NOVATEL (U.S. and Canada)

or 403-295-4900

China 0086-21-68882300

Europe 44-1993-848-736

SE Asia and Australia 61-400-883-601

Version 6 Specifications subject to change without notice. ()2015 NovAtel Inc. All rights reserved.

NovAtel, OEMStar and OEMV are registered trademarks of NovAtel Inc.

GLIDE, FlexPak-G2 and NovAtel Connect are trademarks of NovAtel Inc.

Printed in Canada.

D13800 November 2015

(0) 


\section{A Tallysman Accutenna ${ }^{\circledR}$ \\ TW1421/TW1422 Compact Dual Feed Embedded GPS/GLONASS}

The TW1421/TW1422 employ Tallysman's unique Accutenna ${ }^{\circledR}$ technology covering the GPS L1, GLONASS G1, and SBAS (WAAS, EGNOS \& MSAS) frequency band (1574 to $1606 \mathrm{MHz}$ ). It provides truly circular response over its entire bandwidth thereby producing superior multipath signal rejection. It also offers high out of band signal rejection.

The antennas feature a novel $25 \mathrm{~mm}$ wideband patch element with dual-feeds that are summed in a $90^{\circ}$ Hybrid and input to a two stage Low Noise Amplifier (LNA) with a mid-section SAW a second low noise gain stage. This configuration provides excellent axial ratio and cross-polarization rejection across the full frequency band.

The TW1422 has a pre-filter which increases the antenna's immunity to high amplitude interfering signals, such as LTE and other cellular signals.

The built-in $35 \mathrm{~mm}$ circular ground plane should ideally be augmented with a local system ground plane or reflecting surface (DC connection not required).

The height of the RF shield (can) will be selected based upon the connector type. Connectors which require RG174 cable will be used with the taller can. Connectors which require mico-coax cable will be used with the shorter can.

OEM antennas are easily detuned by the local environment. Tallysman offers custom tuning services for optimized integration into OEM end-user modules.

\section{Applications}

- High Accuracy GPS \& GLONASS

- Precision Agriculture, Mining \& Construction

- Avionics

- Law Enforcement \& Public Safety

- $\quad$ Fleet Management \& Asset Tracking

\section{Features}

- Compact Dual Feed Patch Element

- $1 \mathrm{~dB}$ bandwidth $1575-1606 \mathrm{MHz}$

- Very low noise LNA: $<1.25 \mathrm{~dB}(\mathrm{TW} 1421)$

- $\quad<1.5$ dB Axial Ratio @ zenith over bandwidth

- $\quad$ LNA gain: $28 \mathrm{~dB}$ typ. (TW1421) 26dB typ (TW1422)

- Wide Supply voltage: fixed $2.5 \mathrm{~V}$ to $16 \mathrm{~V}$

- $\quad$ ESD circuit protection: $15 \mathrm{KV}$

- Temperature Compensated Gain
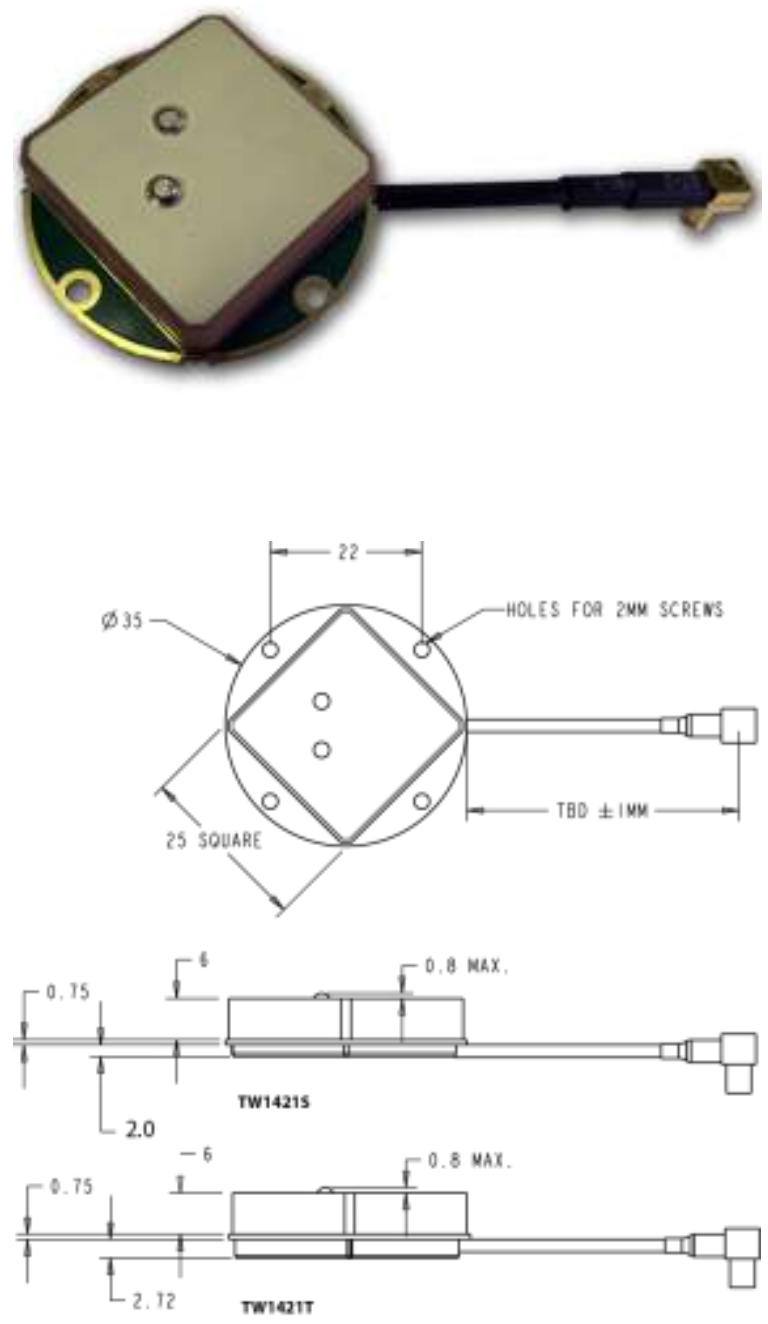

\section{Benefits}

- Great multipath rejection

- Increase system accuracy

- Improved carrier phase linearity

- Excellent signal to noise ratio

- Great out of band signal rejection

- Compact form factor

- RoHS compliant 


\section{TW1421/TW1422 Dual Feed Embedded GPS/GLONASS Antenna}

Specifications $A t ; \mathrm{Vcc}=3 \mathrm{~V}$, over full bandwidth, $\mathrm{T}=25^{\circ} \mathrm{C}$

\section{Antenna}

Architecture

$1 \mathrm{~dB}$ Bandwidth

Antenna Gain (with $100 \mathrm{~mm}$ ground plane)

Axial Ratio over full bandwidth,

\section{Electrical}

Architecture

Filtered LNA Frequency Bandwidth

Polarization

LNA Gain $1575.42 \mathrm{MHz}$ to $1606 \mathrm{MHz}$

Gain flatness

Out-of-Band Rejection

VSWR (at LNA output)

Noise Figure

Supply Voltage Range (over coaxial cable)

Supply Current

ESD Circuit Protection

\section{Mechanicals \& Environmental}

Mechanical Size

Cable

Operating Temp. Range

Weight

Attachment Method

Environmental

Shock

Vibration

Warranty

\section{Ordering Information}

Part Numbers:

TW1421 - GPS L1/GLONASS G1 antenna,

TW1422 - Pre-filtered GPS L1/GLONASS G1 antenna
Dual, Quadrature Feeds

$31 \mathrm{MHz}$

$4.5 \mathrm{dBic}$

$<1.5 \mathrm{~dB} @$ zenith, $\leq 3.0 \mathrm{~dB} \max$

One LNA per feed line, mid-section SAW filter

$1574 \mathrm{MHz}$ to $1606 \mathrm{MHz}$

RHCP

28dB typ., 26dB Min, (TW1421) 26dBtyp. 24dB min (TW1422)

$+/-2 \mathrm{~dB}, 1575 \mathrm{MHz}$ to $1606 \mathrm{MHz}$

$\begin{array}{lll} & \frac{T W 1421}{} & \frac{T W 1422}{260 \mathrm{~dB}} \\ \text { <1500MHz: } & >32 \mathrm{~dB} & >55 \mathrm{MH} \\ \text { >155: } & >25 \mathrm{~dB} & >65 \mathrm{~dB}\end{array}$

$<1.5: 1$ typ. $1.8: 1 \max$

$\leq 1.25 \mathrm{~dB}$ typ.(TW1421) 3.5dBtyp (TW1422)

+2.5 VDC to $16 \mathrm{VDC}$ nominal

10mA typ.15mA max. (@85ㄷ)

$15 \mathrm{KV}$ air discharge

$35 \mathrm{~mm}$ dia. $\times 7.25 \mathrm{~mm}$

$1.38 \mathrm{~mm}$ OD (micro-coax) or 2.6mm OD (RG174)

$-40^{\circ} \mathrm{C}$ to $+85^{\circ} \mathrm{C}$

$18 \mathrm{~g}$

Adhesive or M2 screw mount

RoHS compliant

Vertical axis: $50 \mathrm{G}$, other axes: $30 \mathrm{G}$

3 axis, sweep = 15 min, 10 to $200 \mathrm{~Hz}$ sweep: $3 \mathrm{G}$

One year - parts and labour

Please refer to the Ordering Guide (http://www.tallysman.com/wp-content/uploads/Current-Ordering-Guide.pdf) for the current and complete list of available connectors.

\section{Tallysman Wireless Inc}

36 Steacie Drive

Ottawa ON K2K 2A9 Canada

Tel 6135913131

Fax 6135913121

sales@tallysman.com

The information provided herein is intended as a guide only and is subject to change without notice. This document is not to be regarded as a guarantee of performance. Tallysman Wireless Inc. hereby disclaims any or all warranties and liabilities of any kind. (C) 2015 Tallysman Wireless Inc. All rights reserved. 


\section{Vantage Pro2 ${ }^{\mathrm{TM}}$ Accessories}

Includes both wind speed and wind direction sensors. Rugged components stand up to hurricane-force winds, yet are sensitive to a light breeze. Includes sealed bearings for long life. The range and accuracy specifications have been verified in wind-tunnel tests. In areas where icing of the anemometer is a problem, drip rings deflect water from the joint between moving parts.

\section{General}

Operating Temperature. . . . . . . $\ldots \ldots \ldots \ldots .40^{\circ}$ to $+149^{\circ} \mathrm{F}\left(-40^{\circ}\right.$ to $\left.+65^{\circ} \mathrm{C}\right)$

Sensor Type

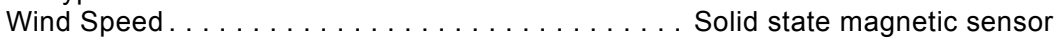

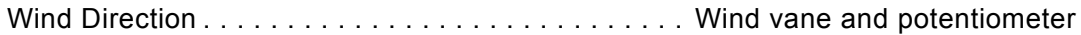

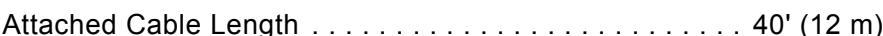

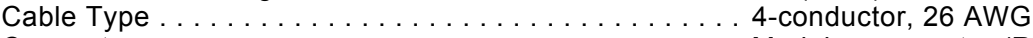

Connector . . . . . . . . . . . . . . . . . . . . . .

Maximum Cable Length. . . . . . . . . . . . 240 $(73 \mathrm{~m})$

Note: $\quad$ Maximum displayable wind speed decreases as cable increases. At 140' (42 m) of cable, maximum displayable wind speed is $135 \mathrm{mph}(60 \mathrm{~m} / \mathrm{s})$; at $240^{\prime}(73 \mathrm{~m})$, maximum wind speed displayed is $100 \mathrm{mph}(45 \mathrm{~m} / \mathrm{s})$.

Material

Wind Vane and Control Head. . . . . . . . . . UV-resistant ABS

Wind Cups................... Polycarbonate

Anemometer Arm . . . . . . . . . . . . . . . . . Black-anodized aluminum

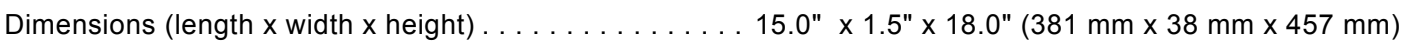

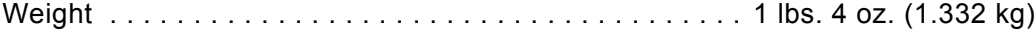

\section{Sensor Output}

\section{Wind Direction}

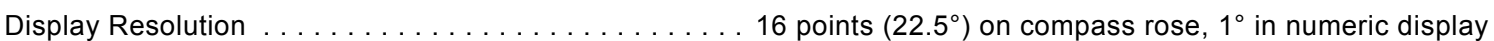

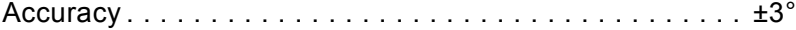

\section{Wind Speed}

Resolution and Units

Measured in $1 \mathrm{mph}$. Other units are converted from $\mathrm{mph}$ and rounded to nearest $1 \mathrm{~km} / \mathrm{h}, 0.1 \mathrm{~m} / \mathrm{s}$, or $1 \mathrm{knot}$

Range . . . . . . . . . . . . . . . . . . . . 1 to $200 \mathrm{mph}, 1$ to $173 \mathrm{knots}, 0.5$ to $89 \mathrm{~m} / \mathrm{s}, 1$ to $322 \mathrm{~km} / \mathrm{h}$

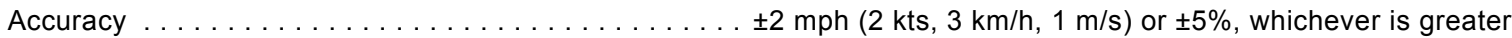

Maximum Cable Length . . . . . . . . . . . . . 240' $(73 \mathrm{~m})$. Maximum wind speed reading decreases as length of cable from Anemometer to ISS increases. At 140' (42 m), maximum speed is $135 \mathrm{mph}(60 \mathrm{~m} / \mathrm{s})$. At $240^{\prime}$, the maximum is $100 \mathrm{mph}$.

\section{Input/Output Connections}

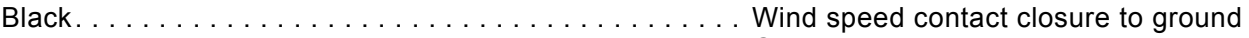

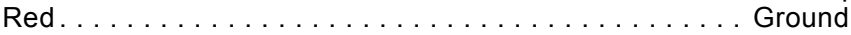

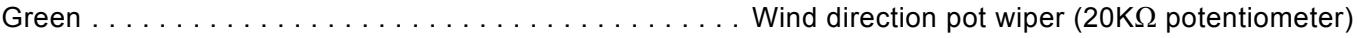

Yellow. . . . . . . . . . . . . . . . . Pot supply voltage

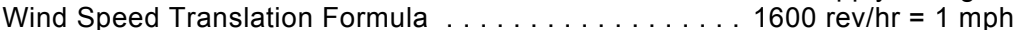

$\mathrm{V}=\mathrm{P}(2.25 / \mathrm{T})(\mathrm{V}=$ speed in $\mathrm{mph}, \mathrm{P}=$ no. of pulses per sample period $T=$ sample period in seconds)

Wind DirectionTranslation . . . . . . . . . . . . . Variable resistance $0-20 \mathrm{~K} \Omega ; 10 \mathrm{~K} \Omega=$ south, $180^{\circ}$

\section{Package Dimensions}

\begin{tabular}{|c|c|c|c|}
\hline Product \# & $\begin{array}{c}\text { Package Dimensions } \\
\text { (Length } \times \text { Width } \times \text { Height) }\end{array}$ & Package Weight & UPC Codes \\
\hline \hline 6410 & $\begin{array}{c}17.75^{\prime \prime} \times 10.50 " \times 3.00 " \\
(451 \mathrm{~mm} \times 267 \mathrm{~mm} \times 76 \mathrm{~mm})\end{array}$ & $2.0 \mathrm{lbs} .(.9 \mathrm{~kg})$ & 011698002375 \\
\hline
\end{tabular}




\section{References}

[1] Spence, C. and Mengistu, S., "Deployment of an unmanned aerial system to assist in mapping an intermittent stream," Hydrological Processes, Vol. 30, No. 3, 2016, pp. 493-500.

[2] Duncan, B. A. and Murphy, R. R., "Autonomous Capabilities for Small Unmanned Aerial Systems Conducting Radiological Response: Findings from a Highfidelity Discovery Experiment," Journal of Field Robotics, Vol. 31, No. 4, 2014, pp. 522-536.

[3] D'Oleire-Oltmanns, S., Marzolff, I., Peter, K. D., and Ries, J. B., "Unmanned aerial vehicle (UAV) for monitoring soil erosion in Morocco," Remote Sensing, Vol. 4, No. 11, 2012, pp. 3390-3416.

[4] Tilly, N., Kelterbaum, D., and Zeese, R., "Geomorphological Mapping With Terrestrial Laser Scanning And Uav-based Imaging," The International Archives of the Photogrammetry, Remote Sensing and Spatial Information Sciences, Vol. 41, No. July, 2016, pp. 591-597.

[5] Bonin, T., Chilson, P., Zielke, B., and Fedorovich, E., "Observations of the Early Evening BoundaryLayer Transition Using a Small Unmanned Aerial System," Boundary-Layer Meteorology, Vol. 146, No. 1, 2013, pp. 119-132.

[6] Pestana, J., Sanchez-Lopez, J. L., Saripalli, S., and Campoy, P., "Computer vision based general object following for GPS-denied multirotor unmanned vehicles," Proceedings of the American Control Conference, 2014, pp. 1886-1891.

[7] Kocer, G., Mansour, M., Chokani, N., Abhari, R. S., and Müller, M., "Full-Scale Wind Turbine Near-Wake Measurements Using an Instrumented Uninhabited Aerial Vehicle," Journal of Solar Energy Engineering, Vol. 133, No. 4, 2011, pp. 041011. 
[8] Spedding, G. R. and Lissaman, P. B. S., "Technical Aspects of Microscale Flight Systems," Journal of Avian Biology, Vol. 29, No. 4, 1998, pp. 458-468.

[9] Kothari, M., Postlethwaite, I., and Gu, D. W., "Uav path following in windy urban environments," Journal of Intelligent and Robotic Systems: Theory and Applications, Vol. 74, No. 3-4, 2014, pp. 1013-1028.

[10] Galway, D., Etele, J., and Fusina, G., "Modeling of the Urban Gust Environment with Application to Autonomous Flight," AIAA Atmospheric Flight Mechanics Conference and Exhibit, , No. August, 2008, pp. 1-20.

[11] Watkins, S., Thompson, M., Loxton, B., and Abdulrahim, M., "On Low Altitude Flight Through The Atmospheric Boundary Layer," International Journal of Micro Air Vehicles, Vol. 2, No. 2, 2010, pp. 55-68.

[12] Langelaan, J. W. and Bramesfeld, G., "Gust Energy Extraction for Mini and Micro Uninhabited Aerial Vehicles," Journal of Guidance, Control, and Dynamics, Vol. 32, No. 2, 2009, pp. 464-473.

[13] Pisano, W. J., The development of an autonomous gust insensitive unmanned aerial vehicle, Ph.D. thesis, University of Colorado, 2009.

[14] Stull, R. B., An Introduction to Boundary Layer Meteorology, Kluwer Academic Publishers, 1988.

[15] Walshe, D. E. J., Wind-excited Oscillations of Structures: Wind-tunnel Techniques for Their Investigation and Prediction, H.M.S.O., 1972.

[16] van den Kroonenberg, A., Martin, T., Buschmann, M., Bange, J., and Vörsmann, P., "Measuring the wind vector using the autonomous mini aerial vehicle M2AV," Journal of Atmospheric and Oceanic Technology, Vol. 25, No. 11, 2008, pp. 1969-1982.

[17] Kramar, V. F. and Kouznetsov, R. D., "A new concept for estimation of turbulent parameter profiles in the ABL using sodar data," Journal of Atmospheric and Oceanic Technology, Vol. 19, No. 8, 2002, pp. 1216-1224.

[18] Langelaan, J. W., Spletzer, J., Montella, C., and Grenestedt, J., "Wind field estimation for autonomous dynamic soaring," Proceedings - IEEE International Conference on Robotics and Automation, , No. c, 2012, pp. 16-22. 
[19] Axford, D., "On the accuracy of wind measurements using an inertial platform in an aircraft, and an example of a measurement of the vertical mesostructure of the atmosphere," Journal of Applied Meteorology, Vol. 7, No. 4, 1968, pp. 645-666.

[20] Zeis, J. E., Lambert, H. H., Calico, R. A., and Gleason, D., "Angle of attack and sideslip estimation using an inertial reference platform," 15th Atmospheric Flight Mechanics Conference, 1988, pp. $1-169$.

[21] Reuder, J., Jonassen, M. O., and Ólafsson, H., "The Small Unmanned Meteorological Observer SUMO: Recent developments and applications of a micro-UAS for atmospheric boundary layer research," Acta Geophysica, Vol. 60, No. 5, 2012, pp. 1454-1473.

[22] Etkin, B., "Turbulent Wind and Its Effect on Flight," Journal of Aircraft, Vol. 18, No. 5, 1981, pp. $327-345$.

[23] Raymer, D. P., Aircraft Design: A Conceptual Approach, American Institute of Aeronautics and Astronautics, 2013.

[24] Nelson, R. C., Flight Stability and Automatic Control, 2nd ed., 1998.

[25] Hoblit, F. M., Gust loads on aircraft : concepts and applications, American Institute of Aeronautics and Astronautics, 1988.

[26] U.S. National Archives and Records Administration, "Code of Federal Regulations. Title 14. Airworthiness Standards: Transport Category Airplanes," 2015.

[27] Gudmundsson, S., General Aviation Aircraft Design: Applied Methods and Procedures, Butterworth-Heinemann, 2013.

[28] Zipfel, P. H., Modeling and Simulation of Aerospace Vehicle Dynamics, American Institute of Aeronautics and Astronautics, 2nd ed., 2007.

[29] U.S. Department of Defense, "U.S. Military Specification MIL-F-8785C," Tech. rep., 1980.

[30] U.S. Department of Defense, "U.S. Military Handbook MIL-HDBK-1797," Tech. rep., 1997.

[31] University of Hamburg, "Hamburg Boundary Layer Measurement Tower," 2016. 
[32] DLR, "Dassault Falcon 20E - D-CMET," 2015.

[33] Yeung, A. and Bramesfeld, G., "Measuring Atmospheric Gusts at Low Altitude," 35th AIAA Applied Aerodynamics Conference, Denver, Colorado, 2016.

[34] Eagle Tree Systems, "Instruction Manual for the Airspeed MicroSensor V3," 2008.

[35] ArduPilot Dev Team, "SITL Simulator (Software in the Loop)," 2016.

[36] "Aventech Research Inc.", "AIMMS-30 Technical Brochure," Tech. rep., 2016.

[37] Shevchenko, A. M., Berezin, D. R., Puzirev, L. N., Tarasov, A. Z., Kharitonov, A. M., and Shmakov, A. S., "Multi-hole pressure probes to air data system for subsonic small-scale air vehicles," Vol. 030005, 2016, pp. 030005.

[38] Bryer, D. W. and Pankhurst, R. C., Pressure-probe methods for determining wind speed and flow direction, H.M.S.O., 1971.

[39] Kjelgaard, S. O., "Theoretical Derivation and Calibration Technique of a Hemisp herical-Tipped, Five-Hole Probe,” Tech. rep., Langley Research Center, Hamfiton, Virginia, 1988.

[40] Reichert, B. a. and Wendt, B. J., "A new algorithm for five-hole probe calibration, data reduction, and uncertainty analysis," , No. September, 1994.

[41] Hood, S., Development Of A Flight Data acquisition System For Small Unmanned Aircraft, Ph.D. thesis, Oklahoma State University, 2012.

[42] Dantec Dynamics, "Flow Field Diagnostics: Constant Temperature Anemometry Solutions," 2012.

[43] NASA Langley Research Center, "Making the Skies Safe from Windshear," 1992.

[44] Bissonnette, W. J. M., An Analysis Tool for the Conceptual Design of High-Lift Systems by, Ph.D. thesis, Ryerson University, 2016.

[45] Groves, P. D., Principles of GNSS, inertial and multisensor integrated navigation systems, Artech House, Boston, Massachusetts, 2nd ed., 2013.

[46] NovAtel, "LOW COST, L1 GPS+GLONASS RECEIVER ENHANCES SATELLITE AVAILABILITY \& POSITIONING," Tech. rep. 
[47] Tallysman Wireless Inc., "TW1421 / TW1422 Compact Dual Feed Embedded GPS / GLONASS Antenna," 2015.

[48] Davis Instruments, "Anemometer DS6410," 2013.

[49] Kristensen, L., "Cup anemometer behavior in turbulent environments," Journal of Atmospheric and Oceanic Technology, Vol. 15, No. 1, 1998, pp. 5-17.

[50] Kristensen, L., Casanova, M., Courtney, M. S., and Troen, I., "In search of a gust definition," Boundary-Layer Meteorology, Vol. 55, No. 1-2, 1991, pp. 91-107.

[51] Piccato, A., Spazzini, P., and Malvano, R., "Cup anemometer calibration: Effect of flow velocity distribution," Metrologia, Vol. 48, No. 5, 2011, pp. 343-351.

[52] Freescale Semiconductor, "I2C Precision Altimeter MPL3115A2," 2012.

[53] Silicon Labs, "I2C Humidity and Temperature Sensor Si7021-A10," 2014.

[54] Barcelos, D., Flow Quality Testing and Improvement of the Ryerson University Low Speed Wind Tunnel, Ph.D. thesis, 2016.

[55] The MathWorks, I., "Periodogram power spectral density estimate," 2006.

[56] The MathWorks, I., "Power Spectral Density Estimates Using FFT," 2017.

[57] Simiu, E. and Scanlan, R. H., Wind effects on structures : an introduction to wind engineering, Wiley, 1978. 
